\title{
DESENVOLVIMENTO E ANÁLISE DE MODELOS AGROMETEOROLÓGICOS DE ESTIMATIVA DE PRODUTIVIDADE PARA A CULTURA DA SOJA NA REGIÃO DE RIBEIRÃO PRETO, SP
}

\section{ADRIANA VIEIRA DE CAMARGO MORAES \\ Engenheira Agrônoma}

Orientador: Dr. MARCELO BENTO PAES DE CAMARGO

Dissertação apresentada à "Escola Superior de Agricultura Luiz de Queiroz", Universidade de São Paulo, para obtenção de título de Mestre em Agronomia, Área de Concentração: Agrometeorologia

PIRACICABA

Estado de São Paulo - Brasil

Fevereiro - 1998 
Dados Internacionais de Catalogação na Publicação (CIP) DIVISĀO DE BIBLIOTECA E DOCUMENTAÇĀO - Campus "Luiz de Queiroz"/USP

Moraes, Adriana Vieira de Camargo Desenvolvimento e análise de modelos agrometeorológicos de estimativa de produtividade para a cultura da soja na regiāo de Ribeirāo Preto, SP / Adriana Vieira de Camargo Moraes. - - Piracicaba, 1998.

$95 \mathrm{p}$.

Dissertação (mestrado) - - Escola Superior de Agricultura Luiz de Queiroz, 1998. Bibliografia.

I. Bioclimatologia 2. Fenologia 3. Meteorologia agricola 4. Produtividade agricola 5. Soja I. Título 


\section{DESENVOLVIMENTO E ANÁLISE DE MODELOS AGROMETEOROLÓGICOS DE ESTIMATIVA DE PRODUTIVIDADE PARA A CULTURA DA SOJA NA REGIÃO DE RIBEIRÃO PRETO, SP}

ADRIANA VIEIRA DE CAMARGO MORAES

Aprovada em: 27.04.1998

Comissão Julgadora:

Dr. Marcelo Bento Paes de Camargo

IAC

Prof. Dr. Luiz Roberto Angelocci

ESALQ/USP

Dr. Rogério Remo Alfonsi

IAC

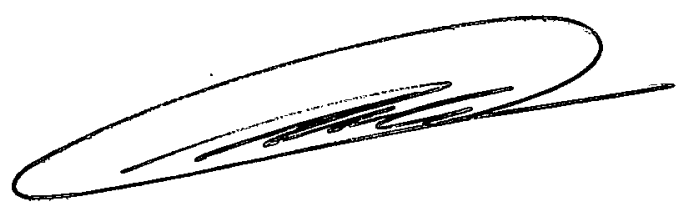

Dr. MARCELO BENTO PAES DE CAMARGO

Orientador 
A Elizabeth, Maria Helena, Carmencita, Denise, Eliane, Maria Goreti, Renata, Romilson, Tio Paulo e familia, Buck e a todos os amigos que, de uma forma ou de outra, contribuíram para a realização deste trabalho

\section{OFEREÇO}

A Lucia, querida mãe, pelo exemplo de vida e amor que sempre me dedicou A Lilia, tia amorosa, esteio sempre presente A Paulo, saudoso pai,

\section{DEDICO}




\section{AGRADECIMENTOS}

Ao Dr. Marcelo Bento Paes de Camargo, da Seção de Climatologia Agrícola (IAC), pela orientação, generosidade, paciência, incentivo e amizade

À Escola Superior de Agricultura "Luiz de Queiroz", pela oportunidade para a realização do curso

À Coordenadoria de Aperfeiçoamento de Pessoal de Nível Superior CAPES/Brasil, pelo auxílio financeiro

Ao Pesquisador Científico Otávio Tisselli Filho (in memoriam), pela oportunidade para a realização do sonho profissional no Instituto Agronômico IAC

À Seção de Climatologia Agrícola (IAC), pela oportunidade concedida para a realização do presente trabalho

Aos Pesquisadores Científicos Altino Aldo Ortolani, Rogério Remo Alfonsi, Ângelo Paes de Camargo, Orivaldo Brunini, Maria Helena de Almeida Mello e Mário José Pedro Júnior, pelas sugestões e apoio constantes

Aos Pesquisadores Científicos Manuel Albino Coelho de Miranda, José Carlos Villa Nova Alves Pereira e Hipólito Assunção Antonio Mascarenhas, pela cessão dos dados experimentais

Aos colegas José Ricardo Macedo Pezzopane e Angélica Giarolla Picini, pela amizade e grande colaboração

Aos Professores, funcionários e alunos do Departamento de Física e Meteorologia da ESALQ/USP, pela amizade, colaboração e apoio

Aos amigos desta jornada, o meu sincero agradecimento. 


\section{SUMÁRIO}

Página

LISTA DE FIGURAS ................................................................................ viii

LISTA DE TABELAS....................................................................................................... $\mathrm{x}$

RESUMO

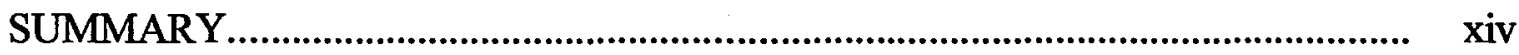

1. INTRODUÇÃO................................................................................................ 1

2. REVISÃO DE LITERATURA......................................................................... 4

2.1. Exigências termofotoperiódicas................................................................................. 4

2.2. Exigências hídricas....................................................................................... 7

2.3. Classificação de modelos agrometeorológicos.......................................................... 9

2.4. Modelos agrometeorológicos de estimativa de produtividade............................... $\quad 10$

2.4.1. Modelos agrometeorológicos de estimativa de produtividade para

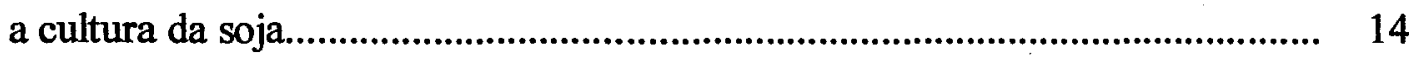

3. MATERIAL E MÉTODOS............................................................................ 16

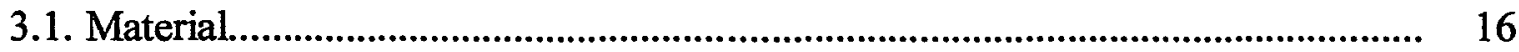

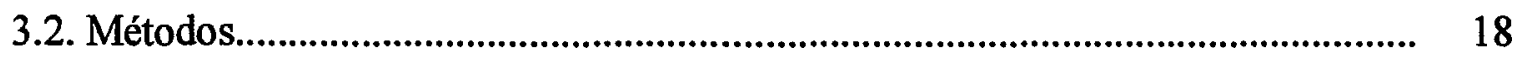

3.3. Teste de modelos existentes na literatura.......................................................... 21

3.3.1. Modelo proposto por Doorenbos \& Kassam (1979)........................................... 21

3.3.2. Modelo aditivo ................................................................................................ 21

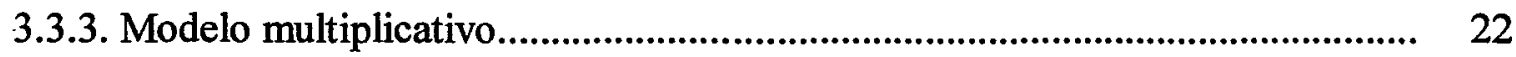


Página

3.3.4. Modelo multiplicativo modificado por Camargo (1986)..................................... 23

3.4. Desenvolvimento, parametrização e teste de modelos........................................... 25

3.4.1. Modelos aditivos e multiplicativos................................................................... 25

3.4.2. Modelo multiplicativo proposto por Jensen (1968)............................................ 25

3.5. Produtividade potencial.............................................................................. 26

3.6. Avaliação do desempenho..................................................................................... 29

4. RESULTADOS E DISCUSSÃO................................................................... 31

4.1. Produtividades Potenciais............................................................................... 31

4.2. Duração dos estádios fenológicos............................................................... 32

4.3. Balanço hídrico decendial................................................................................. 34

4.4. Parametrização dos modelos 5,6 e 7...................................................................... 42

4.5. Teste dos modelos......................................................................................... 47

4.6. Teste com dados independentes..................................................................... 58

5. CONCLUSÕES............................................................................................... 73

REFERÊNCIAS BIBLIOGRÁFICAS............................................................. 75

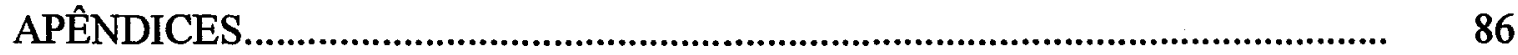




\section{LISTA DE FIGURAS}

Página

1. Produtividades potenciais estimadas em função de épocas de semeadura, para os cultivares de soja IAC-13, IAC-12 e IAC-11, para a região de Ribeirão Preto, SP... 28

2. Produtividades potenciais estimadas em função de épocas de semeadura, para os cultivares de soja IAC-17, IAS-5, IAC-15 e IAC-18, para a região de Ribeirão Preto, SP

3. Extratos do balanço hídrico climatológico decendial, referentes aos anos agrícolas de 1983/84 (a) e 1984/85 (b), para a região de Ribeirão Preto, SP

4. Extratos do balanço hídrico climatológico decendial, referentes aos anos agrícolas de 1989/90 (a) e 1990/91 (b), para a região de Ribeirão Preto, SP

5. Valores de coeficientes de produtividade $\left(\mathrm{ky}_{\mathrm{i}}\right)$ propostos por Doorenbos \& Kassam (1979) e determinados pelo modelo 5, para os cultivares IAC-13, IAC-12 e IAC-11

6. Produtividades $(\mathrm{kg} / \mathrm{ha})$ observadas e estimadas pelo modelo 1 , para os cultivares de soja IAC-13, IAC-12 e IAC-11

7. Produtividades $(\mathrm{kg} / \mathrm{ha})$ observadas e estimadas pelo modelo 2 , para os cultivares de soja IAC-13, IAC-12 e IAC-11

8. Produtividades $(\mathrm{kg} / \mathrm{ha})$ observadas e estimadas pelo modelo 3 , para os cultivares de soja IAC-13, IAC-12 e IAC-11

9. Produtividades $(\mathrm{kg} / \mathrm{ha})$ observadas e estimadas pelo modelo 4 , para os cultivares de soja IAC-13, IAC-12 e IAC-11 
Página

10. Produtividades $(\mathrm{kg} / \mathrm{ha}$ ) observadas e estimadas pelo modelo 5 , para os cultivares de soja IAC-13, IAC-12 e IAC-11 ................................................................... 55

11. Produtividades (kg/ha) observadas e estimadas pelo modelo 6, para os cultivares de soja IAC-13, IAC-12 e IAC-11 ................................................................... 56

12. Produtividades $(\mathrm{kg} / \mathrm{ha}$ ) observadas e estimadas pelo modelo 7 , para os cultivares de soja IAC-13, IAC-12 e IAC-11

13. Extratos do balanço hídrico climatológico decendial, referentes aos anos agrícolas de 1995/96 (a) e 1996/97 (b), para a região de Ribeirão Preto, SP. 59

14. Produtividades (kg/ha) observadas e estimadas pelo modelo 1, para os cultivares IAC-17, IAS-5, IAC-15 e IAC-18 64

15. Produtividades (kg/ha) observadas e estimadas pelo modelo 2, para os cultivares IAC-17, IAS-5, IAC-15 e IAC-18.

16. Produtividades (kg/ha) observadas e estimadas pelo modelo 3, para os cultivares IAC-17, IAS-5, IAC-15 e IAC-18. 66

17. Produtividades (kg/ha) observadas e estimadas pelo modelo 4, para os cultivares IAC-17, IAS-5, IAC-15 e IAC-18.

18. Produtividades (kg/ha) observadas e estimadas pelo modelo 5 , para os cultivares IAC-17, IAS-5, IAC-15 e IAC-18. 68

19. Produtividades (kg/ha) observadas e estimadas pelo modelo 6, para os cultivares IAC-17, IAS-5, IAC-15 e IAC-18. 69

20. Produtividades (kg/ha) observadas e estimadas pelo modelo 7 , para os cultivares IAC-17, IAS-5, IAC-15 e IAC-18 


\section{LISTA DE TABELAS}

Página

1. Valores de coeficientes de cultura (kc) em nivel decendial, para 3 comprimentos de ciclos $(120,130$ e 150) dias da cultura da soja........................................................ 20

2. Valores dos coeficientes de produtividade (ky) utilizados nos modelos 2,3 e 4 .......... 22

3. Valores dos coeficientes de produtividade (ke) utilizados no modelo 4........................ 24

4. Parâmetros $\alpha, \beta$ e $\gamma$ da função curvilínea assimétrica e coeficiente de determinação relativos aos cultivares de soja IAC-13, IAC-12 e IAC-11 ........................................ 27

5. Produtividades potenciais determinadas para os cultivares IAC-17, IAS-5, IAC-15 e IAC-18, em função da época de semeadura

6. Duração média em dias dos estádios fenológicos e do ciclo semeadura-maturação para os três cultivares (IAC-13, IAC-12 e IAC-11) em diferentes épocas de semeadura

7. Duração média em dias dos estádios fenológicos e do ciclo semeadura-maturação para os cultivares precoces IAC-17 E IAS-5 e semiprecoces IAC-15 e IAC-18, em diferentes épocas de semeadura.

8. Relações ER/EP do balanço hídrico climatológico (BHclim) e do balanço hídrico com o uso de coeficiente de cultura (BHkc) para o cultivar IAC-13, em diferentes épocas de semeadura

9. Relações ER/EP do balanço hídrico climatológico (BHclim) e do balanço hídrico com o uso de coeficiente de cultura (BHkc) para o cultivar IAC-12, em diferentes épocas de semeadura. 
10. Relações ER/EP do balanço hídrico climatológico (BHclim) e do balanço hídrico com o uso de coeficiente de cultura (BHkc) para o cultivar IAC-11, em diferentes épocas de semeadura

11. Valores de ky' (coeficientes de produtividade) e $\lambda^{\prime}$ (coeficientes de sensibilidade) determinados a partir de BHclim e BHkc para os modelos 5, 6 e 7, para o cultivar IAC-13 (grupo Precoce)

12. Valores de ky' (coeficientes de produtividade) e $\lambda$ ' (coeficientes de sensibilidade) determinados a partir de BHclim e BHkc para os modelos 5, 6 e 7, para o cultivar IAC-12 (grupo Semiprecoce).

13. Valores de ky' (coeficientes de produtividade) e $\lambda^{\prime}$ (coeficientes de sensibilidade) determinados a partir de BHclim e BHkc para os modelos 5, 6 e 7, para o cultivar IAC-11 (grupo Médio).

14. Valores dos coeficientes de produtividade (ky) propostos por Doorenbos \& Kassam (1979) (a) e determinados pelos modelos 5 (b) e 6 (c), para os cultivares IAC-13, IAC-12 e IAC-11

15. Resultados estatísticos da análise do desempenho dos modelos 1 a 7 referentes ao BHclim para os cultivares IAC-13, IAC-12 e IAC-11. 49

16. Resultados estatísticos da análise do desempenho dos modelos 1 a 7 referentes ao BHkc para os cultivares IAC-13, IAC-12 e IAC-11..

17. Relações ER/EP do balanço hídrico climatológico (BHclim) para os cultivares precoces (IAC-17 e IAS-5) e semiprecoces (IAC-15 e IAC-18), em diferentes épocas de semeadura.

18. Resultados estatísticos da análise do desempenho dos modelos 1 a 7 para os cultivares IAC-17 e IAS-5 (grupo Precoce).

19. Resultados estatísticos da análise do desempenho dos modelos 1 a 7 para os cultivares IAC-15 e IAC-18 (grupo Semiprecoce). 


\title{
DESENVOLVIMENTO E ANÁLISE DE MODELOS
}

AGROMETEOROLÓGICOS DE ESTIMATIVA DE

\section{PRODUTIVIDADE PARA A CULTURA DA SOJA NA REGIÃO DE RIBEIRÃO PRETO, SP.}

\author{
Autora: ADRIANA VIEIRA DE CAMARGO MORAES \\ Orientador: Dr. MARCELO BENTO PAES DE CAMARGO
}

\section{RESUMO}

A modelagem agrometeorológica permite antecipadamente $o$ conhecimento quantitativo da influência das condições climáticas sobre 0 desenvolvimento e a produção de culturas agrícolas. A maior abrangência e confiabilidade de utilização dos modelos de estimativa de produtividade pode ser conseguida através da parametrização dos coeficientes e teste dos modelos para uma determinada região. Os dados fenológicos e de produtividade necessários para as análises foram oriundos de ensaios de épocas de semeadura conduzidos na Estação Experimental de Ribeirão Preto, SP, do IAC. Para o teste e parametrização dos modelos clássicos, utilizou-se dados dos anos agrícolas de 1983/84, 1984/85, 1989/90 e 1990/91. Foram analisados os cultivares de soja IAC-13 (precoce), IAC-12 (semiprecoce) e IAC-11 (médio). Os modelos considerados baseiam-se na penalização da produtividade potencial da cultura em função das relações ER/EP (evapotranspirações real e potencial) ocorridas durante os diferentes estádios fenológicos. Estas relações foram obtidas por meio dos balanços hídricos climatológico (BHclim) e de cultura (BHkc), o qual, além de considerar a capacidade de água disponível (CAD) variável, incorpora um coeficiente de cultura $(\mathrm{kc})$, de acordo com o estádio fenológico. Foram 
determinados os coeficientes de produtividade (ky's) para os modelos aditivos e multiplicativos, que, por meio dos resultados advindos do BHclim, se aproximaram dos propostos por Doorenbos \& Kassam (1979), especialmente para o cultivar de ciclo precoce. Os índices de sensibilidade $\left(\lambda_{\mathrm{s}}^{\prime}\right)$ também se assemelharam aos encontrados na literatura, como os desenvolvidos para condições brasileiras do Rio Grande do Sul e de Nebraska, EUA. Os valores mais elevados coincidiram com os estádios fenológicos do florescimento e enchimento de grãos. Os modelos testados e os parametrizados apresentaram bom desempenho nas estimativas da produtividade para os três grupos de maturação, apresentando coeficientes de determinação $\left(R^{2}\right)$ de 0,69 a 0,87 e índices de concordância (d) de 0,71 a 0,95 . A utilização dos resultados obtidos pelo BHkc não apresentou desempenho superior aos do BHclim.

Para o teste dos modelos parametrizados foram utilizados dados fenológicos e de produtividade dos cultivares precoces IAC-17, IAS-5, e semiprecoces IAC-15 e IAC-18, durante os anos agrícolas de 1995/96 e 1996/97, em virtude da grande evolução na obtenção de novos cultivares de soja, na década de 90 , ter direcionado as pesquisas a se concentrarem nesses novos cultivares. Embora tais cultivares pertencessem aos mesmos grupos de maturação utilizados na parametrização, os desempenhos dos modelos, tanto os clássicos como os parametrizados, não foram satisfatórios, com os mais elevados valores de $R^{2}$ e de índice d, respectivamente, de 0,52 e 0,72, em função, provavelmente, da pequena variabilidade nas produtividades observadas e do não conhecimento específico das produtividades potenciais dos novos cultivares considerados. 


\title{
DEVELOPMENT AND ANALYSIS OF AGROMETEOROLOGICAL MODELS FOR PREDICTING SOYBEAN CROP PRODUCTION IN RIBEIRÃO PRETO REGION (STATE OF SÃO PAULO, BRAZIL).
}

\author{
Author: ADRIANA VIEIRA DE CAMARGO MORAES \\ Advisor: Dr. MARCELO BENTO PAES DE CAMARGO
}

\section{SUMMARY}

The agrometeorological models allow better knowledge of the quantitative influence of the climatic conditions, such as drought effects on the soybean development and grain production. A good model requires the evaluation of the sensitivity indices and test for a specific variety and region. Phenological and yield data were taken from planting date experiments conducted at Ribeirão Preto Instituto Agronômico Experimental Station during four years. Three cultivars were considered according the maturation group: IAC-13 (early), IAC-12 (semi-early) and IAC-11 (median). The models developed and tested are based upon the penalization of the potential crop yield according the ER/EP relation (actual/potential evapotranspiration) and water excess, derived by two 10-day soil water balances, occurred during four growth stages. The soil water balance results were used to derive the ER and EP data, one, climatological (BHclim), and the other one (BHkc) using crop coefficients (ky) and variable CAD, according the growth stage. These ratios were weighted by derivation of the crop phase sensitivity indices (lambda values) and crop phase yield-response coefficients (ky values) in additive and multiplicative type models. The ER/EP relations from BHkc did not improve the performance of the models when compared with those from BHclim. All 
sensitivity indices presented positive values during the flowering, pod formation, and pod fill stages. The ky values were similar to the Doorenbos and Kassam (1979) data, especially for the IAC-13 variety. Based on the model's statistics, all parameterized models presented $R^{2}$ higher than 0.83 and d-index of agreement higher than 0.93 . The parameterized models were tested with independent data set from Ribeirão Preto region. Field data were taken from two growing seasons (1995/96 and 1996/97), using four cultivars: IAC-17 (early), IAS-5 (early), IAC-15 (semi-early), and IAC-18 (semi-early). Although these new cultivars belong to the same maturation groups, the performance of both classical and parameterized models were not satisfactory. Probably due the small yield variation occurred in those years and lack of complete information on the potential yield for these new cultivars. 


\section{INTRODUÇÃo}

A agricultura, entre todas as atividades econômicas, é a que apresenta maior dependência das condições meteorológicas. Os elementos meteorológicos são os principais responsáveis pelas oscilações e frustrações das safras agrícolas em todo o Brasil. As relações entre os parâmetros climáticos e a produção agrícola são bastante complexas, pois os fatores ambientais podem afetar o crescimento e o desenvolvimento das plantas sob diferentes formas nos diversos estádios do ciclo da cultura (Ortolani \& Camargo, 1987). Para a determinação das exigências climáticas de uma cultura, há necessidade de que os estudos agroclimáticos sejam complementados com observações fenológicas. Caracteriza-se assim o estudo de bioclimatologia, pela análise quantitativa e qualitativa da ação do ambiente sobre o desenvolvimento e a produtividade vegetal. Para melhor entendimento dessas interações, modelos agrometeorológicos têm sido utilizados visando caracterizar os efeitos das variações climáticas sobre a produtividade de grãos. São exemplos os modelos de Pedro Júnior et al. (1984), Camargo et al. (1986), Meyer (1990), Camargo (1993), Berlato \& Molion (1993) e Matzenauer (1994).

Os modelos agrometeorológicos consideram que cada elemento climático exerce um certo controle na produtividade da cultura, interferindo como um fator de eficiência, e que a produção final seria função da produtividade potencial da região e da sua interação com os elementos meteorológicos. [Uma boa estimativa de produtividade implica, portanto, na elaboração de modelos que considerem os efeitos ambientais sobre 
processos fisiológicos determinantes da produção, constituindo-se em ferramenta importante tanto para o agricultor e a indústria, quanto para o planejador vinculado a órgãos governamentais, visando a implantação de políticas agrícolas adequadas segundo as projeções resultantes desses modelos.

A soja representa hoje para o país uma importante fonte de divisas, o que justifica a busca de novas pesquisas no sentido de otimizar o seu cultivo. Atualmente destaca-se como a principal fonte para a produção de óleo vegetal no mundo. As pesquisas que visam quantificar a resposta da cultura às condições ambientais aparecem como parte importante nesse universo, uma vez que contribuem sensivelmente para o desenvolvimento de estudos na área de melhoramento genético, bem como para decisões operacionais e estratégicas (Costa \& Costa, 1989).

A produção de grãos vem crescendo bastante no Brasil, porém, para aumentá-la, não é suficiente somente a ampliação das fronteiras agrícolas, é necessário melhorar a produtividade no setor rural, com novas técnicas de plantio, seleção de novos cultivares e, principalmente, utilização mais racional dos recursos naturais e das condições climáticas. Os modelos agrometeorológicos e a interpretação de dados climáticos relacionados com o crescimento, desenvolvimento e produtividade das culturas fornecem informações que permitem ao setor agrícola tomar importantes decisões, tais como: melhor planejamento do uso do solo, adaptação de culturas, monitoramento e previsão de safras, controle de pragas e doenças, estratégia de pesquisa e planejamento (Lazinski, 1993).

Os processos de produção fotossintética e evapotranspiração são relacionados (Hanks \& Rasmussen, 1982). O processo de fotossíntese torna-se limitado quando ocorre déficit hídrico, devido ao fechamento dos estômatos e redução em outras atividades da planta, como os processos de transporte, que permitem a disponibilidade de $\mathrm{CO}_{2}$ para a fotossintese e fornecem água para a evapotranspiração. Assim, a produção pode ser estimada como função da taxa de evapotranspiração. 
Considerando-se essa premissa, este trabalho teve o objetivo de desenvolver, adaptar e testar modelos agrometeorológicos de estimativa de produtividade para a cultura da soja na região de Ribeirão Preto-SP. Procurou-se relacionar a produtividade relativa com a evapotranspiração relativa nos diversos estádios fenológicos da cultura, visando a obtenção de modelos mais consistentes para servir de suporte aos prognósticos de produtividade. 


\section{REVISÃO DE LITERATURA}

\subsection{Exigências termofotoperiódicas}

Para muitas culturas, a duração do ciclo vegetativo pode ser descrito, em termos de exigências bioclimáticas, por um só elemento: a temperatura. Considerada sob diferentes aspectos, desde simples soma, unidades térmicas, unidades calóricas ou grausdia, sugerem a quantidade de energia que determinadas plantas necessitam para atingir um certo grau de maturidade, da emergência à colheita. Sabe-se que o ciclo das culturas, em geral, diminui consideravelmente nos locais onde as temperaturas são mais elevadas, ocorrendo acúmulo mais rápido das unidades de desenvolvimento.

$O$ conceito de graus-dia pressupõe a existência de uma temperatura-base abaixo da qual a planta não se desenvolve, e se o fizer, será a uma taxa muito reduzida. A cada grau de temperatura, acima da temperatura-base, corresponde um grau-dia. Cada espécie vegetal ou variedade possui uma temperatura-base, que pode variar em função da idade ou do estádio fenológico da planta. É comum, no entanto, adotar-se uma única temperatura-base para todo o ciclo da planta, por ser mais fácil a sua aplicação (Camargo, 1984).

O método dos graus-dia baseia-se na premissa de que uma planta necessita de uma certa quantidade de energia, representada pela soma de graus térmicos acima de uma temperatura-base, para completar determinado estádio fenológico ou mesmo o seu ciclo total, e que esta soma seria uma constante, independente da época de plantio ou do local. 
Esta teoria também assume que temperaturas diurnas e noturnas afetam igualmente $o$ crescimento e desenvolvimento da planta, e que a influência dos outros elementos tais como fotoperiodismo e umidade do solo é desprezível quando comparada à da temperatura (Brunini, 1980), bem como admite uma relação linear entre acréscimo de temperatura e desenvolvimento vegetal.

Para a soja, entretanto, tal método não tem apresentado resultados muito consistentes, tendo em vista que o fator fotoperíodo influencia significativamente o desenvolvimento da planta (Camargo, 1984).

Analisando o comportamento de diferentes variedades de soja na Argentina, Pascale et al. (1963) estimam que a temperatura média, que possibilita a semeadura da soja na primavera, deve estar entre 14 e $15^{\circ} \mathrm{C}$, concordando com Brown \& Chapman (1961), que afirmam que o estádio vegetativo da soja se inicia quando a temperatura média do ar se aproxima de $15^{\circ} \mathrm{C}$. Essa exigência é atendida, praticamente, em todo o planalto paulista, inclusive no inverno, o que permitiria o seu cultivo em qualquer período do ano, não fossem as limitações ligadas aos fatores hídricos e fotoperiódicos (Camargo et al., 1971).

Camargo (1984) obteve uma temperatura-base de $14^{\circ} \mathrm{C}$ para o ciclo fenológico semeadura/maturação, para os cultivares de soja analisados e, considerando a interação entre acumulação térmica e fotoperíodo, constatou que a temperatura influenciou mais significativamente nos cultivares menos sensíveis ao fotoperíodo (ciclo curto).

O comprimento do dia ou fotoperíodo crítico é que determina a passagem da planta do estádio vegetativo ao reprodutivo (Pascale, 1969). Como a soja é uma planta de resposta fotoperiódica do tipo quantitativo, isto é, o encurtamento do fotoperíodo acelera o seu desenvolvimento, é considerada planta de dias curtos. As plantas continuam a vegetar em dias longos, até que o período de luz se torne menor que o fotoperíodo crítico de cada variedade, quando então se inicia o estádio do florescimento (Gandolfi \& Muller, 1981). 
O fotoperíodo crítico pode ser diferente entre cultivares de uma mesma espécie e, frequentemente, está associado à latitude de adaptação. Cultivares adaptados às altas latitudes tem fotoperíodo crítico maior que cultivares adaptados às baixas latitudes. Se forem cultivadas em latitudes inferiores, irão florescer e amadurecer em menos tempo, por causa dos dias curtos, ocasionando menor porte e produtividades reduzidas. Inversamente, se uma variedade adaptada a baixas latitudes for cultivada em região de latitude maior, sofrerá influência do dia mais longo, florescerá e atingirá a maturação em maior tempo, ficando demasiadamente tardia (Howell, 1967; Major \& Johnson, 1975; Gandolfi et al., 1977).

Cada variedade exige um mínimo crítico de ausência de luz para que seja induzida ao florescimento. Desta maneira, se os dias forem bastante longos, poderá permanecer em seu estádio vegetativo quase que indefinidamente, ou poderá florescer num período inferior a um mês, se os dias forem suficientemente curtos para a indução do florescimento (Sediyama et al., 1985). Entretanto, existem variedades de soja que apresentam período juvenil bastante longo, independente do fotoperíodo. Entende-se por período juvenil, em soja, que é considerada planta de dias curtos, um estádio de desenvolvimento no qual, mesmo existindo noites com o número de horas de escuro necessárias para indução ao florescimento de determinado cultivar, este deixa de responder ao estímulo reprodutivo (Nogueira, 1983).

O fotoperíodo é a principal variável associada à influência da data de semeadura sobre a maturação, porém outras variáveis, como a acumulação térmica e a umidade do solo, podem apresentar efeitos importantes ( Pascale et al., 1963).

Com relação à interação temperatura-fotoperíodo, Major et al. (1975) concluíram que a temperatura tem influência significativa nos cultivares menos sensíveis ao fotoperíodo, sendo que o método da soma de temperatura apresentou melhor precisão na previsão de maturação, para os cultivares precoces, sugerindo que, para as variedades tardias, o fotoperíodo exerce efeito relativo mais acentuado. 


\subsection{Exigências hídricas}

Uma das informações mais úteis no estudo das relações hídricas no sistema soloplanta-atmosfera é o conhecimento das necessidades hídricas das culturas durante os diversos subperíodos do seu ciclo de desenvolvimento.

As exigências hídricas das culturas e a sensibilidade ao déficit hídrico variam ao longo do ciclo. A quantidade de água que uma cultura consome durante o seu ciclo, sem restrições hídricas no solo depende, basicamente, das condições que determinam a demanda evaporativa da atmosfera e das características da cultura. Em culturas anuais podem ocorrer grandes variações na taxa de evapotranspiração, dependendo do estádio de desenvolvimento em que se encontram as plantas. $\mathrm{O}$ conhecimento dos estádios críticos durante o ciclo de desenvolvimento das culturas, ou seja, os estádios de máxima sensibilidade ao fator água, serve como ferramenta tanto para a tomada de decisões relativas a um eficiente uso da água, como para previsões de rendimento de safras.

É importante conhecer os efeitos da deficiência hídrica sobre as culturas, para que se possa minimizar os danos ocasionados pela falta de água. Os efeitos do déficit hídrico sobre a produtividade de uma cultura vão depender da sua intensidade, duração, época de ocorrência e da interação com outros fatores determinantes da expressão da produtividade final (Cunha \& Bergamaschi, 1992).

Em condições de boa disponibilidade hídrica e alta demanda evaporativa da atmosfera, a taxa de transpiração é elevada. No momento em que a planta não consegue absorver água suficiente para repor as perdas por transpiração, ou seja, quando ocorre um desequilíbrio entre a transpiração e a absorção, o potencial da água na planta começa a diminuir, iniciando o déficit hídrico, podendo ou não conduzir a um estresse hídrico, dependendo da intensidade do déficit. 
O déficit hídrico afeta praticamente todos os aspectos relacionados ao desenvolvimento das plantas, reduzindo a área foliar, diminuindo a fotossíntese e afetando vários outros processos, além de alterar o ambiente físico das culturas, por modificar o balanço de energia do sistema (Bergamaschi, 1992).

O processo da fotossíntese é afetado com o aumento do déficit hídrico, devido ao fechamento dos estômatos e redução da área foliar. $\mathrm{O}$ fechamento dos estômatos limita o fluxo de $\mathrm{CO}_{2}$ para o interior da folha, ao mesmo tempo em que restringe o fluxo de água da folha para a atmosfera, diminuindo a taxa de transpiração.

De acordo com Berlato et al. (1992), as baixas produtividades médias da cultura da soja, no Rio Grande do Sul, estão relacionadas a anos em que ocorreram deficiências hídricas durante os meses de desenvolvimento da cultura e que, em anos considerados muito secos, as produtividades médias estiveram abaixo de uma tonelada por hectare.

Estudando o efeito do fator hídrico durante o ciclo da cultura da soja, nas condições do Estado de São Paulo, Arruda et al. (1978) verificaram sua importância no estádio de estabelecimento da cultura, reduzindo-se na época do crescimento vegetativo e aumentando-se gradativamente a partir do florescimento até a formação de vagens. Pouca importância apresenta no final do ciclo, durante a época de maturação.

Shaw \& Laing (1965) estudaram o efeito de déficits hídricos ocorridos durante vários estádios da cultura da soja, sendo o que provocou maiores reduções na produção de grãos foi o estádio de enchimento de vagens, resultando em um menor número de grãos por vagem. Déficit hídrico durante o florescimento provocou também quebras nas produções, reduzindo o número total de vagens.

Informações semelhantes foram relatadas por Doorenbos \& Kassam (1979). O déficit ou excesso de água, durante o estádio vegetativo, retardam o crescimento. Os estádios de desenvolvimento mais sensíveis ao déficit hídrico são germinação-emergência e floração-enchimento de grãos (desenvolvimento das vagens), quando o déficit hídrico pode ocasionar forte queda de flores e vagens. 
Tem sido observado que a variação anual de produtividade da soja é uma função mais hídrica do que térmica (Camargo et al., 1986). Diversos trabalhos têm sido feitos para avaliar o efeito do déficit hídrico no desenvolvimento e crescimento da soja, por ser um dos principais fatores limitantes da produtividade (Lazinski, 1993).

\subsection{Classificação de modelos agrometeorológicos}

A classificação dos modelos baseia-se nas aproximações que consideram para descrever o efeito da variabilidade climática. Baier (1979) dividiu os modelos das interações solo-planta-atmosfera em:

a) aproximação estatística ou de análise de regressão múltipla;

b) aproximação fisiológica e/ou matemática dos processos envolvidos (mecanístico), que consideram princípios físicos e biológicos do sistema. Por seu grau de detalhamento, a sua aplicação possui pouca restrição à extrapolação geográfica e espacial.

Detalhando essas aproximações, Robertson (1983b) sugeriu três tipos de modelos agroclimáticos:

a) modelo empírico-estatístico, no qual a condição pluviométrica ocorrida durante o ciclo da cultura é, em geral, a variável meteorológica determinante, como no trabalho de Fisher (1924);

b) modelo físico-estatístico, onde os processos envolvidos durante o ciclo são descritos matematicamente, por análises parciais, como no trabalho de Baier (1973);

c) modelo dinâmico, que exige um grau de detalhamento individual para cada processo envolvido, sendo fundamental um grande número de informações climatológicas e fenológicas, como no trabalho de Splinter (1974) com milho.

Acock \& Acock (1991) classificaram os modelos em três tipos: 
Conceitual, físico e matemático (empírico e mecanístico). Com a incorporação da informática, o modelo matemático vem se tornando mais aplicável. $\mathrm{O}$ chamado matemático-empírico (estatístico) descreve as relações entre variáveis sem considerar os processos, apresentando certas restrições para a extrapolação de resultados. O matemático-mecanístico (simulador) descreve a casualidade ou a relação entre as variáveis, baseado no processo que ocorre no sistema real. Suas restrições são poucas em relação à extrapolação de resultados.

\subsection{Modelos agrometeorológicos de estimativa de produtividade}

Os elementos meteorológicos exercem grande influência sobre o crescimento, desenvolvimento e rendimento das plantas, determinando a distribuição e a produção das culturas. A disposição de técnicas que permitam a interpretação dessa variabilidade climática na produção vegetal são as principais propostas dos modelos agrometeorológicos.

Modelos matemáticos podem ser ótimos mecanismos de previsão ou de estimativa de produtividade. Porém, um bom modelo deve ser suficientemente simples para permitir sua manipulação e entendimento, e suficientemente complexo para permitir extrapolações e conclusões (Pereira, 1987).

Os modelos possuem ampla aplicação nas atividades agrícolas e agrometeorológicas (Robertson, 1983a). O zoneamento agrícola e o planejamento de uso da terra podem ser baseados em resultados de vários modelos, pela execução de cartas $\mathrm{e}$ mapas. O planejamento das semeaduras e o monitoramento das épocas de colheita podem ser obtidos pela caracterização da duração dos ciclos das culturas.

A perda de água no solo é uma função conjunta da disponibilidade de energia na atmosfera, que causa a evaporação do solo e transpiração das plantas, e o suprimento de água disponível no solo (Dale \& Shaw, 1965). Esta relação pode ser expressa com um 
índice "R", ou seja, a razão entre a "ER" e a "EP". A "ER" é relacionada com a disponibilidade hídrica no solo, e a "EP" representa a demanda hídrica atmosférica. Assim, $o$ índice " $R$ " seria uma medida do suprimento hídrico para a planta em relação à necessidade ( Yao, 1969). Diferenças significativas podem ser encontradas no valor de "R", dependendo do método utilizado no cálculo de “ER" e "EP" (Yao, 1973).

Grande parte dos trabalhos apresentam modelos que utilizam, como variável independente, alguma expressão da disponibilidade hídrica, como precipitação pluvial, transpiração, evapotranspiração real, deficiência hídrica, relações entre a precipitação e a evapotranspiração de referência, ou ainda entre as evapotranspirações real e potencial. Rao et al. (1988) analisaram uma série de modelos que utilizam alguma expressão do déficit hídrico, como o proposto por Doorenbos \& Kassam (1979), que relaciona estresse por deficiência hídrica e produção, a partir de informações sobre dados experimentais de diversas culturas. Essa função de produção foi correlacionada empiricamente com fatores derivados de coeficientes (ky) que penalizam a produtividade por estresse hídrico durante os diferentes estádios fenológicos das culturas, da seguinte forma:

$$
\frac{Y r}{Y_{p}}=1-k y\left(1-\frac{E R}{E P}\right)
$$

onde Yr é a produtividade estimada; Yp a produtividade máxima ou potencial; ER a evapotranspiração real; EP a evapotranspiração potencial e ky o coeficiente de penalização da produtividade por déficit hídrico.

De acordo com Rao et al. (1988), esse modelo quantifica o efeito do déficit hídrico durante os estádios fenológicos, independentemente uns dos outros. Se o ciclo total de uma cultura for dividido em $n$ estádios fenológicos $(i=1, n)$ e ocorrendo deficiência hídrica durante, por exemplo, o estádio vegetativo isoladamente, o modelo ficaria: 


$$
\frac{Y r_{1}}{Y p}=1-k y_{1}\left(1-\frac{E R}{E P}\right)_{1}
$$

onde o sufixo 1 refere-se ao primeiro estádio fenológico. As respostas aos déficits hídricos ocorridos em qualquer outro estádio seriam similares a essa equação. Para déficit hídrico em mais de um estádio fenológico, a função de produção hídrica combina os efeitos, da seguinte forma:

$$
F=F\left(f_{1}, f_{2}, \ldots, f(n)\right.
$$

onde n é o número de estádios fenológicos, para os valores de ky.

Três hipóteses são consideradas na classificação proposta por Vossen (1990), que relaciona condições hídricas e redução de produtividade:

a) a redução de produção é relacionada com o déficit hídrico acumulado durante todo o ciclo da cultura;

b) a deficiência hídrica afeta diferentemente a produção, dependendo do estádio fenológico em que ocorre o estresse hídrico, sendo o efeito final aditivo;

c) a deficiência hídrica afeta diferentemente a produção, dependendo do estádio fenológico em que ocorre o estresse hídrico, sendo o efeito final multiplicativo.

Algumas formulações têm sido propostas para descrever a função $F$, sendo que as mais utilizadas são as de forma aditiva e multiplicativa.

Um modelo aditivo foi proposto por Doorenbos \& Kassam (1979), baseado no modelo de Stewart et al. (1976):

$$
\frac{Y r}{Y p}=1-\sum_{i=1}^{n} k y_{i}\left(1-\frac{E R_{i}}{E P_{i}}\right)
$$


onde ky são os coeficientes de produtividade, que substituíram as relações de resposta da produção $\mathrm{YRR}_{i}$ originais de Stewart et al. (1976).

Posteriormente, Rao et al. (1988) alteraram a formulação proposta por Doorenbos \& Kassam (1979) para a forma multiplicativa, da seguinte forma:

$$
\frac{Y r}{Y_{p}}=\prod_{i=1}^{n}\left[1-k y_{i}\left(1-\frac{E R_{i}}{E P_{i}}\right)\right]
$$

Jensen (1968) também apresentou um modelo multiplicativo, em função de diferentes índices de sensibilidade a déficit hídrico. Considera um produtório, o que reduzirá a produção final à medida em que as necessidades hídricas da cultura não forem satisfeitas, nos diferentes estádios fenológicos, da seguinte forma:

$$
\frac{Y r}{Y p}=\prod_{i=1}^{n}\left(\frac{E R_{i}}{E P_{i}}\right)^{\lambda i}
$$

Segundo Rao et al. (1988), essas três formulações apresentam resultados semelhantes, porém sob baixos níveis de umidade do solo, ou seja, sob baixos valores da relação ER/EP, o modelo aditivo pode apresentar problemas. Os modelos multiplicativos não apresentam essa limitação, porém o modelo de Jensen (1968) necessita da determinação dos índices de sensibilidade $(\lambda)$ ao déficit hídrico nos diferentes estádios fenológicos.

Nos estudos da variabilidade da produtividade de culturas, muitos autores utilizaram a razão "ER/EP”, entre eles: Nix \& Fitzpatrick (1969); Hillel \& Guron (1973); Pascale et al. (1973); Hanks (1974); Yao (1974); Shaw (1978); Segovia \& Andrade (1982); Camargo et al. (1986, 1988); Meyer (1990); Berlato et al. (1992); Berlato \& 
Molion (1993); Camargo (1993); Matzenauer (1994); Meyer \& Hubbard (1995); Ortolani et al. (1996).

\subsubsection{Modelos agrometeorológicos de estimativa de produtividade para a cultura da soja}

A precipitação pluvial é o elemento meteorológico que mais tem sido utilizado no desenvolvimento de modelos previsores de safra, sendo o primeiro a ser utilizado para caracterizar o efeito da seca na cultura da soja ( Thompson, 1970).

Considerando diferentes estádios do desenvolvimento da cultura da soja e as precipitações ocorridas em cada um, Arruda et al. (1978) concluíram ser possível fazer estimativas de produção de grãos com relativa precisão.

Do efeito quantitativo da baixa disponibilidade hídrica no solo e sua consequêencia na redução das safras de soja no Estado do Rio Grande do Sul, Mota (1981) estabeleceu um índice de seca, que corresponde ao somatório dos valores diários de (1-ER/EP), no período trimestral de dezembro a fevereiro. Verificou também a necessidade da utilização de um fator de ajuste, porque as produtividades estimadas foram demasiadamente mais baixas do que se poderia esperar, quando o citado índice de seca era superior a 0,45. Ponderação semelhante foi usada por Shaw (1977) em milho, com resultados satisfatórios.

Segovia \& Andrade (1982) propuseram um modelo que penaliza a produtividade máxima de uma cultura qualquer, quando o teor de umidade do solo se torna menor que o considerado ideal. Estabeleceram as variações de produtividade de uma cultura em função de precipitação pluvial e porcentagem de espaço poroso no solo. A partir deste modelo, Brunini et al. (1982) obtiveram a relação "ER/EP" e teores de água disponível no solo, baseados em trabalho de Mason et al. (1980), para a penalização da produtividade da cultura da soja em decorrência do déficit hídrico. Foi introduzido 
também um fator de correção para excedentes hídricos, o "fator excedente", diferenciando assim, no modelo original de Segovia \& Andrade (1982), os efeitos do déficit e do excedente hídricos.

Pedro Júnior et al. (1984) aplicaram o modelo proposto por Doorenbos \& Kassam (1979) em sua forma multiplicativa, para a estimativa da produtividade da soja de ciclo precoce, para as condições do Estado de São Paulo. Encontraram resultados bastante satisfatórios, principalmente nos anos sem ocorrência de excedentes hídricos elevados. Entretanto, a definição da produtividade potencial para diferentes regiões de Estado foi uma dificuldade inerente ao método. Posteriormente, Camargo et al. (1988) adaptaram um modelo agrometeorológico de estimativa da produtividade potencial para a soja, para as condições de Ribeirão Preto, baseado em modelo proposto por Doorenbos \& Kassam (1979), em função de diferentes épocas de semeadura, visando solucionar esta dificuldade.

Berlato et al. (1992) e Berlato \& Molion (1993) também relacionaram a produtividade de grãos de soja com variáveis meteorológicas. A precipitação esteve fortemente correlacionada com a produtividade de grãos durante o estádio reprodutivo. A correlação mais alta encontrada foi entre a produtividade de grãos e o índice "ER/EP" (evapotranspiração real sobre evapotranspiração potencial), durante o estádio reprodutivo. 


\section{MATERIAL E MÉTODOS}

\subsection{Material}

Dados fenológicos e de produtividade da cultura da soja necessários para a parametrização e teste dos modelos foram obtidos de experimentos conduzidos pela Seção de Leguminosas do Instituto Agronômico (IAC) na Estação Experimental de Ribeirão Preto, SP (lat.: $21^{\circ} 12^{\prime} \mathrm{S}$, long.: $47^{\circ} 57^{\prime} \mathrm{W}$ e alt.: $621 \mathrm{~m}$ ), dentro do programa de ensaios de épocas de semeadura.

Os cultivares de soja utilizados para a parametrização, segundo os grupos de maturação (Miranda et al., 1985), foram: IAC-13, do grupo precoce; IAC-12, semiprecoce; e IAC-11, do grupo de maturação médio.

Os experimentos foram conduzidos durante os anos agrícolas de 1983/84, 1984/85, 1989/90 e 1990/91. As épocas de semeadura variaram de setembro a janeiro.

Para o teste dos modelos foram utilizados dados independentes. Porém, como a cultura da soja apresenta rápida evolução na obtenção de novos cultivares, não foi possível testar os modelos com os mesmos materiais genéticos. Apesar dos cultivares IAC-13, IAC-12 e IAC-11 ainda serem recomendados para o Estado de São Paulo (Fahl et al., 1998), eles não têm sido incluídos nos ensaios de épocas de semeadura desde 1992. Os cultivares utilizados nos testes foram: IAC-17 (precoce); IAS-5 (precoce); IAC-15 (semiprecoce) e IAC-18 (semiprecoce). 
Os dados independentes foram obtidos de ensaios de épocas de semeadura conduzidos durante os anos agrícolas de 1995/96 e 1996/97, na Estação Experimental, de Ribeirão Preto do IAC, sendo as semeaduras realizadas de outubro a dezembro.

O delineamento experimental adotado foi o de blocos casualizados com parcelas subdivididas, sendo as parcelas as épocas de semeadura e as sub-parcelas, os cultivares. Cada parcela experimental continha seis linhas de $5 \mathrm{~m}$ de comprimento, espaçadas de $0,60 \mathrm{~m}$, com uma densidade de vinte plantas por metro linear, e quatro repetições. Para efeito de amostragem, foram colhidas apenas as duas linhas centrais de cada parcela.

Os tratos culturais foram semelhantes em todos os anos agrícolas, efetuando-se os controles fitossanitários necessários. O ensaio foi conduzido em latossolo roxo eutrófico.

Durante o ciclo de cada cultura, assinalaram-se os seguintes dados:

- data de semeadura;

- data de início de florescimento, quando $50 \%$ das plantas tinham pelo menos uma flor;

- data de colheita;

- produtividade de grãos.

Os dados meteorológicos diários, relativos aos períodos considerados, foram obtidos no posto meteorológico, pertencente à Seção de Climatologia Agrícola, do Instituto Agronômico, situado a aproximadamente $500 \mathrm{~m}$ do local dos experimentos.

A precipitação pluvial foi medida em pluviômetros, tipo Ville de Paris, com a área de captação à altura de $1,50 \mathrm{~m}$ do solo.

A temperatura do ar foi obtida em abrigos meteorológicos padronizados, segundo a Organização Meteorológica Mundial (OMM), com termômetros meteorológicos, de vidro, com mercúrio e álcool como elementos sensíveis, localizados a 1,70 m de altura.

As temperaturas médias diárias foram obtidas através da média aritmética entre as temperaturas máxima e mínima absolutas. 
Foram considerados quatro estádios fenológicos para a cultura da soja:

I. desenvolvimento vegetativo;

II. florescimento;

III. formação da vagem e enchimento de grãos e

IV. maturação

\subsection{Métodos}

Para a estimativa da disponibilidade hídrica durante o ciclo da cultura utilizou-se dois tipos de balanços hídricos. O primeiro, o método do balanço hídrico climatológico (BHclim) de Thornthwaite \& Mather (1955), um método tradicional na caracterização do fator hídrico. É baseado no cotejo de duas curvas, uma referente à marcha da precipitação e outra à evapotranspiração potencial (EP), que corresponde à precipitação ideal no período, de forma a não sobrar nem faltar água no solo para uso das plantas (Camargo, 1962). Os valores de EP representam o consumo de água referente a um extenso gramado em crescimento ativo, sem restrições de umidade do solo.

Para o cálculo dos balanços hídricos (BHclim), em forma seqüencial e decendial, foi utilizado programa desenvolvido para microcomputador (Barbieri et al., 1991), para o qual foram fornecidas as informações das coordenadas geográficas e os dados de precipitação pluvial e temperatura média.

Considerou-se $100 \mathrm{~mm}$ como capacidade de água disponível (CAD) no solo, em função das suas características (latossolo roxo eutrófico), conforme Alfonsi et al. (1990): capacidade de campo (31\%), ponto de murcha permanente (21\%), densidade global do solo $\left(1,1 \mathrm{~g} / \mathrm{cm}^{3}\right)$. A profundidade de exploração de $80 \%$ das raízes foi considerada como $90 \mathrm{~cm}$, de acordo com Gandolfi et al. (1983), e a partir da expressão: 


$$
\begin{aligned}
& C A D=\frac{C C-P M P}{10} * d g * h \quad \text {, têm-se que: } \\
& C A D=\frac{31-21}{10} * 1,1 * 90 \cong 100 \mathrm{~mm}
\end{aligned}
$$

Uma segunda forma de estimativa de disponibilidade hídrica foi também calculada, específica para a cultura da soja, por meio de balanços hídricos que consideram coeficientes de cultura, em função dos diferentes estádios fenológicos ( $\mathrm{BH} \mathrm{kc}$ ). Os valores dos coeficientes de cultura (kc) foram obtidos de Doorenbos \& Kassam (1979) e adaptados às condições paulistas por Alfonsi et al. (1990), os quais estão apresentados na Tabela 1.

Para o cálculo do BHkc, a CAD foi considerada em função dos estádios fenológicos, apresentando valores variáveis de acordo com o crescimento e desenvolvimento das plantas, especialmente quanto à profundidade de exploração das raízes. Nesta estimativa da disponibilidade hídrica, também em forma decendial, foi utilizada a versão 3.21a do programa para microcomputador BHÍDRICO (van Lier \& Dourado Neto, 1993), para o qual foram especificados o local, tipo de solo, cultura, métodos para os cálculos da EP e água disponível, e datas de semeadura. Os dados de armazenamento inicial, profundidade de molhamento e kc anterior à emergência foram os estabelecidos pelo programa, em função das informações fornecidas. Para os cálculos da EP e água disponível, foram selecionados os métodos de Thornthwaite (1948) e Thornthwaite \& Mather (1955), respectivamente, de maneira similar aos empregados no cálculo do BHclim.

A utilização do modelo de balanço hídrico decendial, considerando-se valores de kc diferenciados para cada estádio fenológico (BHkc) e CAD variável, visou a melhoria do desempenho dos modelos agrometeorológicos de estimativa de produtividade para a cultura da soja. 
Tabela 1. Valores de coeficientes de cultura (kc) em nível decendial, para 3 comprimentos de ciclos $(120,130$ e 150 dias $)$ da cultura da soja, utilizados no cálculo do balanço hídrico (BHkc).

\begin{tabular}{cccc}
\hline $\begin{array}{c}\text { Dias após } \\
\text { germinação }\end{array}$ & \multicolumn{3}{c}{ Ciclo em dias } \\
\cline { 2 - 4 } $1-10$ & 0,3 & 130 & 150 \\
$11-20$ & 0,4 & 0,3 & 0,3 \\
$21-30$ & 0,5 & 0,4 & 0,4 \\
\hline $31-40$ & 0,7 & 0,5 & 0,5 \\
$41-50$ & 0,9 & 0,7 & 0,7 \\
$51-60$ & 1,0 & 0,8 & 0,8 \\
$61-70$ & 1,2 & 1,0 & 0,9 \\
$71-80$ & 1,1 & 1,1 & 1,0 \\
$81-90$ & 1,0 & 1,2 & 1,1 \\
$91-100$ & 0,8 & 1,1 & 1,2 \\
$101-110$ & 0,7 & 1,0 & 1,1 \\
$111-120$ & 0,5 & 0,8 & 1,0 \\
$121-130$ & & 0,7 & 0,9 \\
$131-140$ & & 0,5 & 0,8 \\
$141-150$ & & & 0,7 \\
\hline
\end{tabular}

Fonte: Doorenbos \& Kassam (1979) e Alfonsi et al. (1990). 


\subsection{Teste de modelos existentes na literatura}

\subsubsection{Modelo proposto por Doorenbos \& Kassam (1979)}

Quantifica o efeito da falta de água disponível no solo sobre o decréscimo da produtividade potencial. Este modelo se baseia na penalização da produtividade potencial da cultura em função da relação “ER/EP”, ocorrida durante o ciclo da cultura, de modo que:

$$
\frac{Y r}{Y p}=1-k y\left(1-\frac{E R}{E P}\right)
$$

onde: Yr é a produtividade estimada $(\mathrm{kg} / \mathrm{ha}), \mathrm{Yp}$ a produtividade potencial $(\mathrm{kg} / \mathrm{ha}), \mathrm{ER}$ a evapotranspiração real (mm), EP a evapotranspiração potencial $(\mathrm{mm})$ e ky o coeficiente de penalização da produtividade por déficit hídrico, com valor de 0,85 para todo o ciclo.

\subsubsection{Modelo aditivo desenvolvido por Stewart et al. (1976) e proposto por Doorenbos \& Kassam (1979).}

Este modelo é baseado no modelo 1, porém considera o somatório das relações ER/EP em nível decendial, reduzindo a produtividade à medida que as necessidades hídricas da cultura da soja deixam de ser satisfeitas durante os estádios fenológicos considerados, como segue:

$$
\frac{Y r}{Y p}=1-\left[\sum_{i=1}^{4} k y_{i}\left(1-\frac{E R}{E P}\right)_{i}\right]
$$


onde $\sum$ significa somatório, $\mathrm{ky}_{\mathrm{i}}$ é o coeficiente de penalização da produtividade por déficit hídrico para cada estádio fenológico considerado, de acordo com Doorenbos \& Kassam (1979) e Camargo et al. (1986), os quais estão apresentados na Tabela 2.

Tabela 2. Valores dos coeficientes de produtividade (ky) utilizados nos modelos 2,3 e 4 .

\begin{tabular}{lc}
\hline \multicolumn{1}{c}{ Estádio fenológico } & Coeficiente de produtividade (ky) \\
\hline Desenvolvimento vegetativo & 0,2 \\
Florescimento & 0,8 \\
Enchimento de grãos & 1,0 \\
Maturação & 0,2 \\
\hline
\end{tabular}

Fonte: Doorenbos \& Kassam (1979) e Camargo et al. (1986).

\subsubsection{Modelo multiplicativo baseado em Doorenbos \& Kassam (1979) e proposto por Rao et al. (1988).}

Este modelo é baseado no anterior, porém considera o produtório das relações ER/EP em nível decendial, reduzindo a produção à medida que as necessidades hídricas da cultura da soja deixam de ser satisfeitas durante os estádios fenológicos considerados, da seguinte forma:

$$
\frac{Y r}{Y p}=\prod_{i=1}^{4}\left[1-k y_{i}\left(1-\frac{E R}{E P}\right)_{i}\right]
$$


onde $\prod$ significa produtório. Os valores de ky utilizados durante os quatro estádios fenológicos $_{(i)}$ da cultura da soja foram os mesmos do modelo aditivo, e estão apresentados na Tabela 2.

\subsubsection{Modelo multiplicativo baseado em Doorenbos \& Kassam (1979) e modificado por Camargo (1986).}

Um fator relativo à penalização para excedentes hídricos, denominado fator excedente (fe) foi proposto por Brunini et al. (1982) e adotado por Camargo et al. (1986) para a cultura da soja. A inclusão desse fator no modelo multiplicativo de Doorenbos \& Kassam (1979) melhorou o desempenho do modelo, visto que períodos com excesso de chuva, especialmente durante o florescimento até a maturação, resultam em considerável redução na produtividade de grãos (Fukui \& Ojima, 1957). O fator excedente é a relação entre o excedente do balanço hídrico (EXC) e a EP em nível decendial da seguinte forma:

$$
f e=\left[1-\frac{(E X C-E P)}{E X C}\right]
$$

Na utilização desse modelo, o excedente hídrico deve ser superior ou igual à EP. Quando a EP for maior que o excedente, o "fe" será igual à unidade, independente do resultado (Brunini et al., 1982).

Com as modificações incorporadas por Camargo et al. (1986), o modelo ficou:

$$
\frac{Y r}{Y p}=\prod_{i=1}^{4}\left[1-k y_{i}\left(1-\frac{E R}{E P}\right)_{i} *\left[1-k e_{i}\left(1-f e_{i}\right)\right]\right]
$$


onde os valores de ky foram os mesmos utilizados nos modelos 2 e 3 e ke é o coeficiente de penalização da produtividade por excedente hídrico, proposto por Camargo et al. (1986), de acordo com os estádios fenológicos da cultura, que estão apresentados na Tabela 3.

Tabela 3. Valores dos coeficientes de penalização da produtividade por excedente hídrico (ke) utilizados no modelo 4.

\begin{tabular}{ll}
\hline \multicolumn{1}{c}{ Estádio fenológico } & $\mathrm{ke}$ \\
\hline Desenvolvimento vegetativo & 0,0 \\
Florescimento & 0,1 \\
Enchimento de grãos & 0,1 \\
Maturação & 0,1 \\
\hline
\end{tabular}

Fonte: Camargo et al. (1986). 


\subsection{Desenvolvimento, parametrização e teste}

\subsubsection{Modelos aditivos e multiplicativos de Doorenbos \& Kassam (1979).}

Foram determinados os valores dos coeficientes de produtividade (ky') para os modelos aditivos e multiplicativos de Doorenbos \& Kassam (1979) nas condições de Ribeirão Preto, de acordo com os grupos de maturação da cultura da soja. Para a solução dos ky', foram utilizadas regressões lineares múltiplas entre as produtividades relativas [1-(Yr/Yp)] e as evapotranspiraçãoes relativas [1-(ER/EP)], para cada estádio fenológico (i) considerado.

Modelo aditivo: $\quad \frac{Y r}{Y p}=1-\left[\sum_{i=1}^{4} k y_{i}\left(1-\frac{E R}{E P}\right)_{i}\right]$ (modelo 5)

Modelo multiplicativo: $\quad \frac{Y r}{Y p}=\prod_{i=1}^{4}\left[1-k y_{i}^{\prime}\left(1-\frac{E R}{E P}\right)_{i}\right]$ (modelo 6)

\subsubsection{Modelo multiplicativo proposto por Jensen (1968).}

Baseado no modelo de penalização proposto por Jensen (1968), em que a produtividade de uma cultura pode ser relacionada às condições hídricas ocorridas durante estádios fenológicos críticos, através de um modelo multiplicativo, no qual são determinados índices de sensibilidade. Meyer (1990), Camargo (1993) e Meyer \& 
Hubbard (1995), adaptaram esse modelo, respectivamente, para as culturas de milho, sorgo e soja para as condições das planícies norte-americanas.

O modelo é:

$$
\frac{Y r}{Y p}=\prod_{i=1}^{4}\left(\frac{\sum E R_{i}}{\sum E P_{i}}\right)^{\lambda i}
$$

onde" $\lambda$ " é o coeficiente ou índice de sensibilidade e "i" é o estádio fenológico da cultura. Esse modelo baseia-se, portanto, na penalização da produtividade à medida que haja restrição hídrica, sendo dependente do estádio fenológico da cultura. A penalização é contabilizada através de coeficientes de sensibilidade, os quais foram determinados por meio de regressão múltipla transformada semelhante ao método empregado por Meyer (1990) e Camargo (1993).

\subsection{Produtividade Potencial}

A produtividade potencial dos cultivares de soja IAC-13, IAC-12 e IAC-11 foi estimada através de modelo matemático proposto por Camargo et al. (1988), o qual contempla também estes três cultivares. É uma função matemática que ajusta dados de produtividade potencial em função de diferentes épocas de semeadura, específico para a região de Ribeirão Preto. A função curvilínea assimétrica é a seguinte:

$$
Y=\alpha * x^{\beta} * \exp (-\gamma * x)
$$

onde $\mathrm{Y}$ é a produtividade potencial estimada $\mathrm{em} \mathrm{kg} / \mathrm{ha} ; \alpha, \beta$ e $\gamma$ são os parâmetros da função e x é a época de semeadura em dias a partir de $1^{\circ}$ de agosto. Os parâmetros $\alpha$, 
$\beta$ e $\gamma$, assim como o $\mathrm{R}^{2}$, relativos aos três cultivares de soja (IAC-13, IAC-12 e IAC-11), estão listados na Tabela 4.

Tabela 4. Parâmetros $\alpha, \beta$ e $\gamma$ da função curvilínea assimétrica e coeficiente de determinação relativos aos cultivares de soja IAC-13, IAC-12 e IAC-11.

\begin{tabular}{cccccc}
\hline & Grupo de & \multicolumn{3}{c}{ Parâmetros } & \multirow{2}{*}{$\mathrm{R}^{2}$} \\
\cline { 3 - 5 } Cultivar & maturação & $\alpha$ & $\beta$ & $\gamma$ & 0,94 \\
IAC-13 & Precoce & 2,260 & 2,258 & 0,031 & 0,94 \\
IAC-12 & Semiprecoce & 24,250 & 1,714 & 0,028 & 0,93 \\
IAC-11 & Médio & 630,114 & 0,799 & 0,019 & 0,97 \\
\hline
\end{tabular}

Fonte: Camargo et al. (1988).

A Figura 1 apresenta a produtividade potencial estimada para os cultivares IAC13, IAC-12 e IAC-11 em função das épocas de semeadura, de setembro a janeiro.

Devido à ausência de informações sobre a produtividade potencial para os cultivares IAC-17, IAS-5, IAC-15 e IAC-18, foi considerada como produtividade potencial a maior produtividade obtida nos anos considerados, conforme a época (mês) de semeadura, acrescida de 10\%, segundo o critério utilizado por Kanemasu (1983). Essas produtividades potenciais estão apresentadas na Tabela 5.

Tabela 5. Produtividades potenciais determinadas para os cultivares IAC-17, LAS-5, IAC-15 e IAC-18, em função da época de semeadura.

\begin{tabular}{ccccc}
\hline Época de & \multicolumn{4}{c}{ Produtividades potenciais (kg/ha) } \\
\cline { 2 - 5 } semeadura & IAC-17 & IAS-5 & IAC-15 & IAC-18 \\
\hline Outubro & 3220 & 3395 & 3419 & 3805 \\
Novembro & 3494 & 3676 & 3338 & 3900 \\
Dezembro & 3321 & 3456 & 3265 & 3456 \\
\hline
\end{tabular}




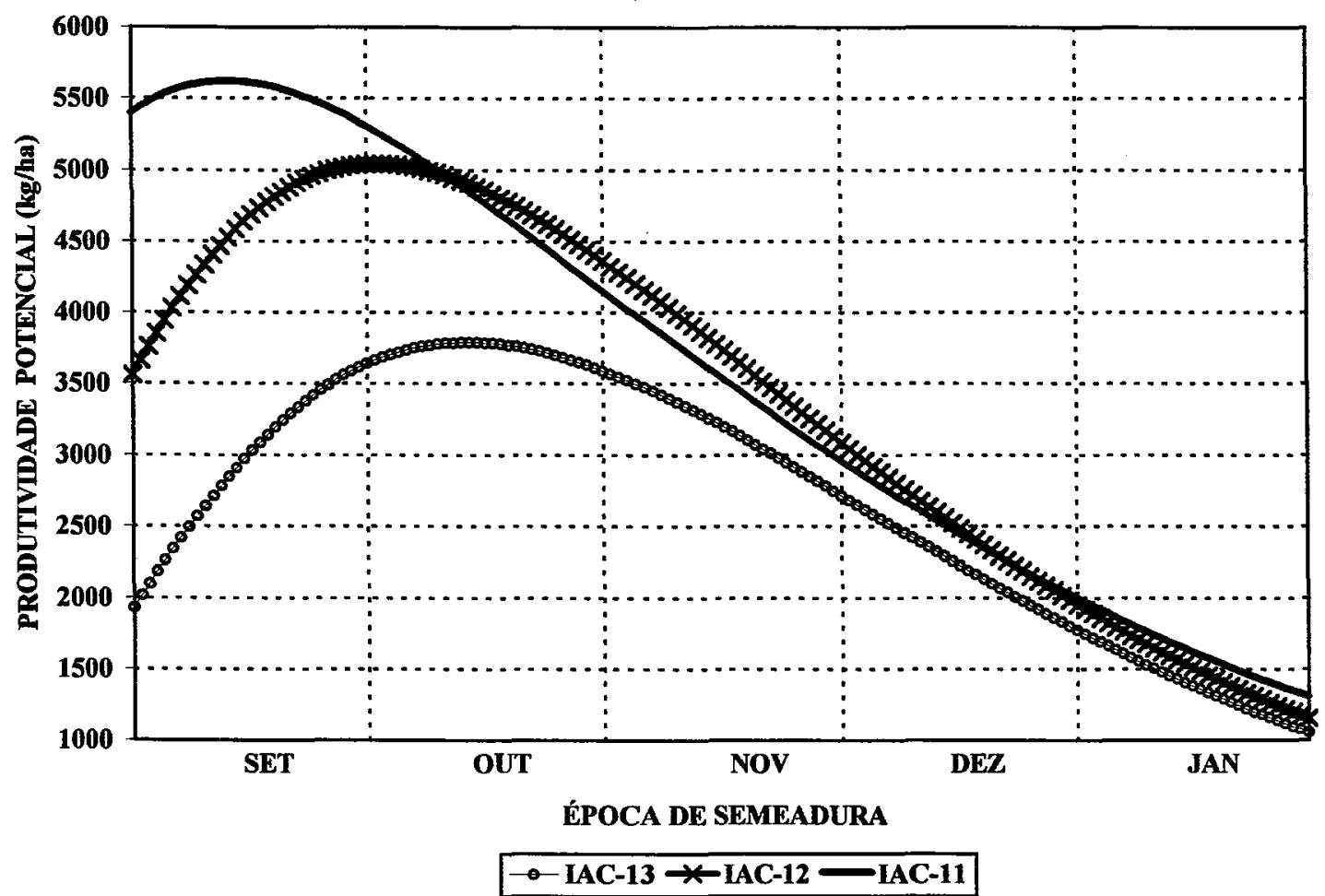

Figura 1 - Produtividades potenciais estimadas em função de épocas de semeadura, para os cultivares de soja IAC-13, IAC-12 e IAC-11 para a região de Ribeirão Preto, SP.

Fonte: Camargo et al. (1988). 
A Figura 2 apresenta de forma gráfica as produtividades potenciais estimadas em função da época de semeadura, para os cultivares IAC-17, IAS-5, IAC-15 e IAC-18.

\subsection{Avaliação do desempenho}

Para a avaliação do desempenho dos modelos, foram utilizadas análises de regressão, envolvendo coeficientes de determinação $\left(R^{2}\right)$ e o índice " $d$ " (índice de concordância), proposto por Willmott et al. (1985). Quando se relacionam valores estimados com valores observados pela regressão, pode-se obter informações da precisão e da exatidão, que conjuntamente indicam a consistência dos dados estimados com os medidos. A precisão, ou seja, o grau de dispersão dos valores em torno da média, é dada pelo coeficiente de determinação. Indica apenas o grau de dispersão dos dados obtidos, o erro aleatório, não considerando o erro sistemático. $O$ índice $d$ quantifica numericamente a exatidão, sendo um coeficiente de concordância (Willmott et al., 1985). Também indica como o modelo simula os valores observados, refletindo numa escala de 0 a 1 o grau do desvio da linha 1:1 em uma figura, o quanto a inclinação da linha de regressão difere de 1 e a linha de interceptação de zero.

O modelo de avaliação de Willmott et al. (1985) fornece também outras importantes informações, como o erro sistemático (Es) e o não sistemático (aleatório) (Ea) dos componentes do erro absoluto médio (EAM), que é a medida de magnitude média das diferenças entre os valores estimados e observados. 


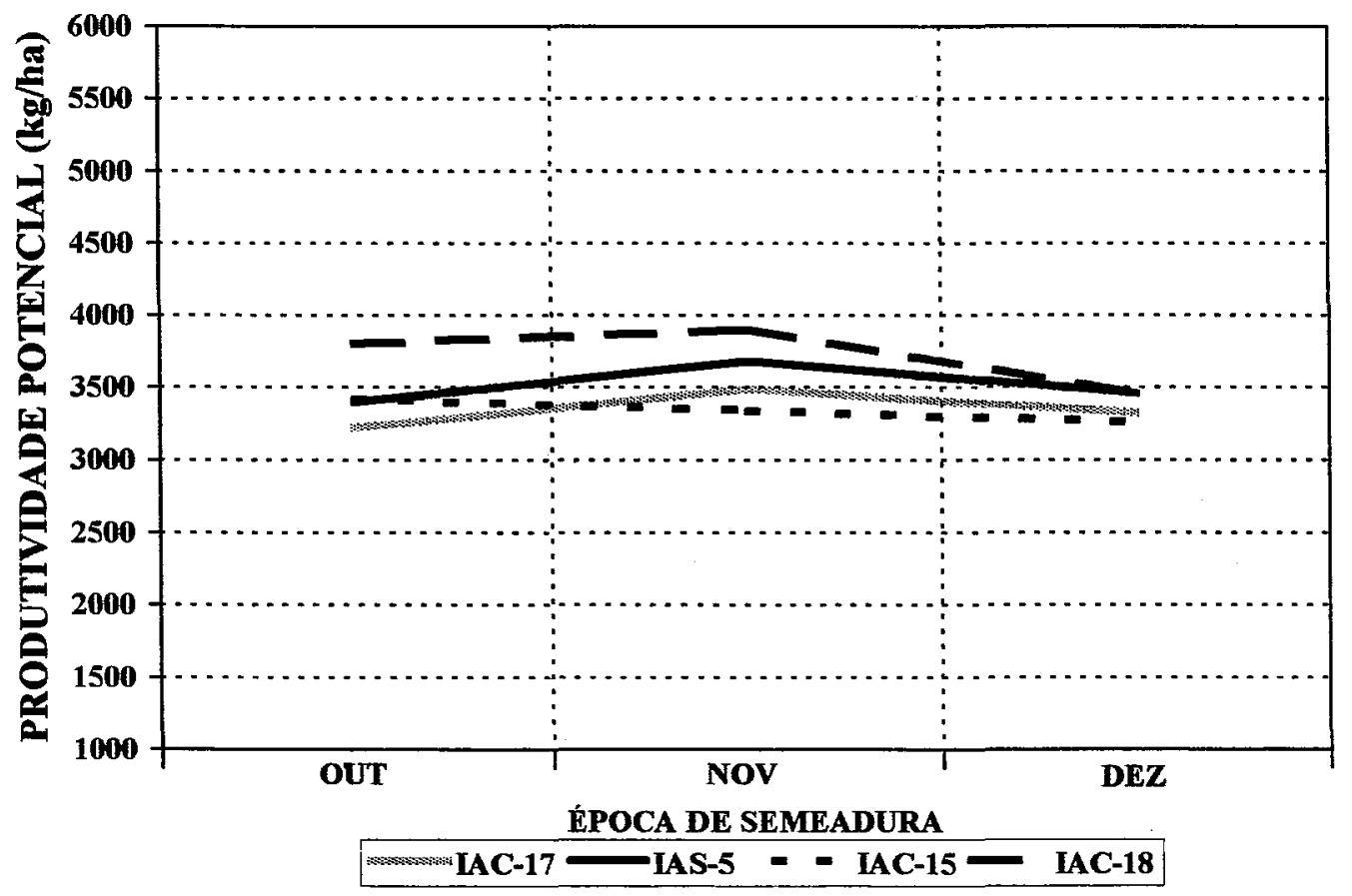

Figura 2 - Produtividades potenciais adotadas em função de épocas de semeadura, para os cultivares de soja IAC-17, IAS-5, IAC-15 e IAC-18, para a região de Ribeirão Preto, SP. 


\section{RESULTADOS E DISCUSSÃO}

\subsection{Produtividades Potenciais}

Uma das restrições para o emprego de modelos agrometeorológicos de estimativa de produtividade para a cultura da soja é a falta de informação sobre a produtividade potencial dos diferentes cultivares. Como a soja é uma planta fotoperiódica, ela sofre grande influência da época de semeadura. Por esta razão, utilizou-se, para a estimativa das produtividades potenciais dos cultivares IAC-13, IAC-12 e IAC-11, um modelo matemático desenvolvido por Camargo et al. (1988) para a região de Ribeirão Preto, o qual considera os efeitos fotoperiódicos influentes nos três cultivares, em função das datas de semeadura .

Conforme apresentado na Figura 1, onde estão demonstradas as produtividades potenciais para os cultivares IAC-13, IAC-12 e IAC-11, em função da época de semeadura, observa-se que os cultivares IAC-11 e IAC-12, por apresentarem período juvenil bem definido (Miranda et al., 1985) , permitem produtividades potenciais mais elevadas nas semeaduras precoces, com valores superiores a $5000 \mathrm{~kg} / \mathrm{ha}$. Já o cultivar IAC-13 apresenta as produtividades potenciais mais elevadas nas semeaduras em meados de outubro. Os três cultivares apresentam decréscimo acentuado nas produtividades potenciais a partir de semeaduras em final de novembro, apresentando uma média de $3000 \mathrm{~kg} / \mathrm{ha}$. Esses valores de produtividade potencial (Yp) foram utilizados no teste e 
parametrização dos modelos agrometeorológicos clássicos de estimativa de produtividade

\subsection{Duração dos estádios fenológicos}

A duração média dos estádios fenológicos da cultura da soja está apresentada na Tabela 6, de forma resumida, onde pode-se observar que o ciclo total do cultivar IAC-13 foi de 90 a 125 dias, em função da época de semeadura, ao passo que o cultivar IAC-12, de 100 a 135 dias e o cultivar IAC-11, de 110 a 155 dias. De um modo geral, a duração do estádio fenológico do florescimento (II) variou, para os três cultivares, de 20 a 30 dias, enquanto a do estádio fenológico da formação da vagem e enchimento de grãos (III), de 30 a 45 dias. Os mesmos dados são apresentados para os cultivares utilizados nos testes dos modelos parametrizados (Tabela 7), indicando ciclos com comportamentos semelhantes, de acordo com o grupo de maturação. Os cultivares precoces (IAC-17 e IAS-5), semeados em outubro, novembro e dezembro tiveram ciclos médios de 115, 110 e 100 dias, respectivamente. Os cultivares semiprecoces (IAC-15 e IAC-18), da mesma forma, apresentaram ciclos médios de 125, 120 e 110 dias, para semeaduras em outubro, novembro e dezembro. A duração dos estádios fenológicos para os cultivares precoces variou de 35 a 45 dias para o desenvolvimento vegetativo (I), de 25 a 30 dias para o florescimento (II) e de 30 dias para o enchimento de grãos (III). Para os cultivares semiprecoces, a duração do estádio de desenvolvimento vegetativo (I) foi de 45 a 55 dias. Os estádios do florescimento (II) e enchimento de grãos (III) também tiveram duração de 25 a 30 dias e 30 dias, respectivamente. Essas informações foram utilizadas nas correlações de ER/EP dos balanços hídricos com os modelos agrometeorológicos de estimativa de produtividade. 
Tabela 6. Duração média em dias dos estádios fenológicos e do ciclo semeaduramaturação para os três cultivares (IAC-13, IAC-12 e IAC-11), em diferentes épocas de semeadura.

\begin{tabular}{|c|c|c|c|c|c|}
\hline \multirow{2}{*}{$\begin{array}{l}\text { IAC-13 (precoce) } \\
\text { Época de semeadura }\end{array}$} & \multicolumn{4}{|c|}{ Estádios fenológicos (dias) } & \multirow{2}{*}{$\begin{array}{l}\text { Ciclo } \\
\text { Total }\end{array}$} \\
\hline & I & II & III & IV & \\
\hline $15 /$ Set & 50 & 30 & 35 & 10 & 125 \\
\hline 15/Out & 45 & 30 & 30 & 10 & 115 \\
\hline $15 / \mathrm{Nov}$ & 40 & 30 & 30 & 10 & 110 \\
\hline 15/Dez & 35 & 25 & 30 & 10 & 100 \\
\hline $15 /$ Jan & 30 & 20 & 30 & 10 & 90 \\
\hline \multicolumn{6}{|l|}{ IAC-12 (semiprecoce) } \\
\hline $15 /$ Set & 60 & 30 & 35 & 10 & 135 \\
\hline $15 /$ Out & 55 & 30 & 30 & 10 & 125 \\
\hline $15 / \mathrm{Nov}$ & 50 & 30 & 30 & 10 & 120 \\
\hline 15/Dez & 45 & 25 & 30 & 10 & 110 \\
\hline $15 / \mathrm{Jan}$ & 40 & 20 & 30 & 10 & 100 \\
\hline \multicolumn{6}{|l|}{ IAC-11 (médio) } \\
\hline $15 /$ Set & 70 & 30 & 45 & 10 & 155 \\
\hline $15 /$ Out & 65 & 30 & 40 & 10 & 145 \\
\hline $15 / \mathrm{Nov}$ & 60 & 30 & 35 & 10 & 135 \\
\hline 15/Dez & 55 & 25 & 30 & 10 & 120 \\
\hline 15/Jan & 50 & 20 & 30 & 10 & 110 \\
\hline
\end{tabular}

Tabela 7. Duração média em dias dos estádios fenológicos e do ciclo semeadura-maturação para os cultivares precoces IAC-17 e IAS-5 e semiprecoces IAC-15 e IAC-18, em diferentes épocas de semeadura.

\begin{tabular}{|c|c|c|c|c|c|}
\hline \multirow{2}{*}{$\begin{array}{l}\text { IAC-17 e IAS-5 } \\
\text { Época de semeadura }\end{array}$} & \multicolumn{4}{|c|}{ Estádios fenológicos (dias) } & \multirow{2}{*}{$\begin{array}{l}\text { Ciclo } \\
\text { Total }\end{array}$} \\
\hline & $\bar{I}$ & III & III & IV & \\
\hline $15 /$ Out & 45 & 30 & 30 & 10 & 115 \\
\hline $15 / \mathrm{Nov}$ & 40 & 30 & 30 & 10 & 110 \\
\hline 15/Dez & 35 & 25 & 30 & 10 & 100 \\
\hline \multicolumn{6}{|l|}{ IAC-15 e IAC-18 } \\
\hline $15 /$ Out & 55 & 30 & 30 & 10 & 125 \\
\hline $15 /$ Nov & 50 & 30 & 30 & 10 & 120 \\
\hline 15/Dez & 45 & 25 & 30 & 10 & 110 \\
\hline
\end{tabular}




\subsection{Balanço hídrico decendial}

Para a estimativa da disponibilidade hídrica e da relação ER/EP durante o ciclo da cultura, foram utilizados dois tipos de balanço hídrico. $\mathrm{O}$ primeiro, tradicional, conhecido como climatológico (BHclim), considera o valor do coeficiente de cultura ( $\mathrm{kc}$ ) unitário durante todo o ciclo da cultura. A CAD é mantida fixa, com valor de $100 \mathrm{~mm}$. O segundo (BHkc), considera, no cálculo do balanço hídrico, os valores de kc em função dos diferentes estádios fenológicos. A CAD, neste caso, é variável, sendo modificada conforme a alteração da profundidade do sistema radicular, alcançando valores superiores aos $100 \mathrm{~mm}$ calculados para o BHclim, uma vez que a simulação da profundidade das raízes do programa BHIDRICO (van Lier \& Dourado Neto, 1993) supera os $90 \mathrm{~cm}$ considerados no balanço hídrico climatológico.

Os dados decendiais dos componentes dos balanços hídricos (temperatura média, precipitação pluvial, ER, EP, armazenamento, deficiência e excedente hídricos), bem como os das relações ER/EP, referentes aos anos e períodos estudados, se encontram em Apêndices. As Figuras 3 e 4 apresentam de forma gráfica simplificada (Camargo \& Camargo, 1993) os extratos dos balanços hídricos climatológicos sequenciais, em nível decendial, referentes aos anos agrícolas 1983/84, 1984/85, 1989/90 e 1990/91, para a região de Ribeirão Preto. Por essas figuras é possível observar períodos com excedentes e deficiências hídricas durante todo o ciclo da cultura, e assim relacioná-los com as possíveis quebras de produtividade.

O ano agrícola de 1983/84 apresentou períodos com altos excedentes hídricos durante os meses de outubro e novembro, porém ocorreram períodos com deficiências hídricas em janeiro e fevereiro de 1984. Essas condições coincidiram com os períodos fenológicos críticos da cultura, as quais provocaram reduções nas produtividades observadas, especialmente nas semeaduras a partir de meados de outubro, com valores médios de $2100 \mathrm{~kg} / \mathrm{ha}$ para os três cultivares. 
No ano agrícola de 1984/85 houve ocorrência de decêndios com deficiências hídricas acentuadas, principalmente em outubro e início de novembro e ausência de períodos com deficiência hídrica nos meses de dezembro e janeiro. Excedentes hídricos foram observados de fevereiro a março, coincidindo com as épocas de enchimento de grãos (III) e maturação (IV) da soja, ocasionando produtividades médias em torno de $2400 \mathrm{~kg} / \mathrm{ha}$.

O ano agrícola de 1989/90 apresentou similaridade com o ano agrícola de 1984/85, porém com deficiências hídricas ainda mais reduzidas e excedentes hídricos menores, ocasionando produtividades maiores, em torno de $3600 \mathrm{~kg} / \mathrm{ha}$, em média, para os três cultivares.

Deficiências hídricas nos meses de outubro a início de dezembro caracterizaram o ano agrícola de 1990/91, que ainda apresentou elevados valores de excedentes hídricos durante os meses de janeiro a abril, o que induziu a produtividades médias de $2800 \mathrm{~kg} / \mathrm{ha}$. Essa umidade elevada, notadamente quando coincidiu com os estádios fenológicos de enchimento de grãos (III) e maturação (IV), induziu a reduções na produtividade. 

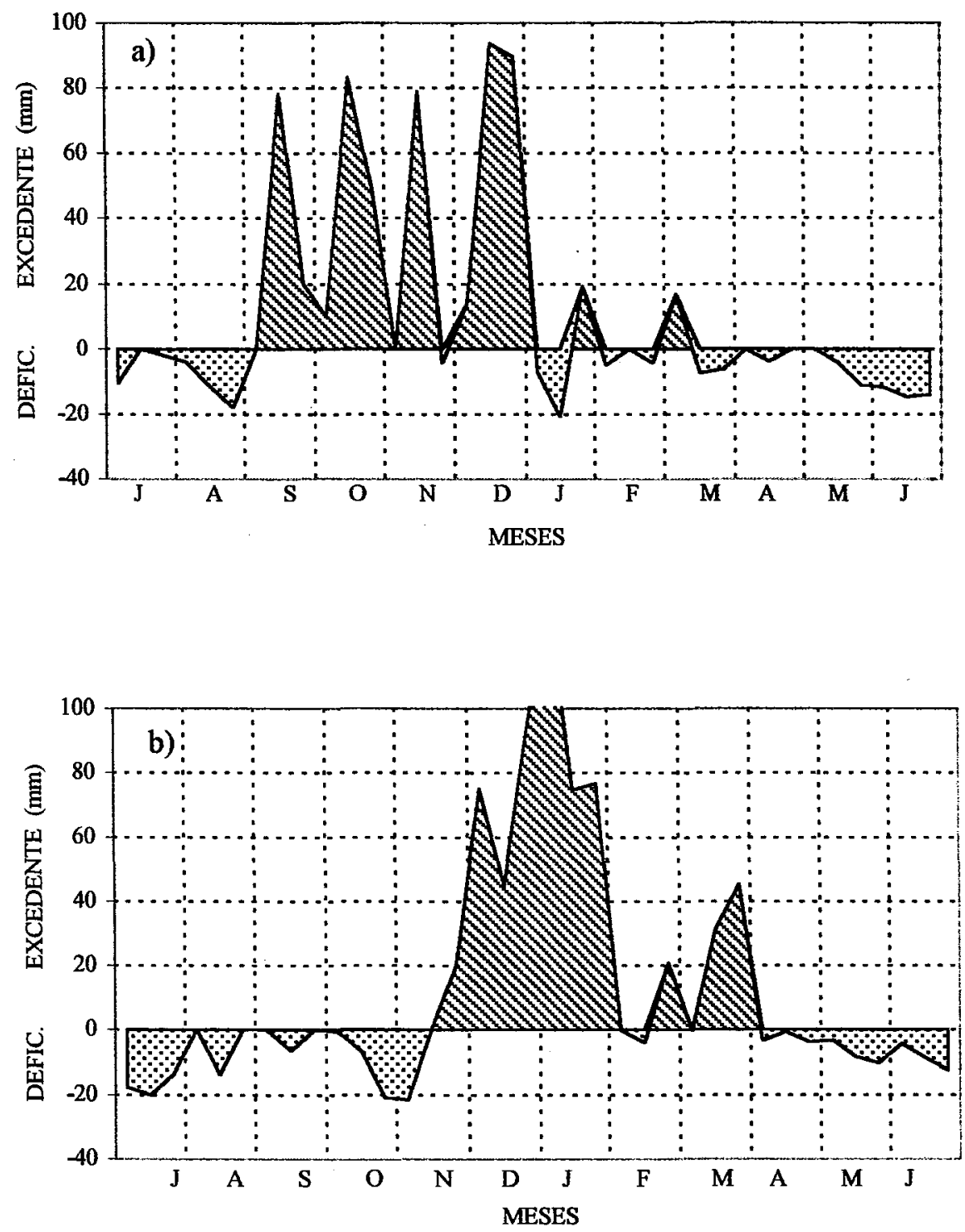

Figura 3 - Extratos do balanço hídrico climatológico decendial, referentes aos anos agrícolas de 1983/84 (a) e 1984/85 (b), para a região de Ribeirão Preto, SP. 

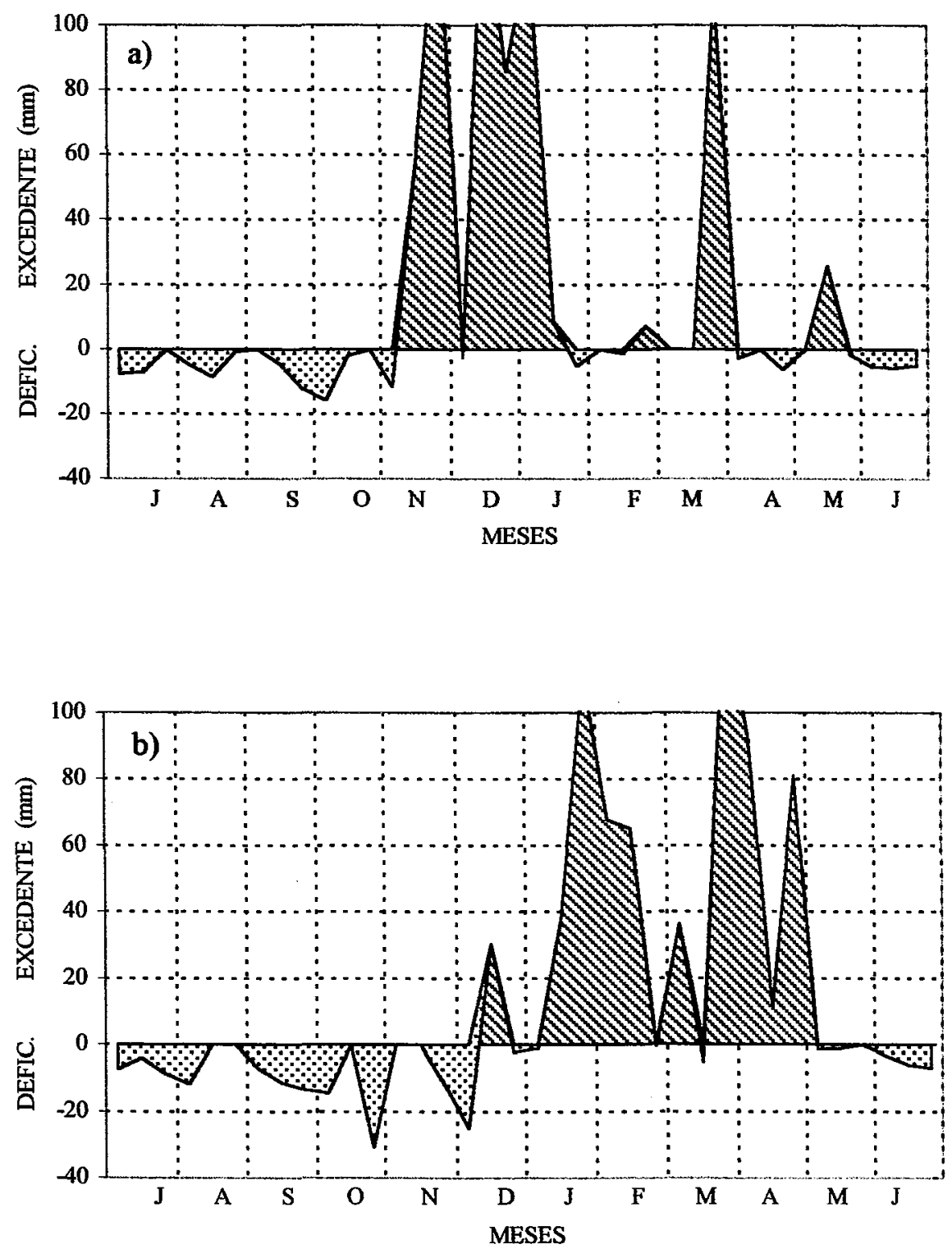

Figura 4 - Extratos do balanço hídrico climatológico decendial, referentes aos anos agrícolas de 1989/90 (a) e 1990/91 (b), para a região de Ribeirão Preto, SP. 
As relações ER/EP, obtidas a partir de balanços hí dricos climatológicos (BHclim) e com o uso de coeficiente de cultura (BHkc), utilizadas na parametrização dos modelos agrometeorológicos, estão apresentadas nas Tabelas 8 a 10, para os cultivares IAC-13, IAC-12 e IAC-11, em função das épocas de semeadura. Esses números correspondem a valores médios ocorridos em cada estádio fenológico considerado no estudo. Observou-se que, para o BHclim, a variabilidade durante o estádio do desenvolvimento vegetativo (I) foi de 0,71 a 1,00 . O estádio do florescimento (II) apresentou valores de ER/EP variando de 0,80 a 1,00 , enquanto o de enchimento de grãos (III), de 0,81 a 1,00. O estádio de maturação (IV) apresentou valores de 0,72 a 1,00.

Considerando-se o BHkc, a amplitude dos valores de ER/EP para cada estádio fenológico variou da seguinte forma: no estádio do desenvolvimento vegetativo (I), de 0,88 a 1,00; no florescimento (II), de 0,79 a 1,00 ; no enchimento de grãos (III) e maturação (IV), de 0,81 a 1,00 e 0,77 a 1,00 , respectivamente. 
Tabela 8. Relações ER/EP do balanço hídrico climatológico (BHclim) e do balanço hídrico com o uso de coeficiente de cultura ( BHkc), para o cultivar IAC-13, em diferentes épocas de semeadura.

\begin{tabular}{|c|c|c|c|c|c|c|c|c|}
\hline \multirow{2}{*}{$\begin{array}{c}\text { Data de } \\
\text { semeadura }\end{array}$} & \multicolumn{4}{|c|}{ BHclim } & \multicolumn{4}{|c|}{ BHkc } \\
\hline & $\overline{E R / E P_{1}}$ & $\mathrm{ER} / \mathrm{EP}_{2}$ & $\mathrm{ER} / \mathrm{EP}_{3}$ & $\mathrm{ER} / \mathrm{EP}_{4}$ & $\mathrm{ER} / \mathrm{EP}_{1}$ & $\mathrm{ER} / \mathrm{EP}_{2}$ & ${\mathrm{ER} / \mathrm{EP}_{3}}$ & $\mathrm{ER} / \mathrm{EP}_{4}$ \\
\hline \multicolumn{9}{|l|}{$83 / 84$} \\
\hline $14 /$ Set/83 & 1,00 & 0,96 & 1,00 & 0,72 & 1,00 & 0,95 & 0,98 & 0,77 \\
\hline 03/Out & 1,00 & 0,96 & 0,88 & 0,80 & 1,00 & 0,95 & 0,88 & 0,79 \\
\hline 25/Out & 0,97 & 0,97 & 0,82 & 0,95 & 0,98 & 0,97 & 0,81 & 0,95 \\
\hline $16 /$ Nov & 0,97 & 0,81 & 0,97 & 0,88 & 0,99 & 0,79 & 0,96 & 0,81 \\
\hline 05/Dez & 0,98 & 0,80 & 0,93 & 1,00 & 0,98 & 0,80 & 0,89 & 1,00 \\
\hline 27/Dez & 0,84 & 0,96 & 0,90 & 0,85 & 0,90 & 0,95 & 0,87 & 0,82 \\
\hline \multicolumn{9}{|l|}{$84 / 85$} \\
\hline $12 / \operatorname{Set} / 84$ & 0,82 & 0,86 & 1,00 & 1,00 & 0,93 & 0,87 & 1,00 & 1,00 \\
\hline 08/Out & 0,76 & 1,00 & 1,00 & 1,00 & 0,92 & 1,00 & 1,00 & 1,00 \\
\hline 26/Out & 0,80 & 1,00 & 1,00 & 0,96 & 0,94 & 1,00 & 1,00 & 0,95 \\
\hline 16/Nov & 1,00 & 1,00 & 0,97 & 1,00 & 1,00 & 1,00 & 0,95 & 1,00 \\
\hline 06/Dez & 1,00 & 1,00 & 0,97 & 1,00 & 1,00 & 1,00 & 0,95 & 0,99 \\
\hline 26/Dez & 1,00 & 0,96 & 1,00 & 1,00 & 1,00 & 0,94 & 1,00 & 1,00 \\
\hline $15 / \operatorname{Jan} / 85$ & 1,00 & 0,96 & 1,00 & 0,90 & 1,00 & 0,98 & 1,00 & 0,89 \\
\hline \multicolumn{9}{|l|}{$89 / 90$} \\
\hline $18 /$ Out/89 & 0,91 & 0,98 & 0,98 & 0,95 & 0,98 & 0,97 & 0,98 & 0,95 \\
\hline \multicolumn{9}{|l|}{$90 / 91$} \\
\hline $23 /$ Out/90 & 0,71 & 0,89 & 1,00 & 1,00 & 0,91 & 0,91 & 0,99 & 1,00 \\
\hline
\end{tabular}


Tabela 9. Relações ER/EP do balanço hídrico climatológico (BHclim) e do balanço hídrico com o uso de coeficiente de cultura (BHkc), para o cultivar IAC-12, em diferentes épocas de semeadura.

\begin{tabular}{|c|c|c|c|c|c|c|c|c|}
\hline \multirow{2}{*}{$\begin{array}{c}\text { Data de } \\
\text { semeadura }\end{array}$} & \multicolumn{4}{|c|}{ BHclim } & \multicolumn{4}{|c|}{ BHkc } \\
\hline & $\mathrm{ER}_{\mathrm{EP}}$ & $\mathrm{ER} / \mathrm{EP}_{2}$ & $\mathrm{ER} / \mathrm{EP}_{3}$ & $\mathrm{ER} / \mathrm{EP}_{4}$ & ${\mathrm{ER} / E P_{1}}_{1}$ & $\mathrm{ER}_{\mathrm{EP}}$ & $\mathrm{ER} / \mathrm{EP}_{3}$ & ${\mathrm{ER} / \mathrm{EP}_{4}}_{4}$ \\
\hline \multicolumn{9}{|l|}{$83 / 84$} \\
\hline $14 /$ Set/83 & 1,00 & 0,96 & 0,90 & 0,80 & 1,00 & 0,96 & 0,91 & 0,84 \\
\hline 03/Out & 0,99 & 0,98 & 0,81 & 0,95 & 0,99 & 0,98 & 0,81 & 0,98 \\
\hline 25/Out & 0,98 & 0,88 & 0,90 & 0,94 & 0,98 & 0,87 & 0,89 & 0,96 \\
\hline $16 / \mathrm{Nov}$ & 0,98 & 0,81 & 0,93 & 1,00 & 0,99 & 0,79 & 0,90 & 1,00 \\
\hline 05/Dez & 0,92 & 0,88 & 0,96 & 0,82 & 0,92 & 0,87 & 0,93 & 0,80 \\
\hline 27/Dez & 0,86 & 0,93 & 0,89 & 1,00 & 0,91 & 0,90 & 0,88 & 1,00 \\
\hline \multicolumn{9}{|l|}{$84 / 85$} \\
\hline 12/Set/84 & 0,78 & 1,00 & 1,00 & 1,00 & 0,88 & 1,00 & 1,00 & 1,00 \\
\hline 08/Out & 0,80 & 1,00 & 1,00 & 1,00 & 0,94 & 1,00 & 1,00 & 1,00 \\
\hline $26 /$ Out & 0,84 & 1,00 & 0,99 & 0,96 & 0,95 & 1,00 & 0,98 & 0,95 \\
\hline $16 /$ Nov & 1,00 & 1,00 & 0,97 & 1,00 & 1,00 & 1,00 & 0,95 & 0,99 \\
\hline 06/Dez & 1,00 & 1,00 & 0,97 & 1,00 & 1,00 & 1,00 & 0,95 & 1,00 \\
\hline 26/Dez & 1,00 & 0,96 & 1,00 & 0,90 & 1,00 & 0,94 & 1,00 & 0,89 \\
\hline $15 / \operatorname{Jan} / 85$ & 0,98 & 1,00 & 0,97 & 0,98 & 0,99 & 1,00 & 0,96 & 0,95 \\
\hline \multicolumn{9}{|l|}{$89 / 90$} \\
\hline 18/Out/89 & 0,92 & 0,99 & 0,97 & 0,99 & 0,98 & 0,99 & 0,96 & 1,00 \\
\hline \multicolumn{9}{|l|}{$90 / 91$} \\
\hline 23/Out/90 & 0,72 & 0,97 & 1,00 & 0,99 & 0,90 & 0,95 & 1,00 & 1,00 \\
\hline
\end{tabular}


Tabela 10. Relações ER/EP do balanço hídrico climatológico (BHclim) e do balanço hídrico com o uso de coeficiente de cultura (BHkc), para o cultivar IAC-11, em diferentes épocas de semeadura.

\begin{tabular}{|c|c|c|c|c|c|c|c|c|}
\hline \multirow{2}{*}{$\begin{array}{c}\text { Data de } \\
\text { semeadura }\end{array}$} & \multicolumn{4}{|c|}{ BHclim } & \multicolumn{4}{|c|}{ BHkc } \\
\hline & $\mathrm{ER} / \mathrm{EP}_{1}$ & $\mathrm{ER} / \mathrm{EP}_{2}$ & $\mathrm{ER} / \mathrm{EP}_{3}$ & $\mathrm{ER} \mathrm{EP}_{4}$ & $\mathrm{ER} \mathrm{EP}_{1}$ & $\mathrm{ER} / \mathrm{EP}_{2}$ & $\mathrm{ER} / \mathrm{EP}_{3}$ & $\mathrm{ER} / \mathrm{EP}_{4}$ \\
\hline \multicolumn{9}{|l|}{$83 / 84$} \\
\hline 14/Set/83 & 1,00 & 0,96 & 0,86 & 0,95 & 1,00 & 0,96 & 0,89 & 0,98 \\
\hline 03/Out & 0,98 & 0,97 & 0,85 & 0,94 & 0,98 & 0,97 & 0,87 & 0,96 \\
\hline 25/Out & 0,98 & 0,81 & 0,95 & 0,91 & 0,98 & 0,80 & 0,95 & 0,96 \\
\hline $16 /$ Nov & 0,96 & 0,83 & 0,94 & 0,84 & 0,96 & 0,81 & 0,93 & 0,94 \\
\hline 05/Dez & 0,90 & 0,96 & 0,90 & 0,85 & 0,90 & 0,95 & 0,87 & 0,85 \\
\hline 27/Dez & 0,88 & 0,95 & 0,89 & 0,87 & 0,91 & 0,92 & 0,88 & 0,86 \\
\hline \multicolumn{9}{|l|}{$84 / 85$} \\
\hline $12 / \mathrm{Set} / 84$ & 0,81 & 1,00 & 1,00 & 0,96 & 0,90 & 1,00 & 1,00 & 1,00 \\
\hline 08/Out & 0,83 & 1,00 & 0,99 & 0,96 & 0,95 & 1,00 & 1,00 & 1,00 \\
\hline 26/Out & 0,86 & 1,00 & 0,98 & 1,00 & 0,96 & 1,00 & 0,97 & 1,00 \\
\hline 16/Nov & 1,00 & 1,00 & 0,97 & 1,00 & 1,00 & 1,00 & 0,96 & 1,00 \\
\hline 06/Dez & 1,00 & 0,96 & 1,00 & 1,00 & 1,00 & 0,94 & 1,00 & 1,00 \\
\hline 26/Dez & 0,99 & 0,98 & 0,97 & 0,98 & 0,99 & 0,97 & 0,96 & 0,98 \\
\hline $15 / \operatorname{Jan} / 85$ & 0,98 & 1,00 & 0,96 & 0,86 & 0,99 & 1,00 & 0,95 & 0,81 \\
\hline \multicolumn{9}{|l|}{$89 / 90$} \\
\hline 18/Out/89 & 0,93 & 1,00 & 0,97 & 1,00 & 0,98 & 1,00 & 0,97 & 1,00 \\
\hline \multicolumn{9}{|l|}{$90 / 91$} \\
\hline 23/Out/90 & 0,76 & 0,98 & 1,00 & 0,93 & 0,91 & 0,96 & 1,00 & 0,99 \\
\hline
\end{tabular}




\subsection{Parametrização dos modelos 5,6 e 7 .}

Os valores dos coeficientes de produtividade (ky') para os modelos aditivo (5) e multiplicativo (6) de Doorenbos \& Kassam (1979) e os valores dos coeficientes de sensibilidade $(\lambda$ ') do modelo multiplicativo (7) de Jensen (1968) foram determinados por meio de regressões múltiplas transformadas, assumindo-se o valor de intersecção "a" igual a zero. Desta maneira, o valores de a ficaram intrínsecos aos primeiros coeficientes determinados, no caso, os do desenvolvimento vegetativo (I). Assim, estes coeficientes acentuaram a penalização para déficit hídrico no estádio inicial da cultura de forma muito maior que a esperada e encontrada na literatura. Houve, então, a necessidade da realização de um ajuste nos valores dos coeficientes de produtividade (ky') e índices de sensibilidade $(\lambda$ ') referentes ao estádio fenológico do desenvolvimento vegetativo (I), de acordo com o método utilizado por Meyer (1990), que propôs $\lambda_{1}{ }^{\prime}-1$ para o modelo 7 . Assumiu-se o mesmo critério para os modelos 5 e $6\left(\mathrm{ky}_{1}{ }^{\prime}-1\right)$.

Os valores dos coeficientes de produtividade e de sensibilidade estão apresentados nas Tabelas 11 a 13, para os cultivares IAC-13, IAC-12 e IAC-11, respectivamente. Observou-se uma grande diferença entre os coeficientes, de acordo com o balanço hídrico considerado. Os coeficientes, tanto de produtividade (ky'), como de sensibilidade $\left(\lambda^{\prime}\right)$, apresentaram valores de $\mathbf{R}^{2}$ mais elevados quando foi utilizado o BHclim, sugerindo uma melhor resposta à utilização deste tipo de balanço hídrico. As maiores diferenças, de acordo com o estádio fenológico, foram durante o estádio vegetativo, quando o BHkc apresentou valores de coeficientes muito elevados, superiores até a 3,00.

A magnitude dos coeficientes revelam a importância da sensibilidade relativa desses índices sobre a produtividade da cultura da soja. Um valor positivo, seja de ky, seja de $\lambda$, significa que a produtividade é particularmente sensível ao déficit hídrico durante aquele estádio fenológico. Por outro lado, um coeficiente com valor negativo sugere que a produtividade pode ser incrementada por déficit hídrico durante aquele estádio 
fenológico, como ocorreu com o cultivar IAC-11 durante o estádio da maturação. Já um valor com magnitude próxima a zero, seja positivo ou negativo, indica que a produtividade é insensível às condições hídricas durante aquele estádio fenológico.

Tabela 11. Valores de ky' (coeficiente de produtividade) e $\lambda^{\prime}$ (coeficiente de sensibilidade) determinados a partir de BHclim e de BHkc para os modelos 5, 6 e 7, para o cultivar IAC-13 (grupo Precoce).

\begin{tabular}{|c|c|c|c|c|}
\hline \multicolumn{5}{|c|}{ Estádios fenológicos } \\
\hline & $\bar{I}$ & II & III & IV \\
\hline Modelo 5 & $\mathbf{k y}_{1}$ & $\mathbf{k y} \mathbf{y}_{2}$ & $\mathbf{k y}_{3}$ & $\mathbf{k y}_{4}$ \\
\hline BHclim & 0,38 & 0,95 & 1,25 & 0,37 \\
\hline BHkc & 2,81 & 0,96 & 0,62 & 0,33 \\
\hline Modelo 6 & $k y_{1}$ & $\mathbf{k y}_{2}$ & $\mathbf{k y}_{3}$ & $\mathrm{ky}_{4}$ \\
\hline BHclim & 0,49 & 1,13 & 1,42 & 0,35 \\
\hline BHkc & 3,24 & 1,03 & 0,90 & 0,37 \\
\hline Modelo 7 & $\lambda_{1}$ & $\lambda_{2}$ & $\lambda_{3}$ & $\lambda_{4}$ \\
\hline BHclim & 0,62 & $\overline{1,12}$ & 1,49 & 0,32 \\
\hline BHkc & 4,09 & 0,98 & 0,86 & 0,36 \\
\hline
\end{tabular}


Tabela 12. Valores de ky' (coeficiente de produtividade) e $\lambda$ ' (coeficiente de sensibilidade) determinados a partir de BHclim e de BHkc para os modelos 5, 6 e 7, para o cultivar IAC-12 (grupo Semiprecoce).

\begin{tabular}{ccccc}
\hline & \multicolumn{4}{c}{ Estádios fenológicos } \\
\cline { 2 - 5 } Modelo 5 & I & II & III & IV \\
\cline { 2 - 5 } $\mathbf{k y}_{\mathbf{1}}$ & $\mathbf{k y}_{\mathbf{2}}$ & $\mathbf{k y}_{\mathbf{3}}$ & $\mathbf{k y}_{\mathbf{4}}$ \\
\hline BHclim & 0,38 & 1,43 & 1,56 & 0,63 \\
BHkc & 2,17 & $\mathbf{0 , 8 0}$ & 1,53 & $\mathbf{0 , 4 5}$ \\
\hline Modelo 6 & $\mathbf{k y}_{\mathbf{1}}$ & $\mathbf{k y}_{\mathbf{2}}$ & $\mathbf{k y}_{\mathbf{3}}$ & $\mathbf{k y}_{\mathbf{4}}$ \\
\hline BHclim & 0,43 & 1,78 & 1,69 & $\mathbf{0 , 7 0}$ \\
BHkc & 2,45 & 1,13 & 1,63 & 0,54 \\
\hline Modelo 7 & $\lambda_{1}$ & $\lambda_{\mathbf{2}}$ & $\lambda_{\mathbf{3}}$ & $\lambda_{\mathbf{4}}$ \\
\hline BHclim & 0,55 & 1,90 & 1,78 & $\mathbf{0 , 6 3}$ \\
BHkc & 3,06 & 1,09 & 1,70 & 0,48 \\
\hline
\end{tabular}

Tabela 13. Valores de ky' (coeficiente de produtividade) e $\lambda$ ' (coeficiente de sensibilidade) determinados a partir de BHclim e de BHkc para os modelos 5, 6 e 7, para o cultivar IAC-11 (grupo Médio).

\begin{tabular}{ccccc}
\hline & \multicolumn{4}{c}{ Estádios fenológicos } \\
\cline { 2 - 5 } Modelo 5 & I & II & III & IV \\
\cline { 2 - 5 } $\mathbf{k y}_{\mathbf{1}}$ & $\mathbf{k y}_{\mathbf{2}}$ & $\mathbf{k y}_{\mathbf{3}}$ & $\mathbf{k y}_{\mathbf{4}}$ \\
\hline BHclim & 0,57 & 1,89 & 2,53 & $-0,85$ \\
BHkc & 1,91 & 1,38 & 2,35 & $-1,35$ \\
\hline Modelo 6 & $\mathbf{k y}_{\mathbf{1}}$ & $\mathbf{k y}_{\mathbf{2}}$ & $\mathbf{k y}_{\mathbf{3}}$ & $\mathbf{k y}_{\mathbf{4}}$ \\
\hline BHclim & 0,58 & 1,99 & 2,62 & $-0,76$ \\
BHkc & 2,07 & 1,62 & 2,36 & $-1,13$ \\
\hline Modelo 7 & $\lambda_{\mathbf{1}}$ & $\lambda_{\mathbf{2}}$ & $\lambda_{\mathbf{3}}$ & $\lambda_{\mathbf{4}}$ \\
\hline BHclim & 0,70 & 2,27 & 2,94 & $-0,79$ \\
BHkc & 2,52 & 1,65 & 2,57 & $-0,97$ \\
\hline
\end{tabular}


Os valores mais elevados dos coeficientes foram durante os estádios fenológicos do florescimento (II) e formação de vagens e enchimento de grãos (III), especialmente para os cultivares IAC-12 e IAC-11. Os valores de ky, determinados pelos resultados do BHclim para o cultivar IAC-13 (modelos $5 \mathrm{e} 6$ ) foram semelhantes aos $\mathrm{ky}_{\mathrm{i}}$ propostos por Doorenbos \& Kassam (1979) e utilizados nos modelos 2, 3 e 4. A tabela 14 apresenta estes valores de $\mathrm{ky}_{\mathrm{i}}$ propostos e os determinados pelo modelo 5 para os cultivares IAC-13, IAC-12 e IAC-11, e a Figura 5 apresenta de forma gráfica esses valores.

Tabela 14. Valores dos coeficientes de produtividade (ky) propostos por Doorenbos \& Kassam (1979) e determinados pelo modelo 5, para os cultivares IAC-13, IAC-12 e IAC-11.

\begin{tabular}{ccccc}
\hline Coeficientes de & Doorenbos \& & \multicolumn{3}{c}{ Modelo 5 } \\
\cline { 3 - 5 } produtividade & Kassam (1979) & IAC-13 & IAC-12 & IAC-11 \\
\hline $\mathbf{k y}_{1}$ & 0,2 & 0,4 & 0,4 & 0,6 \\
$\mathbf{k y}_{2}$ & 0,8 & 0,9 & 1,4 & 1,9 \\
$\mathbf{k y}_{3}$ & 1,0 & 1,2 & 1,6 & 2,5 \\
$\mathbf{k y}_{4}$ & 0,2 & 0,4 & 0,6 & $-0,8$ \\
\hline
\end{tabular}




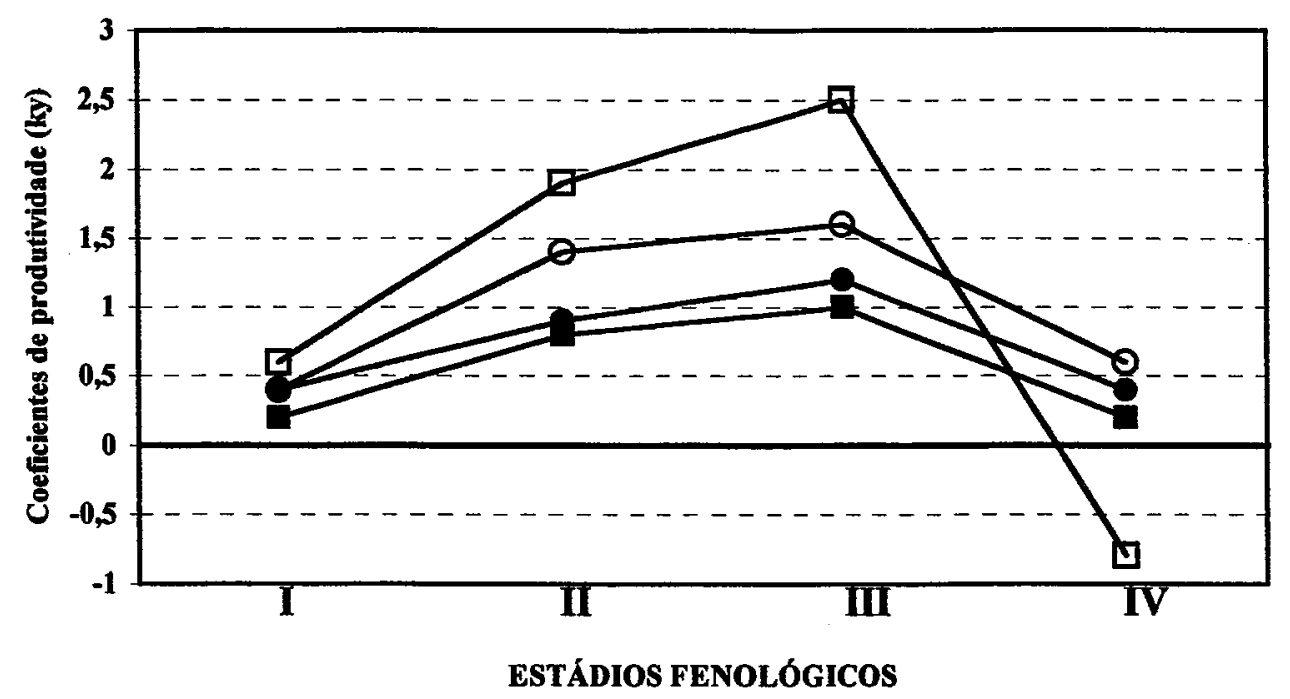

-D Doorenbos \& Kassam (1979) -IAC-13 - O-IAC-12 Ð-IAC-11

Figura 5. Valores dos coeficientes de produtividade $\left(\mathrm{ky}_{\mathrm{i}}\right)$ propostos por Doorenbos \& Kassam (1979) e determinados pelo modelo 5, para os cultivares IAC-13, IAC-12 e IAC-11.

Os índices de sensibilidade determinados para o modelo $7(\lambda)$ também se aproximaram dos encontrados na literatura, como os apresentados por Berlato \& Molion (1993), que determinaram valores de $\lambda$ de 0,9 para o estádio reprodutivo da soja de ciclo precoce no sul do Brasil. Para os cultivares de soja de ciclo semiprecoce e médio, os resultados se assemelharam aos encontrados por Meyer \& Hubbard (1995) na região central dos EUA, cujos valores de $\lambda$ para o estádio fenológico do florescimento foram de 2,0 e para o estádio de enchimento de grãos, de 1,4. 


\subsection{Teste dos modelos}

O desempenho de cada modelo foi avaliado através de análises estatísticas. As tabelas 15 e 16 apresentam, para os modelos 1 a 7 , os coeficientes de determinação $\left(R^{2}\right)$ e índice d, bem como outras informações relevantes, como erro absoluto médio (EAM), erros sistemático (Es) e aleatório (Ea), tanto para o BHclim como para o BHkc.

Observou-se claramente que, para todos os sete modelos, a utilização dos resultados do BHkc não apresentou melhora no desempenho (Tabela 16), com valores de $R^{2}$ e índice $d$ mais baixos, e erros mais elevados do que os apresentados com a utilização do BHclim (Tabela 15). Ao contrário do que se esperava, a inclusão dos valores de kc e da $\mathrm{CAD}$ variável no balanço hídrico não melhorou o desempenho dos modelos agrometeorológicos de estimativa de produtividade. Provavelmente, devido aos valores de kc e da $\mathrm{CAD}$ variável considerados nos balanços hídricos, especialmente durante os estádios do desenvolvimento vegetativo (I) e do florescimento (II).

Considerando-se apenas o BHclim, nota-se que os 4 modelos clássicos testados (modelos 1, 2, 3 e 4) apresentaram valores relativamente altos de $R^{2}$ e do índice d. Foi observada tendência de superestimativa das produtividades, principalmente para os cultivares de ciclo semiprecoce (IAC-12) e médio IAC-11). Analisando-se os valores dos erros (EAM, Es e Ea), notou-se uma acentuada redução quando da comparação entre o modelo 1, que considera um único coeficiente de penalização da produtividade para todo o ciclo da cultura, e os demais modelos, que utilizam coeficientes distintos para cada estádio fenológico. No teste do modelo 1 , os erros estiveram, de maneira geral, muito elevados, com valores de Ea muito superiores aos de Es. Os modelos 2 e 3 apresentaram desempenhos semelhantes entre si, tanto em valores de $\mathrm{R}^{2}$ e índice $\mathrm{d}$, quanto em relação aos valores dos erros. 
O modelo 4, que considera o fator de penalização para excedentes hídricos, apresentou as melhores estimativas, com os menores valores dos erros, bem como valores de $\mathrm{R}^{2} \mathrm{e}$ índice $\mathrm{d}$ superiores aos demais modelos testados.

Os modelos parametrizados para a região de Ribeirão Preto, ou seja, modelos 5 , 6 e 7, apresentaram os melhores desempenhos, quando comparados aos modelos testados, com valores superiores de $\mathrm{R}^{2} \mathrm{e}$ índice $\mathrm{d}$, e principalmente, redução nos valores dos erros. Estes modelos apresentaram desempenhos semelhantes entre si, inclusive o modelo 7. A tendência de superestimativa das produtividades apresentou grande redução, especialmente para os cultivares de ciclo precoce (IAC-13) e semiprecoce (IAC-12).

$\mathrm{Na}$ análise do desempenho dos modelos entre os cultivares, notou-se que as melhores estimativas foram as referentes ao cultivar IAC-13, do grupo de maturação precoce, tanto para os modelos testados quanto para os parametrizados. Para este cultivar, os valores dos erros foram sempre menores do que os obtidos para os demais cultivares, especialmente o IAC-11, de ciclo médio. Esses resultados sugerem que o teste dos modelos clássicos e a sua parametrização se adequaram melhor aos grupos de maturação precoce e semiprecoce.

As Figuras 6 a 12 apresentam, graficamente, as produtividades observadas e estimadas pelos sete modelos. 
Tabela 15. Resultados estatísticos da análise do desempenho dos modelos 1 a 7 referentes ao BHclim para os cultivares IAC-13, IAC-12 e IAC-11.

\begin{tabular}{cccccc}
\hline IAC-13 & $\mathbf{R}^{2}$ & $\mathrm{~d}$ & EAM & Es & Ea \\
\cline { 1 - 3 } Modelos & & & & $\mathrm{kg} / \mathrm{ha}$ & \\
\cline { 1 - 3 } 1 & 0,69 & 0,71 & 647 & 449 & 622 \\
2 & 0,71 & 0,78 & 460 & 440 & 435 \\
3 & 0,71 & 0,78 & 472 & 440 & 447 \\
4 & 0,76 & 0,85 & 322 & 339 & 305 \\
5 & 0,83 & 0,94 & 247 & 484 & 54 \\
6 & 0,84 & 0,95 & 36 & 252 & 59 \\
7 & 0,84 & 0,95 & 31 & 249 & 61 \\
\hline IAC-12 & & & & & \\
\hline 1 & 0,72 & 0,73 & 895 & 585 & 903 \\
2 & 0,77 & 0,81 & 665 & 510 & 677 \\
3 & 0,77 & 0,81 & 680 & 514 & 692 \\
4 & 0,79 & 0,86 & 516 & 430 & 517 \\
5 & 0,84 & 0,95 & 171 & 333 & 175 \\
6 & 0,84 & 0,95 & 134 & 333 & 148 \\
7 & 0,84 & 0,95 & 124 & 326 & 141 \\
\hline IAC-11 & & & & & \\
\cline { 1 - 2 } 1 & 0,79 & 0,73 & 994 & 566 & 1038 \\
2 & 0,87 & 0,81 & 757 & 429 & 818 \\
3 & 0,87 & 0,80 & 774 & 435 & 832 \\
4 & 0,87 & 0,84 & 659 & 393 & 690 \\
5 & 0,85 & 0,93 & 272 & 380 & 293 \\
6 & 0,86 & 0,94 & 246 & 362 & 257 \\
7 & 0,85 & 0,94 & 232 & 363 & 242 \\
\hline
\end{tabular}


Tabela 16. Resultados estatísticos da análise do desempenho dos modelos 1 a 7 referentes ao BHkc para os cultivares IAC-13, IAC-12 e IAC-11.

\begin{tabular}{cccccc}
\hline IAC-13 & $\mathbf{R}^{2}$ & $\mathbf{d}$ & EAM & Es & Ea \\
\cline { 1 - 3 } Modelos & & & & $\mathrm{kg} / \mathrm{ha}$ & \\
\cline { 1 - 3 } 1 & 0,66 & 0,69 & 674 & 487 & 648 \\
2 & 0,65 & 0,76 & 459 & 503 & 434 \\
3 & 0,66 & 0,78 & 474 & 498 & 449 \\
4 & 0,71 & 0,83 & 321 & 388 & 302 \\
5 & 0,73 & 0,85 & 247 & 433 & 222 \\
6 & 0,73 & 0,85 & 230 & 426 & 205 \\
7 & 0,73 & 0,86 & 223 & 419 & 199 \\
\hline IAC-12 & & & & & \\
\hline 1 & 0,72 & 0,72 & 929 & 606 & 943 \\
2 & 0,76 & 0,81 & 662 & 551 & 685 \\
3 & 0,76 & 0,80 & 679 & 555 & 700 \\
4 & 0,78 & 0,86 & 514 & 462 & 517 \\
5 & 0,85 & 0,91 & 384 & 404 & 416 \\
6 & 0,85 & 0,91 & 357 & 405 & 382 \\
7 & 0,85 & 0,91 & 344 & 397 & 369 \\
\hline IAC-11 & & & & & \\
\cline { 1 - 2 } 1 & 0,79 & 0,71 & 1044 & 586 & 1100 \\
2 & 0,86 & 0,79 & 793 & 476 & 881 \\
3 & 0,86 & 0,79 & 808 & 481 & 891 \\
4 & 0,84 & 0,85 & 598 & 443 & 634 \\
5 & 0,90 & 0,88 & 511 & 379 & 622 \\
6 & 0,91 & 0,89 & 485 & 362 & 585 \\
7 & 0,91 & 0,89 & 470 & 358 & 569 \\
\hline
\end{tabular}



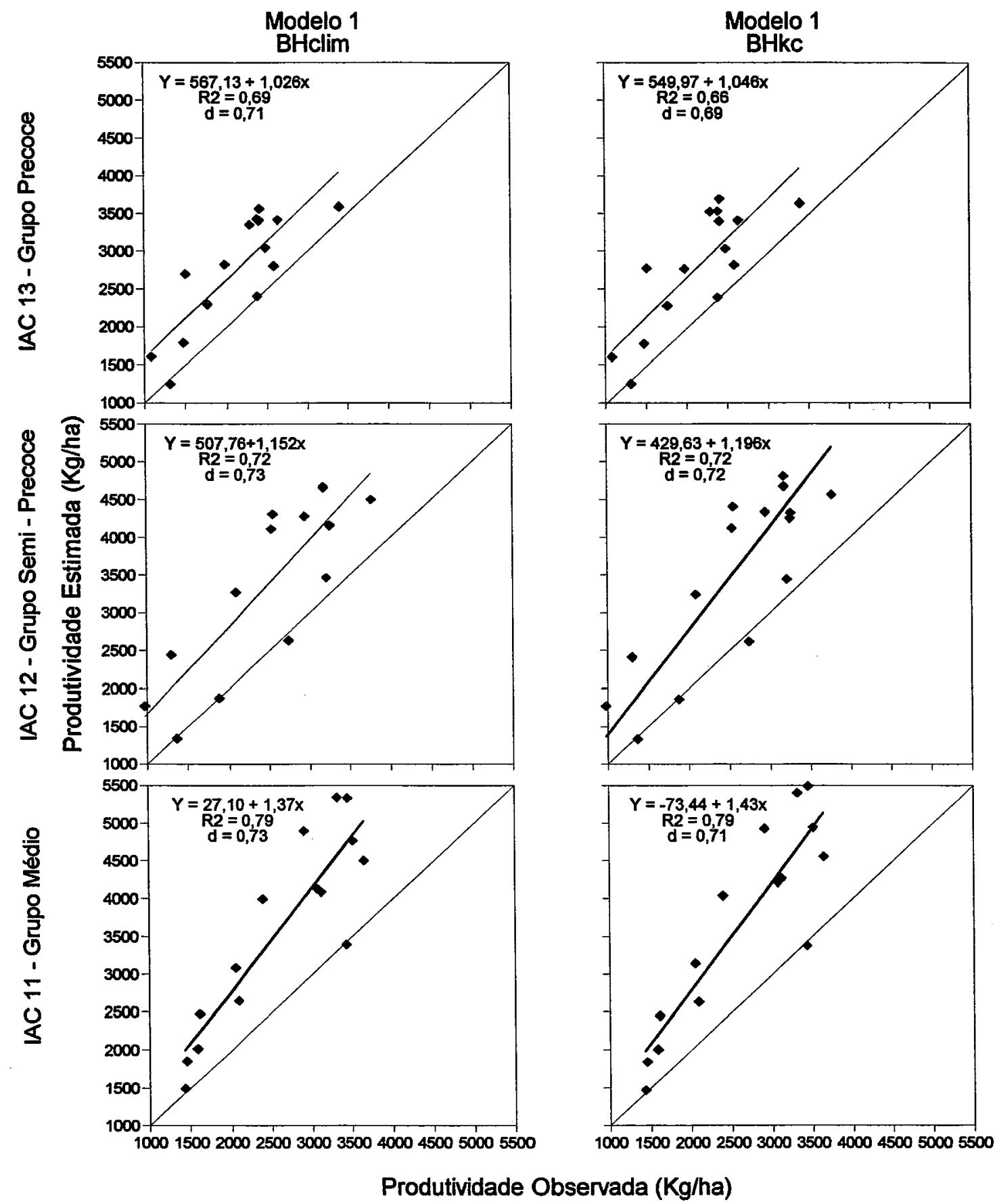

Figura 6 - Produtividades $(\mathrm{kg} / \mathrm{ha}$ ) observadas e estimadas pelo modelo 1, para os cultivares IAC-13, IAC-12 e IAC-11. 


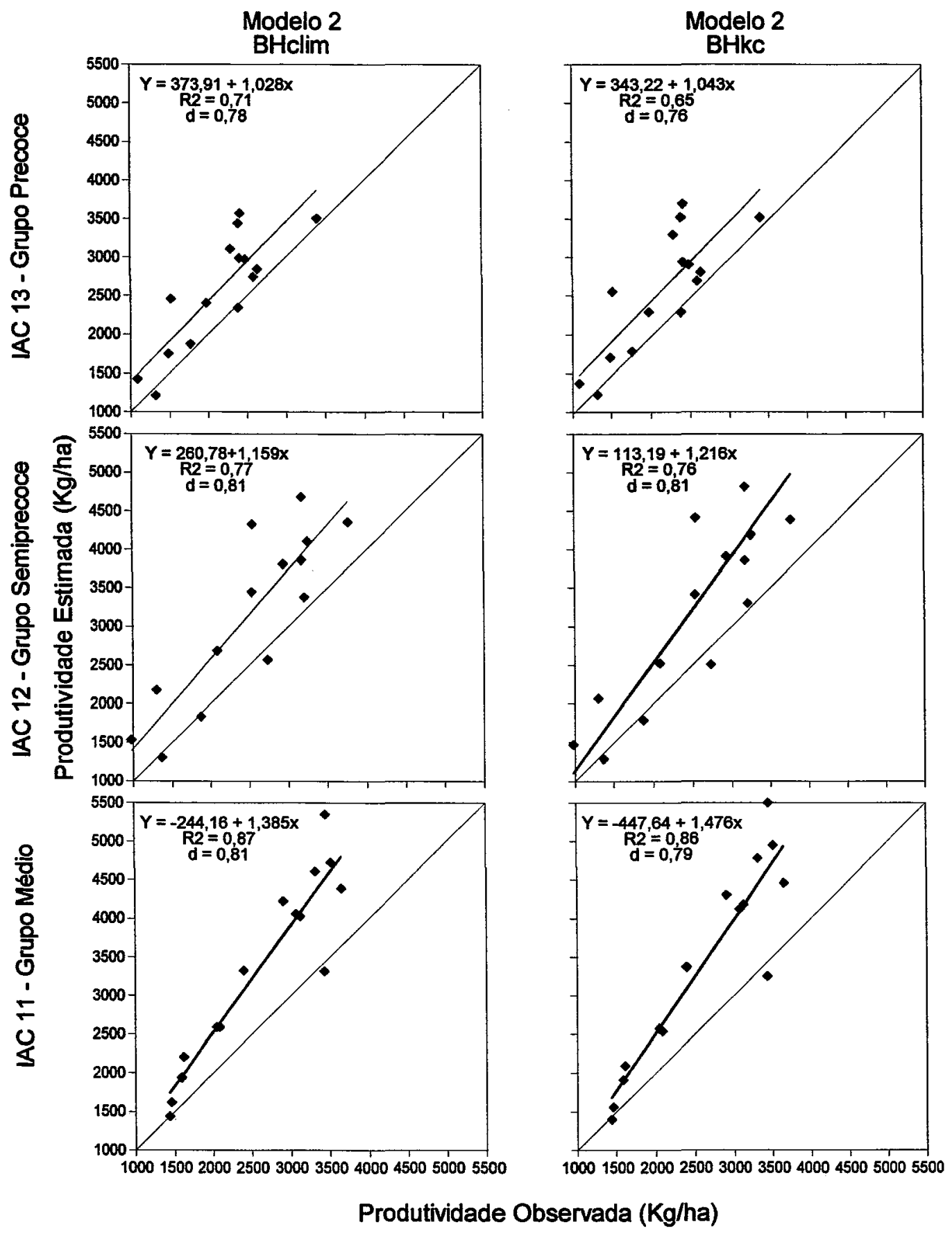

Figura 7 - Produtividades (kg/ha) observadas e estimadas pelo modelo 2, para os cultivares IAC-13, IAC-12 e IAC-11. 


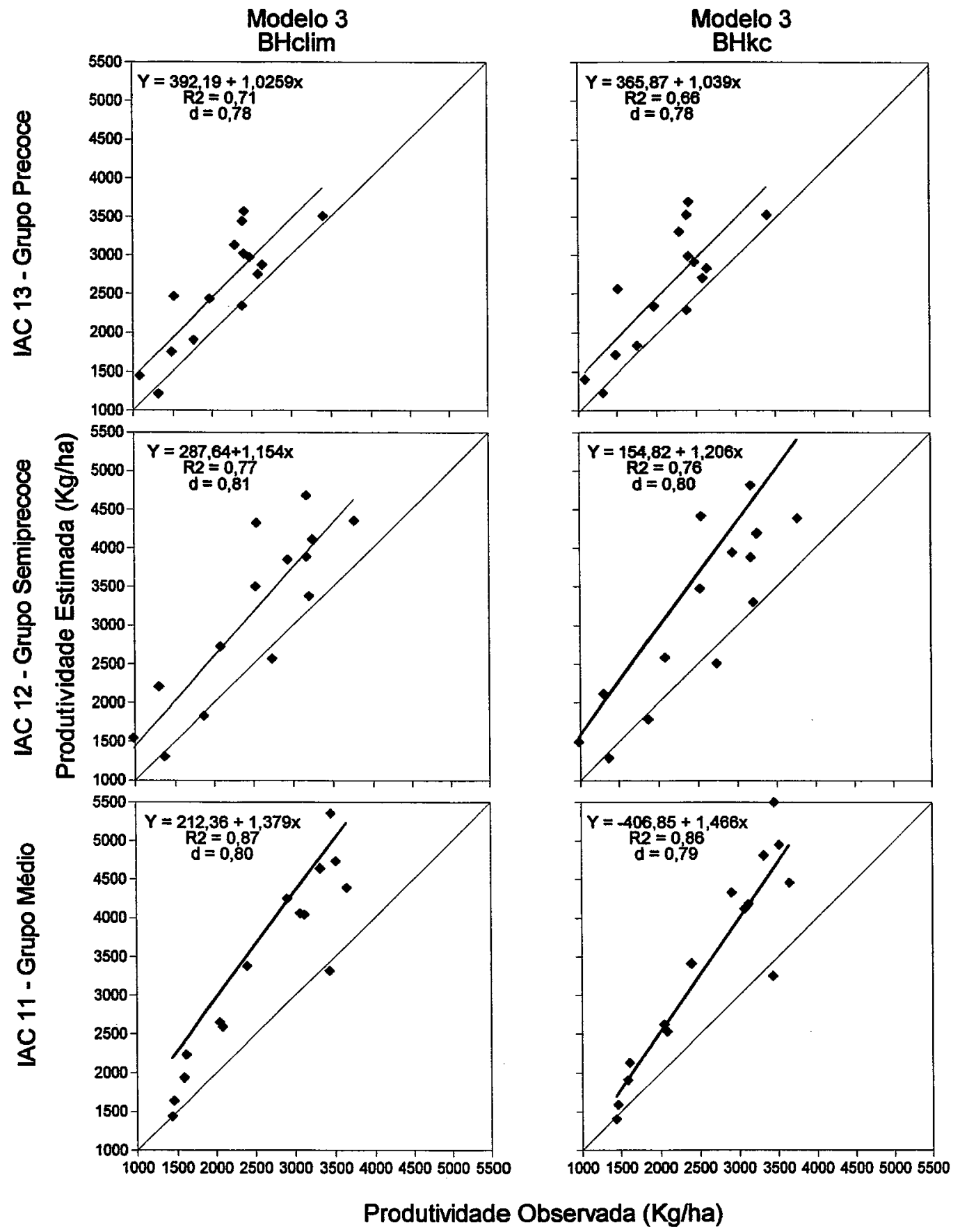

Figura 8 - Produtividades (kg/ha) observadas e estimadas pelo modelo 3, para os cultivares IAC-13, IAC-12 e IAC-11. 

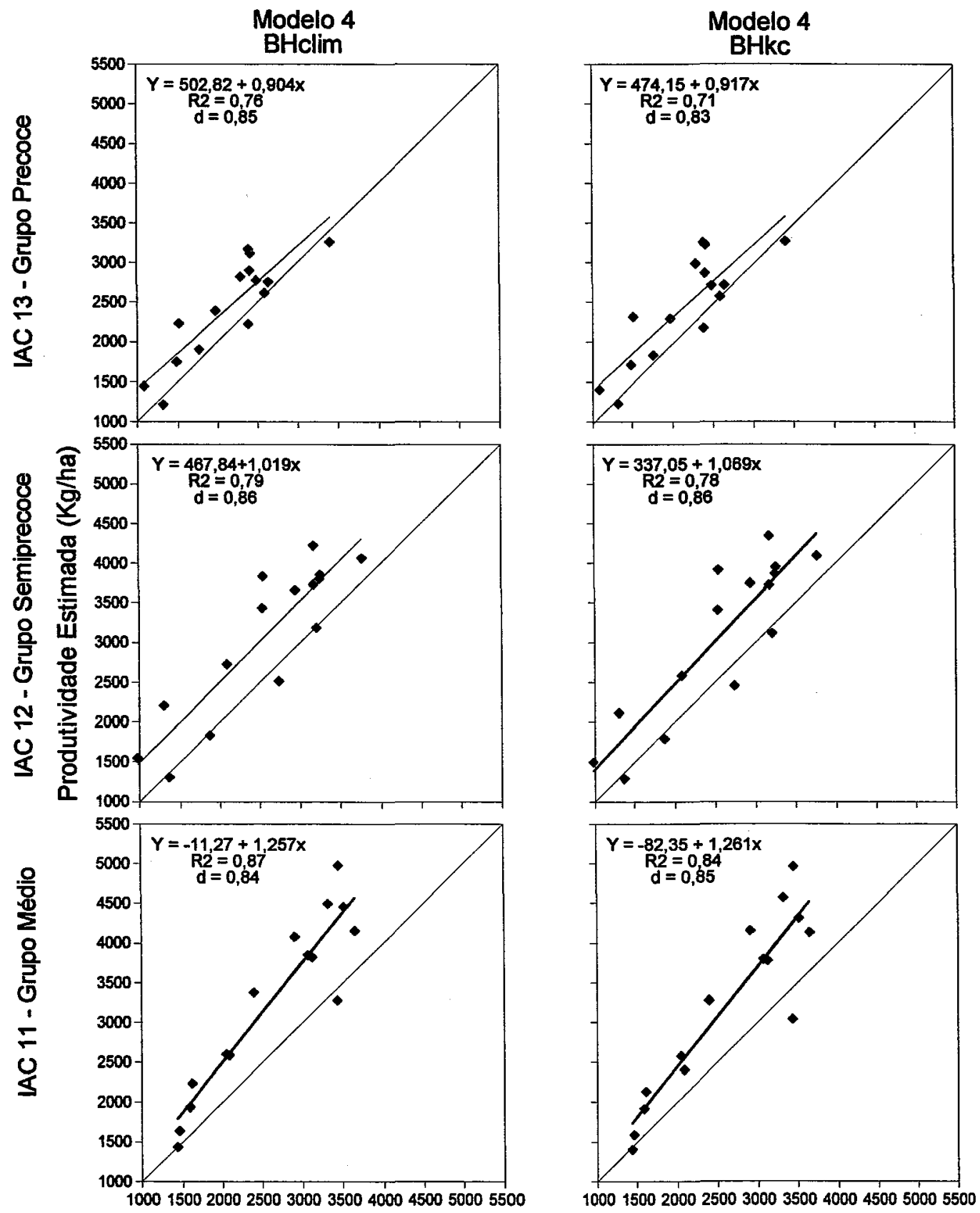

Produtividade Observada (Kg/ha)

Figura 9 - Produtividades (kg/ha) observadas e estimadas pelo modelo 4, para os cultivares IAC-13, IAC-12 e IAC-11. 

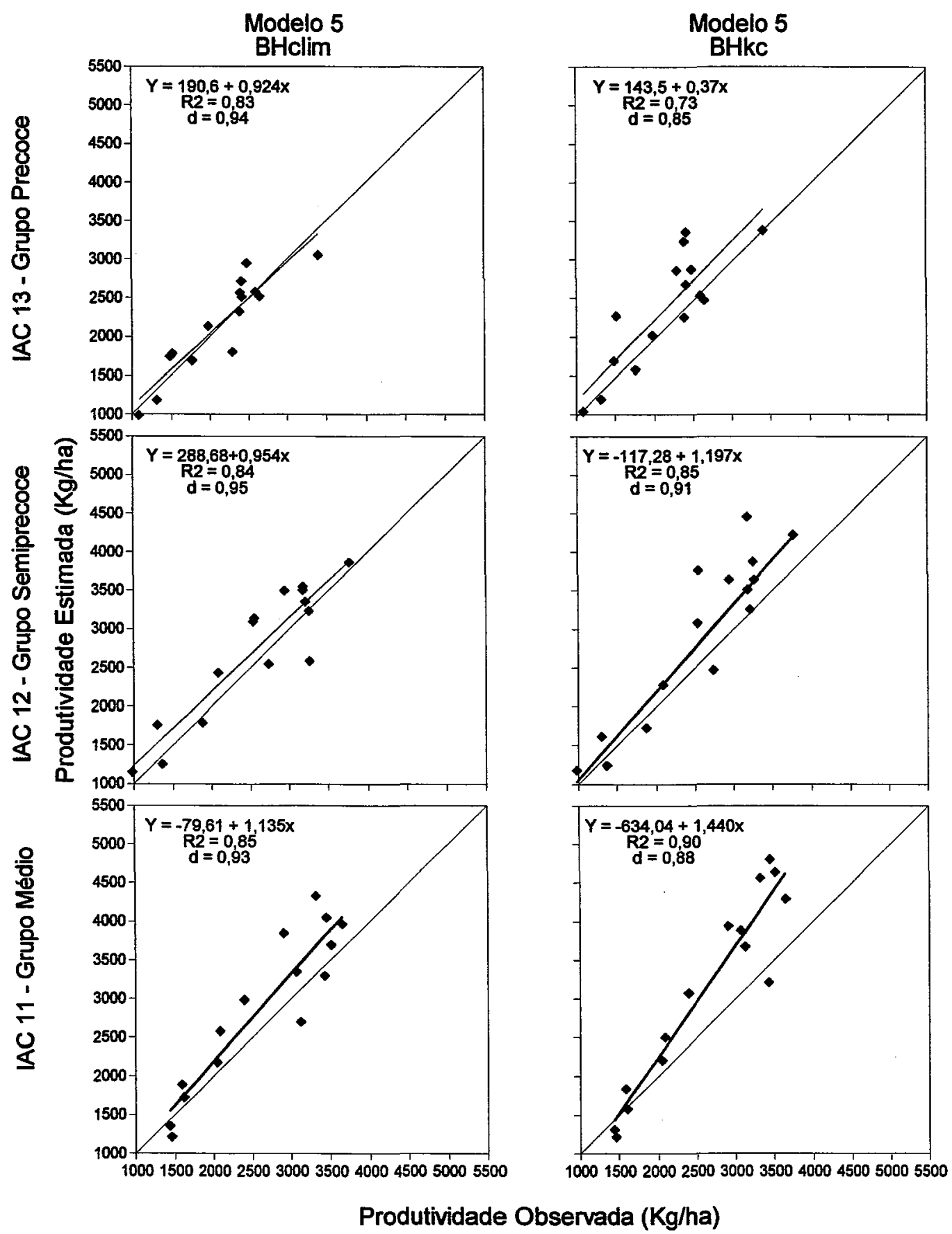

Figura 10 - Produtividades ( $\mathrm{kg} / \mathrm{ha}$ ) observadas e estimadas pelo modelo 5, para os cultivares IAC-13, IAC-12 e IAC-11. 


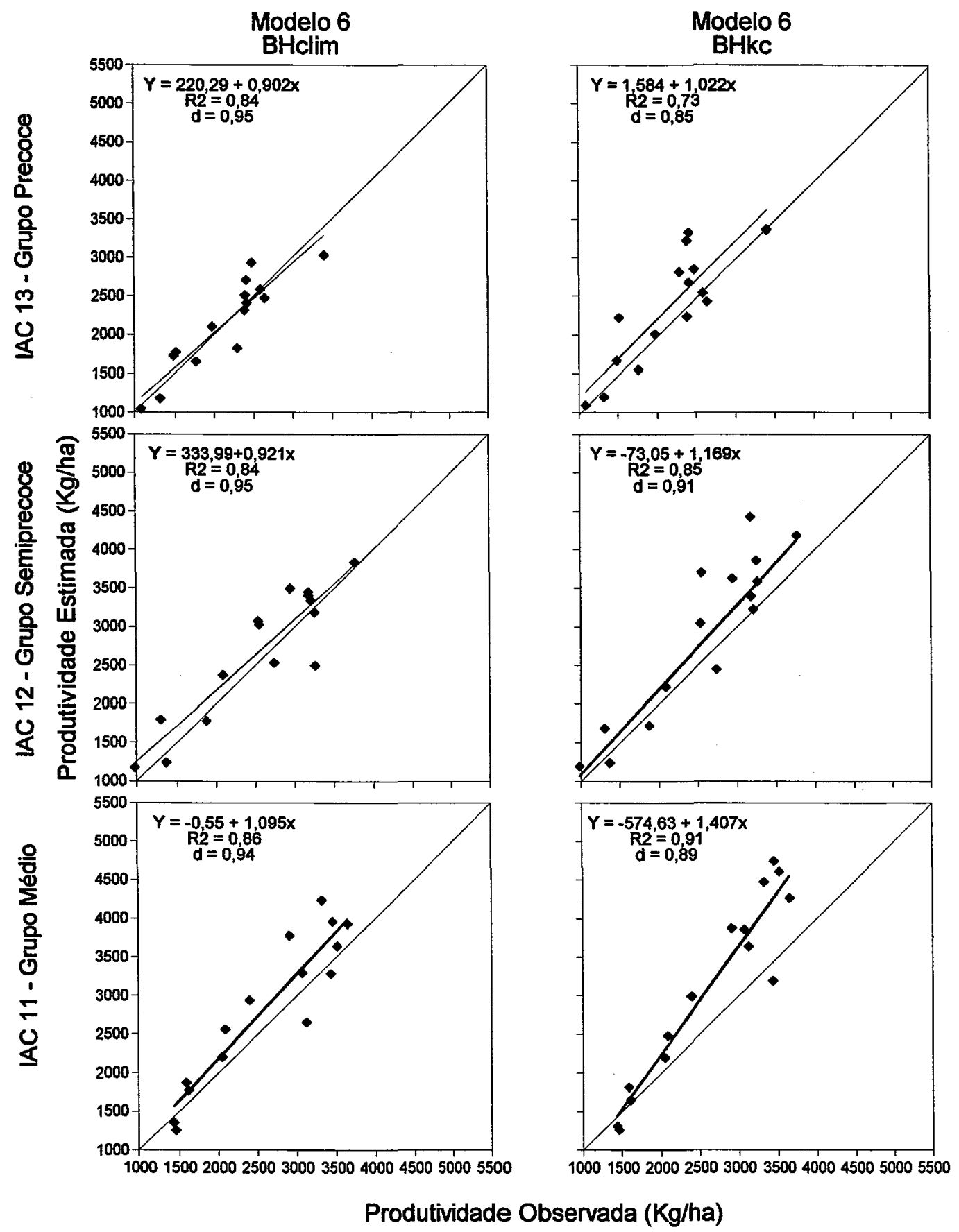

Figura 11 - Produtividades (kg/ha) observadas e estimadas pelo modelo 6, para os cultivares IAC-13, IAC-12 e IAC-11. 

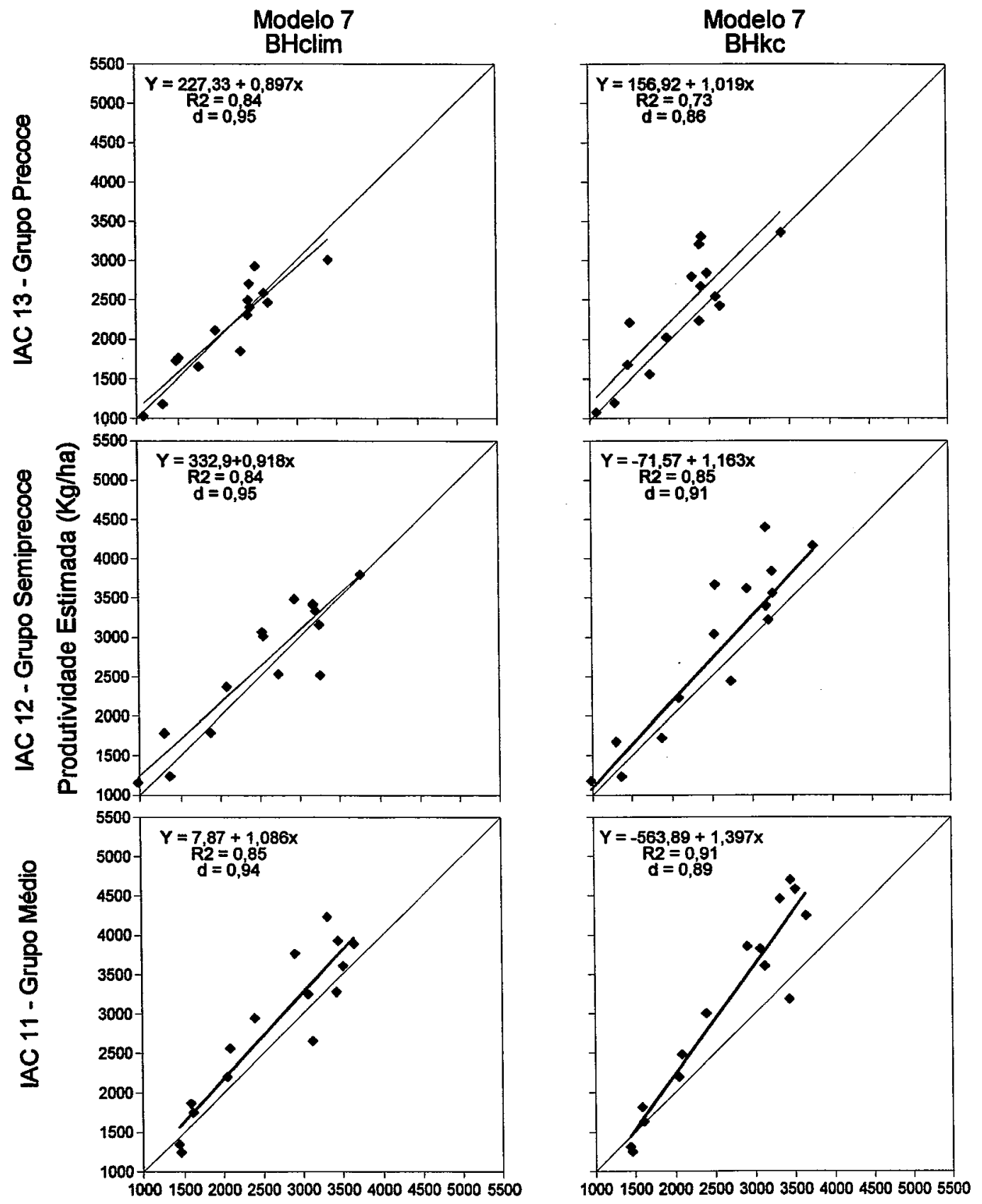

Produtividade Observada (Kg/ha)

Figura 12 - Produtividades (kg/ha) observadas e estimadas pelo modelo 7, para os cultivares IAC-13, IAC-12 e IAC-11. 


\subsection{Teste com dados independentes}

Para os testes com dados independentes utilizou-se apenas os resultados do BHclim, por este ter apresentado resultados mais consistentes do que a utilização dos parâmetros do BHkc. Os extratos do balanço hídrico climatológico, em escala decendial, para os anos agrícolas de 1995/96 e 1996/97, estão apresentados na Figura 13. Decêndios com déficits hídricos no final de novembro e início de dezembro foram observados no ano agrícola 1995/96, com uma pequena deficiência hídrica também no fim de janeiro/início de fevereiro. Já o ano agrícola de 1996/97 apresentou, a partir de novembro de 1996 até o final de fevereiro de 1997, excedentes hídricos elevados, caracterizando-se como um período extremamente úmido.

$\mathrm{Na}$ Tabela 17 são apresentadas as relações ER/EP estimadas para os cultivares precoces (IAC-17 e IAS-5) e semiprecoces (IAC-15 e IAC-18). Para o ano agrícola de 1995/96, no grupo dos cultivares precoces, a variação foi de 0,82 a 0,97 no estádio fenológico do desenvolvimento vegetativo (I); de 0,91 a 0,96 no florescimento (II); de 0,93 a 1,00 no enchimento de grãos (III). No estádio da maturação (IV), todos os valores de ER/EP foram iguais a 1,00. Valores semelhantes foram encontrados para os cultivares semiprecoces, cuja variação ficou entre 0,84 a 0,95 para o desenvolvimento vegetativo (I); 0,93 a 1,00 para os estádios do florescimento (II) e enchimento de grãos (III) e entre 0,80 a 1,00 para o da maturação (IV). Já o ano agrícola de 1996/97 foi considerado bastante úmido no período total do ciclo da cultura, tanto para os ciclos precoces quanto para os semiprecoces, não apresentando variação no estádio do desenvolvimento vegetativo (I); no florescimento (II), apenas uma data de semeadura para o grupo das semiprecoces apresentou valor inferior a 1,00 (0,92); nos demais estádios fenológicos, de enchimento de grãos (III) e maturação (IV), praticamente não houve deficiência hídrica, com apenas um valor inferior a 0,90 verificado no estádio da maturação. 

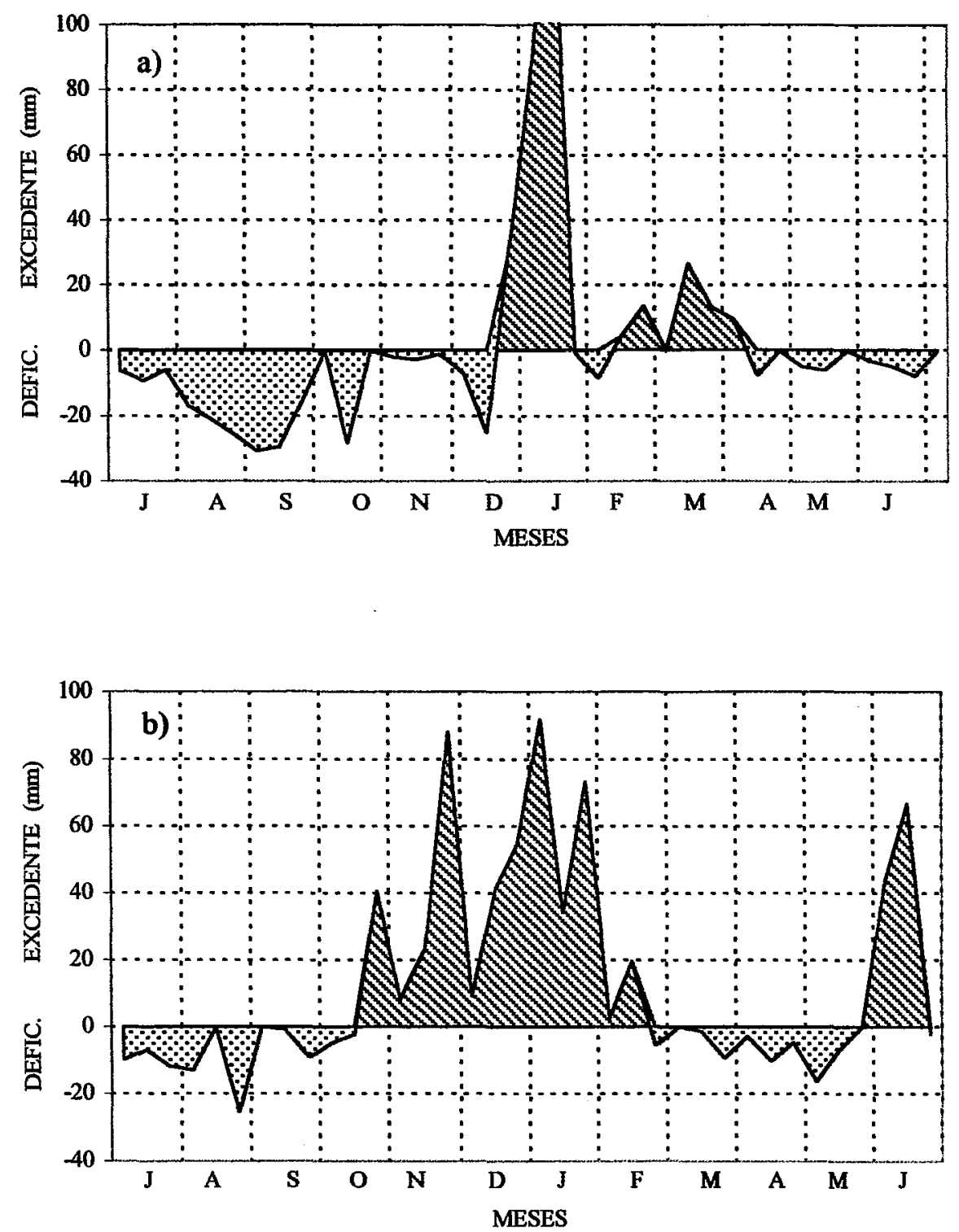

Figura 13 - Extratos do balanço hídrico climatológico decendial, referentes aos anos agrícolas de 1995/96 (a) e 1996/97 (b), para a região de Ribeirão Preto, SP. 
Tabela 17. Relações ER/EP do balanço hídrico climatológico (BHclim) para os cultivares precoces (IAC-17 e IAS-5) e semiprecoces (IAC-15 e IAC-18), em diferentes épocas de semeadura.

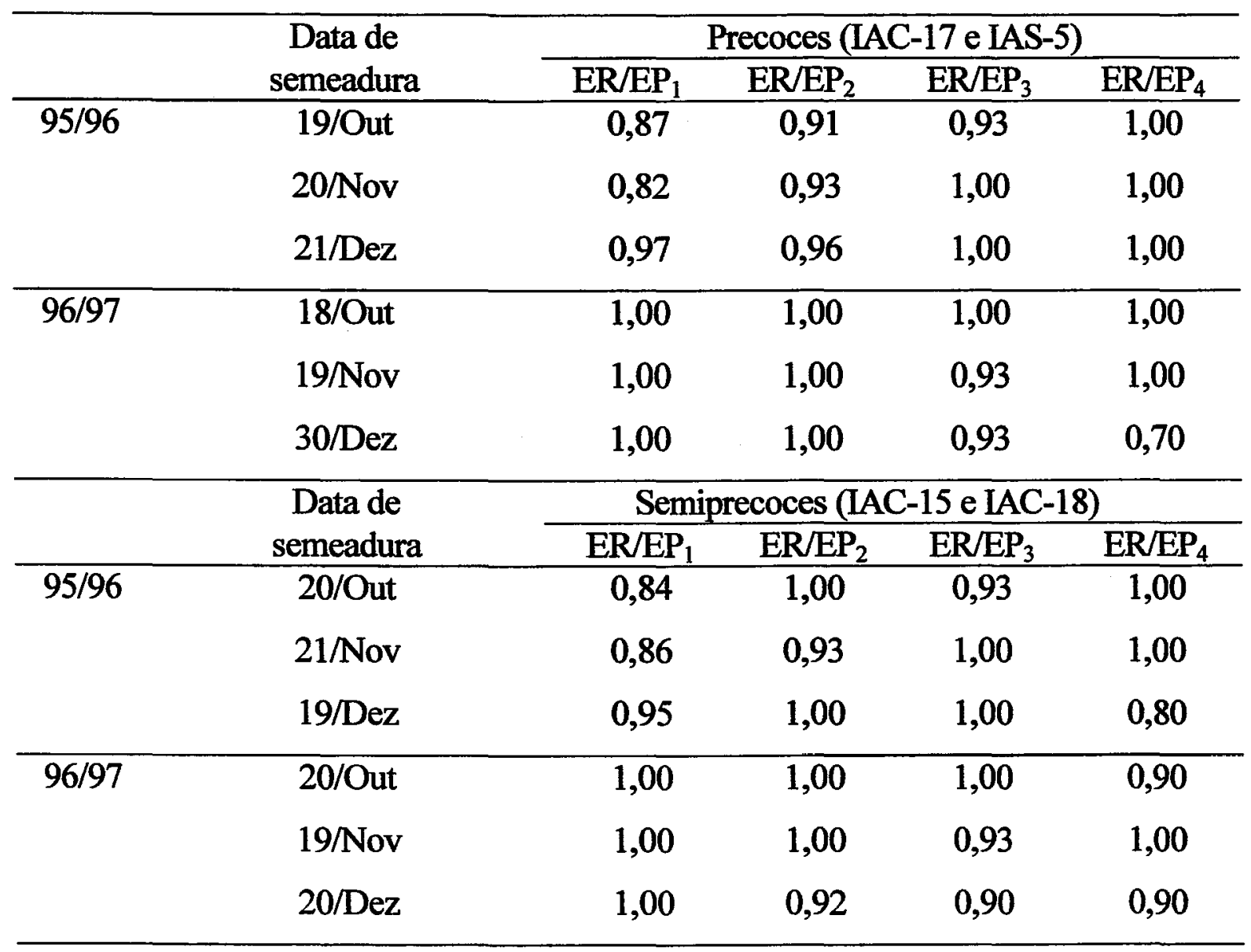


As Tabelas 18 e 19 apresentam os resultados estatísticos do desempenho dos modelos 1 a 7, referentes aos cultivares IAC-17, IAS-5, IAC-15 e IAC-18.

Tabela 18. Resultados estatísticos da análise do desempenho dos modelos 1 a 7 para os cultivares IAC-17 e IAS-5 (grupo Precoce).

\begin{tabular}{cccccc}
\hline IAC-17 & $\mathbf{R}^{2}$ & $\mathbf{d}$ & EAM & Es & Ea \\
\cline { 1 - 3 } Modelos & & & & kg/ha & \\
\cline { 1 - 3 } 1 & 0,01 & 0,41 & 342 & 144 & 373 \\
2 & 0,03 & 0,51 & 194 & 205 & 227 \\
3 & 0,04 & 0,50 & 202 & 196 & 234 \\
4 & 0,08 & 0,58 & 105 & 195 & 127 \\
5 & 0,01 & 0,45 & 88 & 273 & 159 \\
6 & 0,01 & 0,40 & 53 & 278 & 154 \\
7 & 0,01 & 0,34 & 23 & 294 & 162 \\
\hline IAS-5 & & & & & \\
\hline 1 & 0,04 & 0,45 & 391 & 120 & 527 \\
2 & 0,19 & 0,34 & 244 & 197 & 492 \\
3 & 0,19 & 0,35 & 254 & 189 & 492 \\
4 & 0,18 & 0,28 & 156 & 191 & 448 \\
5 & 0,36 & 0,20 & 122 & 234 & 518 \\
6 & 0,43 & 0,14 & 86 & 224 & 532 \\
7 & 0,51 & 0,06 & 51 & 219 & 555 \\
\hline
\end{tabular}


Tabela 19. Resultados estatísticos da análise do desempenho dos modelos 1 a 7 para os cultivares IAC-15 e IAC-18(grupo Semiprecoce).

\begin{tabular}{cccccc}
\hline IAC-15 & $\mathbf{R}^{2}$ & $\mathrm{~d}$ & EAM & Es & Ea \\
\cline { 1 - 3 } Modelos & & & & $\mathrm{kg} / \mathrm{ha}$ & \\
\cline { 1 - 3 } 1 & 0,03 & 0,36 & 249 & 99 & 280 \\
2 & 0,04 & 0,32 & 105 & 199 & 186 \\
3 & 0,05 & 0,32 & 112 & 188 & 191 \\
4 & 0,10 & 0,22 & 39 & 160 & 169 \\
5 & 0,06 & 0,21 & 12 & 232 & 171 \\
6 & 0,12 & 0,19 & 46 & 235 & 202 \\
7 & 0,19 & 0,17 & 74 & 232 & 236 \\
\hline IAC-18 & & & & & \\
\hline 1 & 0,52 & 0,60 & 244 & 158 & 244 \\
2 & 0,15 & 0,71 & 85 & 223 & 95 \\
3 & 0,47 & 0,72 & 93 & 213 & 101 \\
4 & 0,33 & 0,70 & 11 & 220 & 13 \\
5 & 0,39 & 0,67 & 44 & 266 & 69 \\
6 & 0,32 & 0,62 & 83 & 283 & 89 \\
7 & 0,24 & 0,58 & 114 & 300 & 114 \\
\hline
\end{tabular}

Observa-se que todos os modelos apresentaram baixos valores de $\mathrm{R}^{2} \mathrm{e}$ índice $\mathrm{d}$.

Com relação aos erros absolutos médios (EAM), houve uma sensível melhora no teste dos modelos 4 (com a inclusão do fator excedente), 5, 6 e 7 (parametrizados), para os quatro cultivares usados como dados independentes. No teste do cultivar IAC-17, os valores do EAM, em kg/ha, diminuíram de 342 (modelo 1) para 23 (modelo 7 ). $O$ erro sistemático (Es) apresentou valores maiores que o erro aleatório (Ea), para os modelos 4 a 7.

Para o cultivar IAS-5, o valor do EAM decresceu de $391 \mathrm{~kg} / \mathrm{ha}$ (modelo 1) para $156 \mathrm{~kg} / \mathrm{ha}$ (modelo 4) e $51 \mathrm{~kg} / \mathrm{ha}$ (modelo 7), porém os valores do Ea foram sempre maiores que os do Es, acarretando baixos valores do índice $\mathrm{d}$.

$\mathrm{Na}$ análise do cultivar IAC-15, o valor do EAM foi de $249 \mathrm{~kg} / \mathrm{ha}$ (modelo 1) e de $12 \mathrm{~kg} /$ ha para o modelo 5 , sendo que os modelos 4,6 e 7 também apresentaram valores 
do EAM relativamente mais baixos que os modelos 1,2 e 3 . A tendência dos Es serem mais elevados que os Ea se manteve nos modelos 5 a 7 .

Os números do EAM encontrados para o cultivar IAC-18 tiveram seu menor valor no teste do modelo 4, com $11 \mathrm{~kg} / \mathrm{ha}$. O EAM mais elevado foi o correspondente ao teste do modelo 1, com $244 \mathrm{~kg} / \mathrm{ha}$. No caso deste cultivar, o modelo 4 apresentou valor de Ea muito baixo, de apenas $13 \mathrm{~kg} / \mathrm{ha}$.

Graficamente são apresentadas, nas Figuras 14 a 20, as produtividades observadas e estimadas pelos sete modelos, para os cultivares IAC-17, IAS-5, IAC-15 e IAC-18. 
Modelo 1

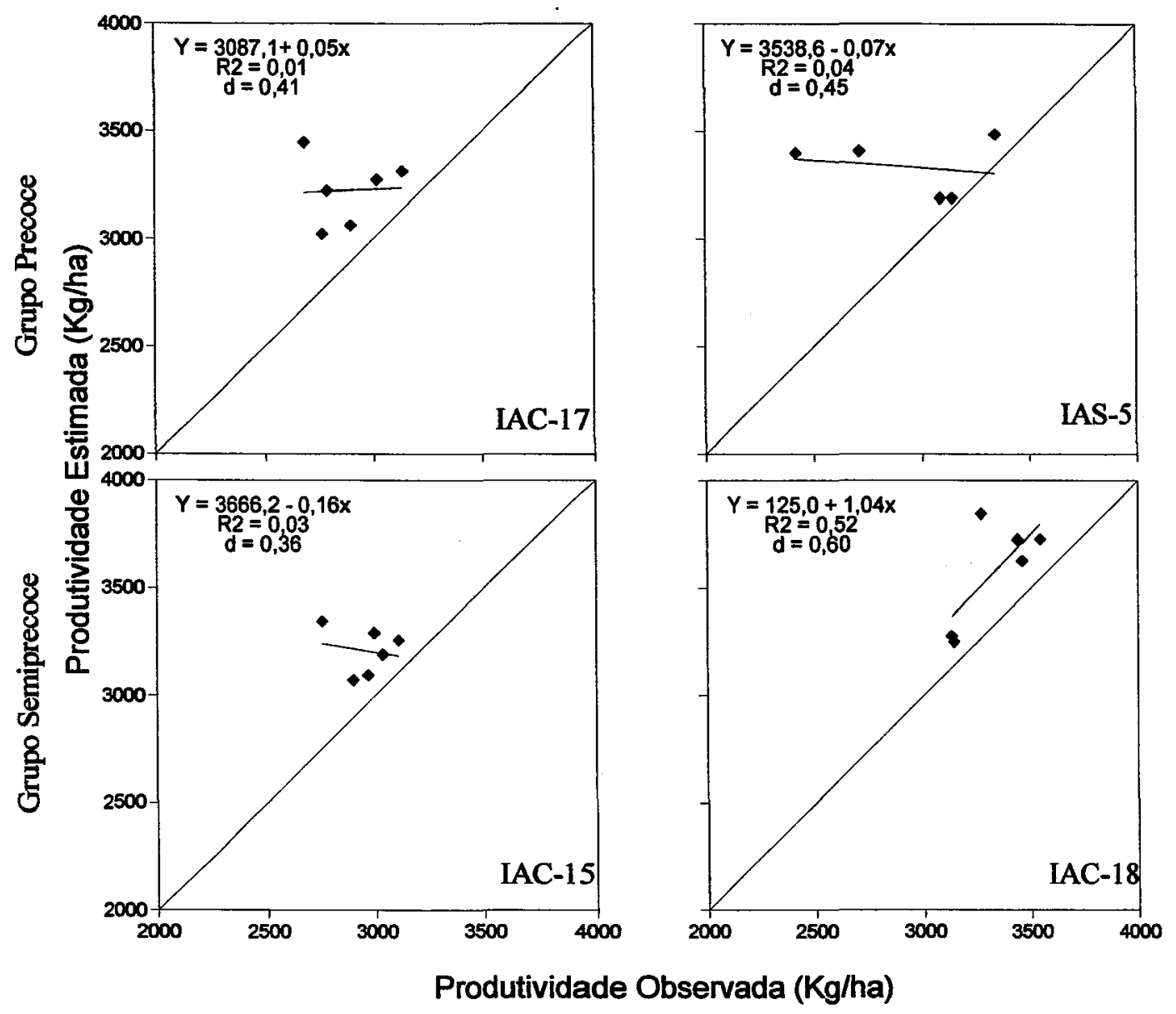

Figura 14. Produtividades (kg/ha) observadas e estimadas pelo modelo 1, para os cultivares IAC-17, IAS-5, IAC-15 E IAC-18. 
Modelo 2

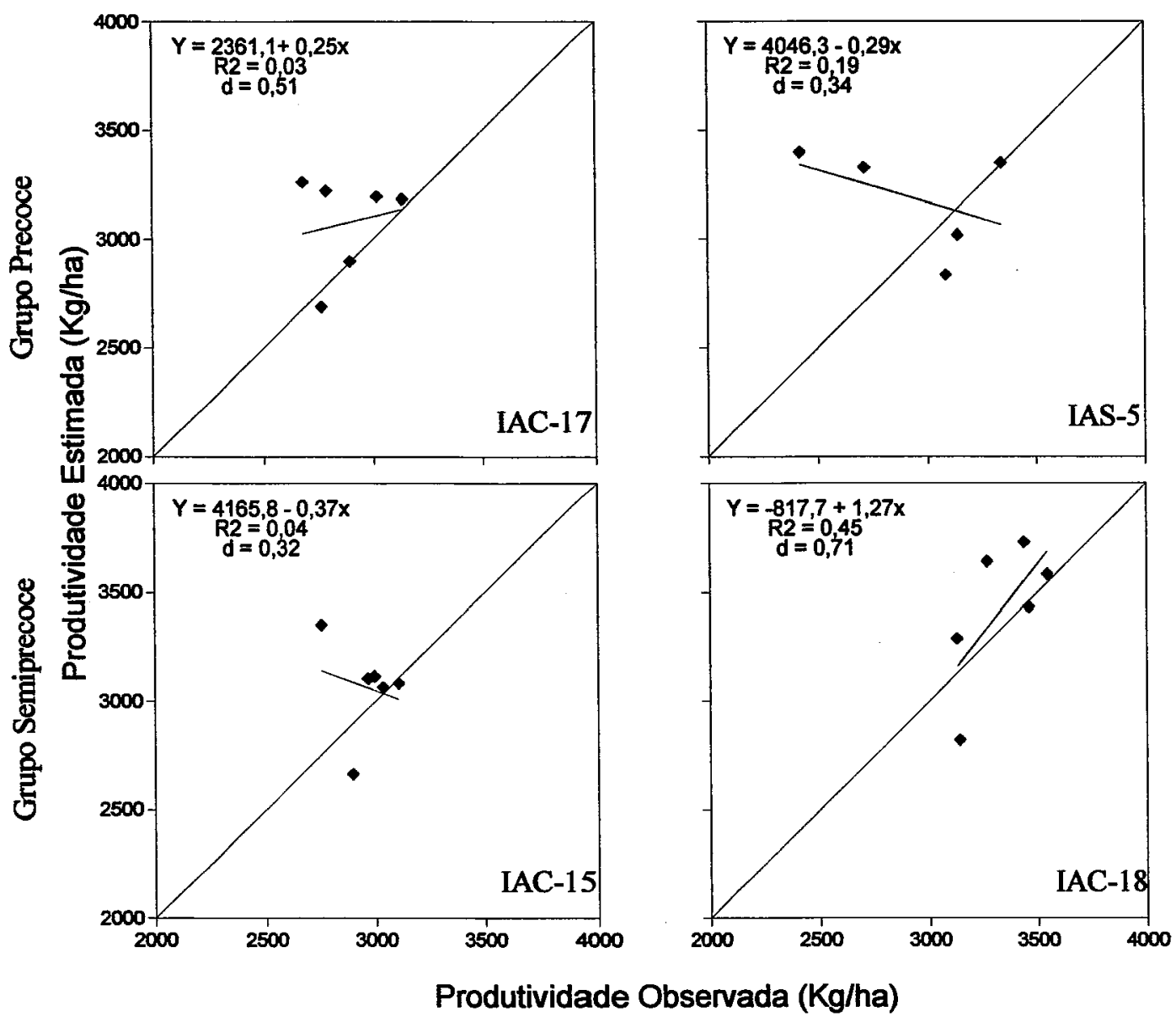

Figura 15. Produtividades $(\mathrm{kg} / \mathrm{ha})$ observadas e estimadas pelo modelo 2, para os cultivares IAC-17, IAS-5, IAC-15 e IAC-18. 
Modelo 3

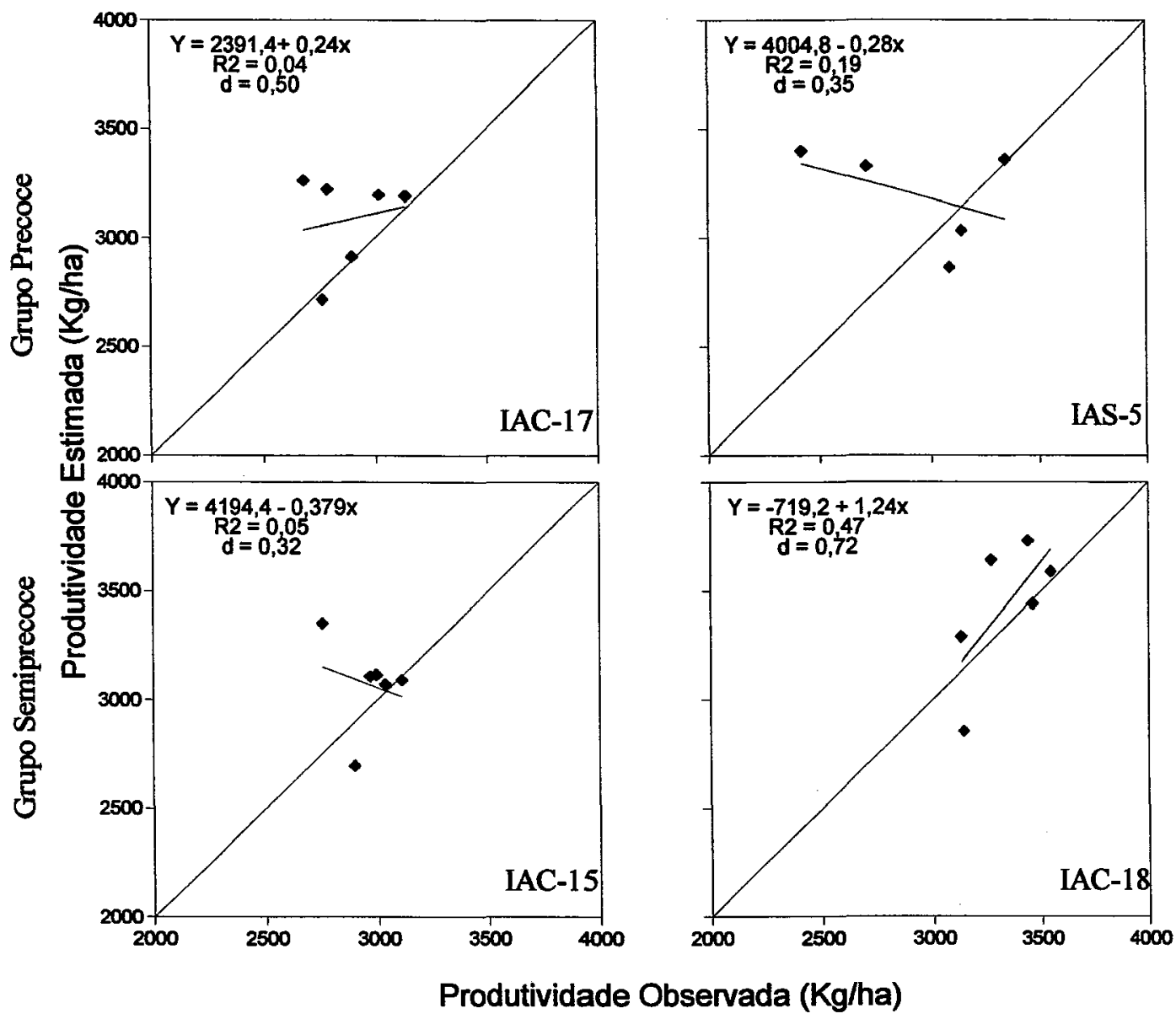

Figura 16. Produtividades ( $\mathrm{kg} / \mathrm{ha}$ ) observadas e estimadas pelo modelo 3 , para os cultivares IAC-17, IAS-5, IAC-15 e IAC-18. 


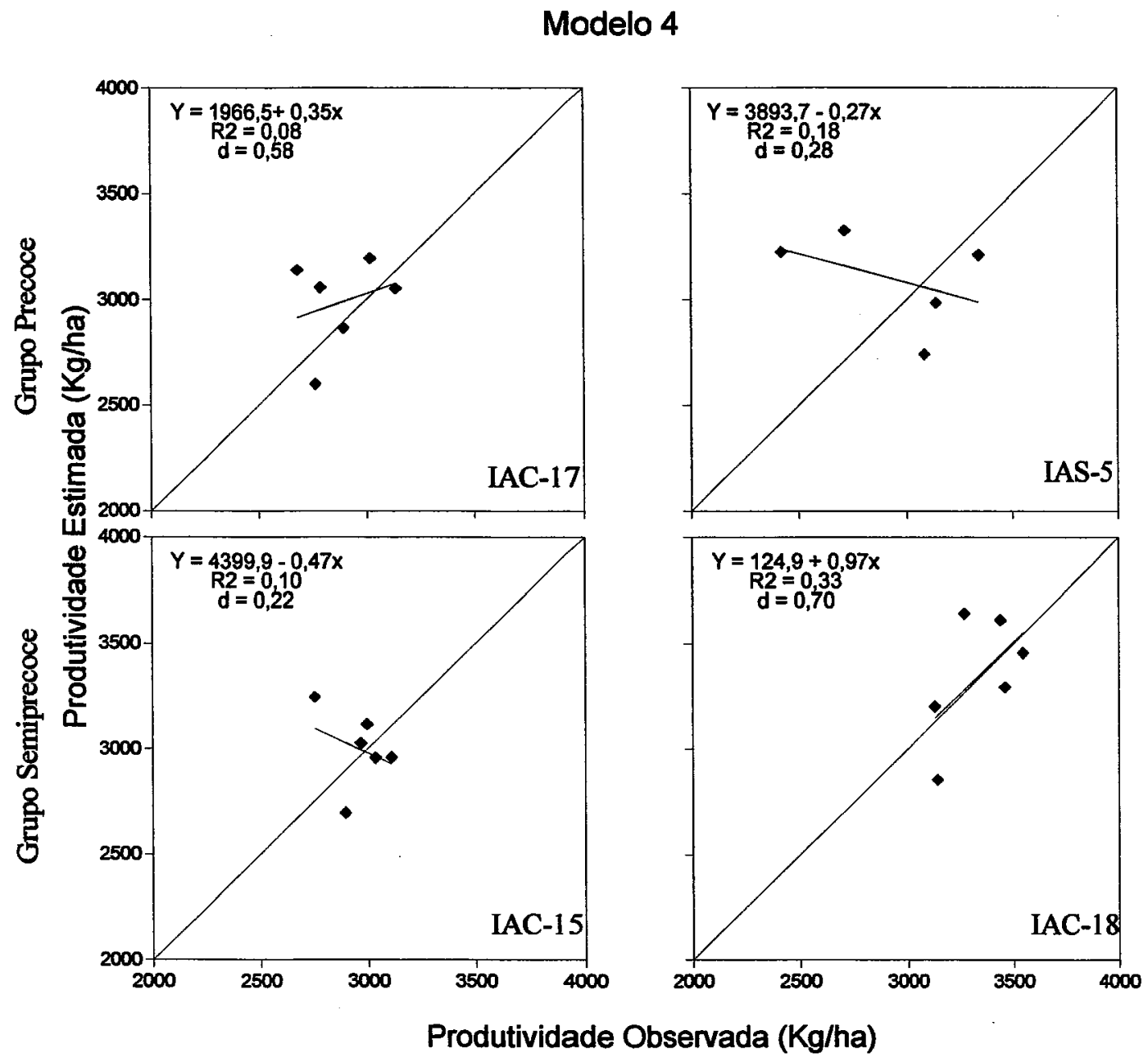

Figura 17 - Produtividades (kg/ha) observadas e estimadas pelo modelo 4, para os cultivares IAC-17, IAS-5, IAC-15 e IAC-18. 
Modelo 5

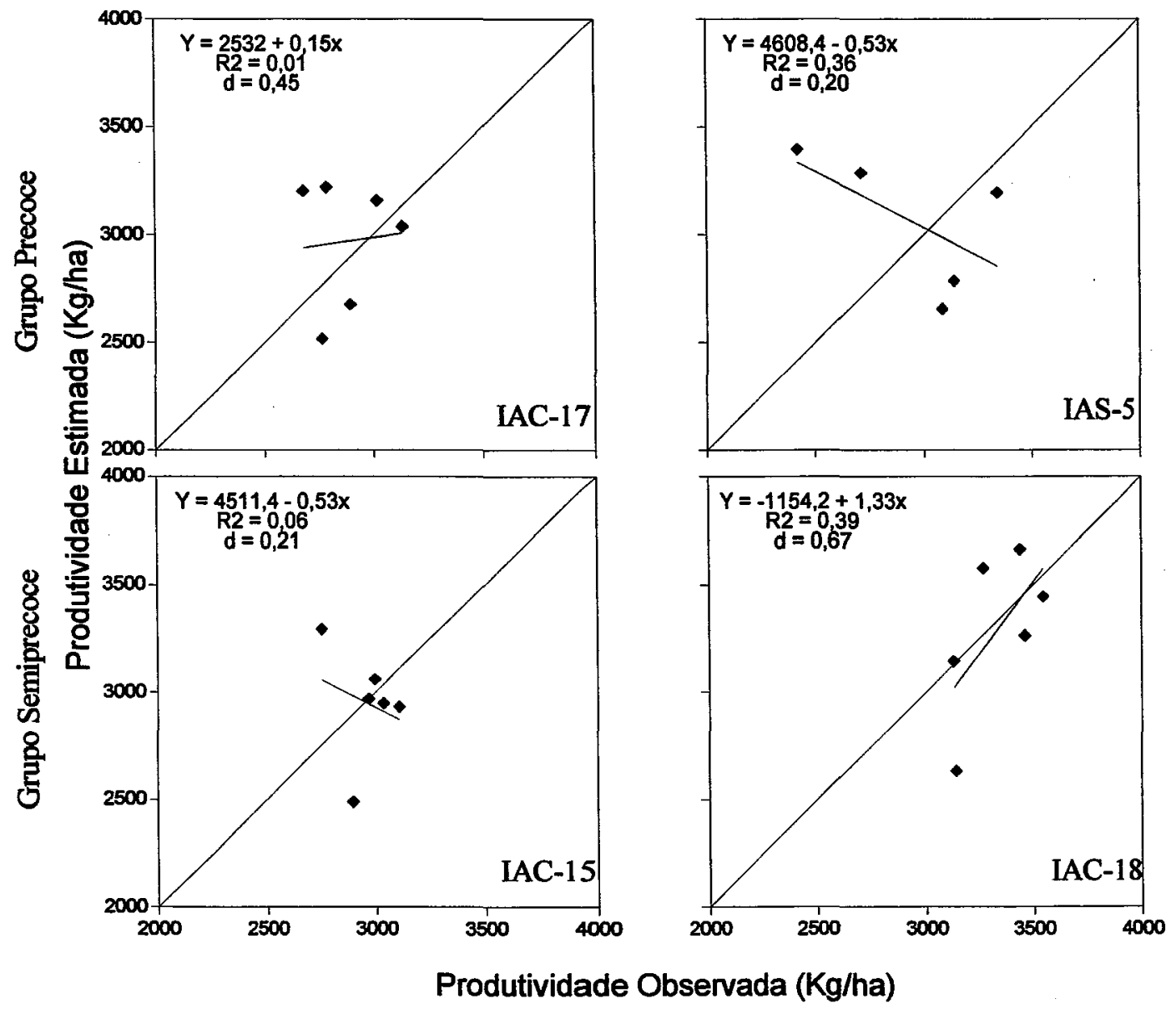

Figura 18 - Produtividades $(\mathrm{kg} / \mathrm{ha}$ ) observadas e estimadas pelo modelo 5, para os cultivares IAC-17, IAS-5, IAC-15 e IAC-18. 


\section{Modelo 6}
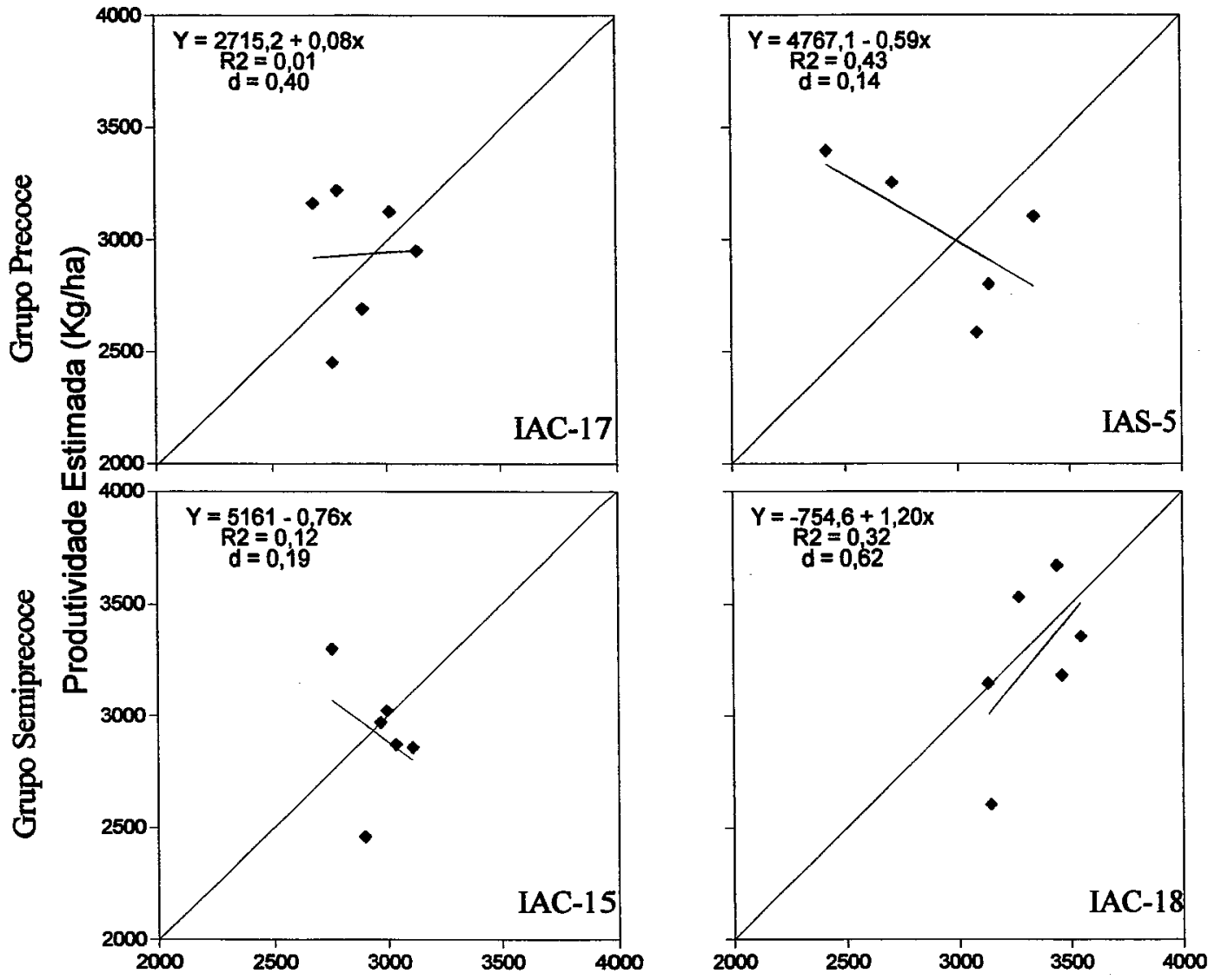

Produtividade Observada (Kg/ha)

Figura 19 - Produtividades (kg/ha) observadas e estimadas pelo modelo 6, para os cultivares IAC-17, IAS-5, IAC-15 e IAC-18. 
Modelo 7

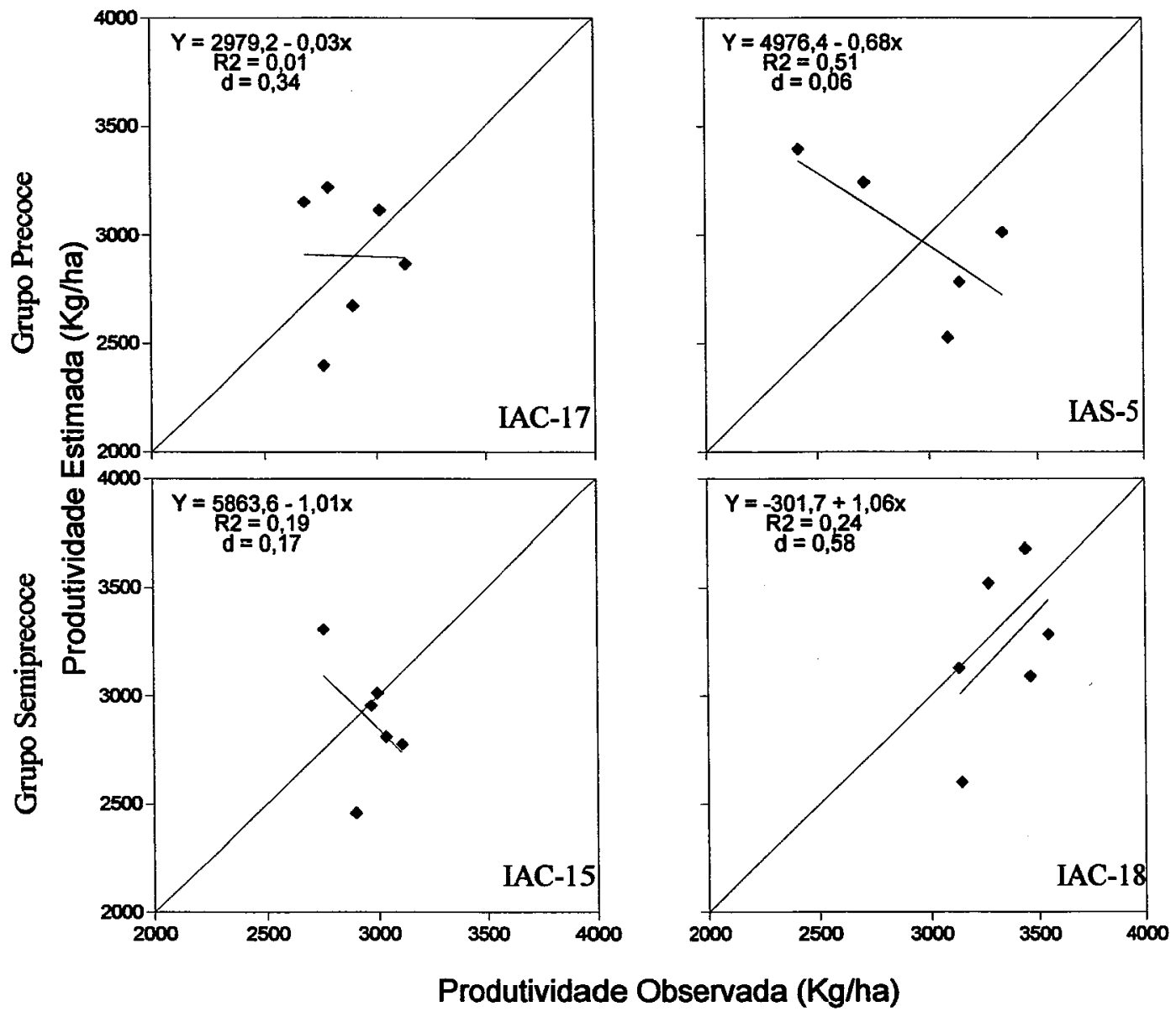

Figura 20 - Produtividades (kg/ha) observadas e estimadas pelo modelo 7, para os cultivares IAC-17, IAS-5, IAC-15 e IAC-18. 
Como justificativa dos baixos valores de $\mathrm{R}^{2} \mathrm{e}$ índice $\mathrm{d}$ encontrados nas análises, destaca-se que os testes dos modelos foram realizados com materiais genéticos diferentes daqueles para os quais foi feita a parametrização. Isto se deve à grande evolução pela qual passa a cultura da soja, com o rápido surgimento de novos cultivares. Apesar desses novos materiais testados pertencerem aos mesmos grupos de maturação precoce e semiprecoce recomendados para a região de Ribeirão Preto (Fahl et al., 1998), eles provavelmente não apresentam as mesmas características fenológicas e produtivas dos cultivares parametrizados neste trabalho. Como decorrência deste fato, o principal problema foi a determinação da produtividade potencial dos novos cultivares, uma vez que ainda não foram obtidas séries com número suficientes de anos que permitissem o conhecimento profundo de seu comportamento, tanto fenológico quanto produtivo. Por esta razão, os resultados dos modelos parametrizados somente têm validade para os cultivares IAC-13, IAC-12 e IAC-11. Recomenda-se a parametrização desses novos cultivares (IAC-17, IAS-5, IAC-15 e IAC-18) com pelo menos 4 anos de cultivo e de pelo menos 2 anos como teste, para permitir o melhor conhecimento dos valores de produtividade potencial e do seu comportamento fenológico.

Uma outra justificativa em relação à discussão do desempenho dos modelos é referente às condições de umidade ocorridas nos dois anos do teste com os dados independentes (1995/96 e 1996/97). Conforme relatado anteriormente, o ano agrícola de 1995/96 apresentou poucos períodos com deficiências hídricas acentuadas (Figura $13 \mathrm{e}$ Tabela 17), enquanto o ano agrícola de 1996/97 foi considerado extremamente úmido, com ausência de períodos secos ou com pequenas magnitudes de deficiências hídricas durante o ciclo da cultura.

Esses fatos são relevantes ao considerarmos a natureza dos modelos testados e desenvolvidos. Todos são baseados nas relações ER/EP, ou seja, na penalização da produtividade potencial pela ocorrência de deficiências hídricas durante $\mathrm{o}$ ciclo da cultura. $O$ desempenho dos modelos não se mostrou satisfatório uma vez que não 
ocorreram períodos com deficiências hídricas suficientemente severas para que seu efeito fosse caracterizado em termos de quebra de produtividade, ou seja, não foi observada variabilidade nas produtividades dos quatro cultivares testados em função das condições hídricas ocorridas ao longo do ciclo da cultura. 


\section{CONCLUSÕES}

a) A utilização dos resultados obtidos pelo BHkc, para os sete modelos considerados, não apresentou desempenho superior aos resultados advindos do BHclim.

b) Os estádios fenológicos do florescimento (II) e enchimento de grãos (III) apresentaram os valores mais elevados de "coeficientes de produtividade" (ky) e "indices de sensibilidade" $(\lambda)$ quando comparados com os demais estádios fenológicos, confirmando, assim, serem aqueles estádios os mais sensíveis ao déficit hídrico.

c) Os coeficientes de produtividade $\left(\mathrm{ky}_{\mathrm{i}}\right)$ determinados para o cultivar IAC-13 (precoce), com a utilização do BHclim, apresentaram valores próximos aos propostos por Doorenbos \& Kassam (1979). Para os cultivares de ciclos semiprecoce (IAC-12) e médio (IAC-11), esses coeficientes apresentaram valores mais elevados.

d) Os modelos agrometeorológicos testados (1 a 4 ) apresentaram desempenhos satisfatórios na estimativa da produtividade para os cultivares de soja considerados, na região de Ribeirão Preto, SP, porém, com tendência de superestimativas das produtividades, especialmente para os cultivares IAC-12 e IAC-11. 
e) As estimativas de produtividade baseadas nos modelos aditivo (modelo 2) e multiplicativo (modelo 3) de Doorenbos \& Kassam (1979) apresentaram desempenhos semelhantes entre si.

f) O modelo agrometeorológico 4, que considera penalização da produtividade por excedente hídrico, apresentou desempenho superior quando comparado aos demais modelos testados (1, 2 e 3), para os cultivares IAC-13, IAC-12 e IAC-11.

g) Os modelos agrometeorológicos parametrizados (modelos 5, 6 e 7) apresentaram desempenhos semelhantes entre si e superiores aos verificados nos modelos 1 a 4 na estimativa de produtividade para a cultura da soja na região de Ribeirão Preto, SP.

h) Os modelos testados e os parametrizados para os cultivares IAC-13, IAC-12 e IAC-11 apresentaram os menores erros na estimativa da produtividade quando aplicados ao cultivar do grupo de maturação precoce (IAC-13).

i) Os modelos agrometeorológicos, tanto os testados quanto os parametrizados, porém, não demonstraram ser eficientes na estimativa de produtividade quando aplicados aos cultivares de soja IAC-17, IAS-5, IAC-15 e IAC-18 na região de Ribeirão Preto, SP, provavelmente devido ao desconhecimento de suas produtividades potenciais e às condições de umidade excessiva observadas nos anos considerados. 


\section{REFERÊNCIAS BIBLIOGRÁFICAS}

ACOCK, B.; ACOCK, M.C. Potential for using long-term field research data to develop and validate crop simulators. Agronomy Journal. v.83. p.56-61. 1991.

ALFONSI, R. R.; PEDRO JÚNIOR, M. J.; ARRUDA, F. B.; ORTOLANI, A. A.; CAMARGO, M. B. P.; BRUNINI, O. Métodos agrometeorológicos para controle da irrigação. Campinas, SP. Instituto Agronômico. 1990. 62p. (Boletim Técnico n. 133).

ARRUDA, F. B. ; MASCARENHAS, H. A. A.; VIEIRA, S. R. Efeito hídrico na produção de soja: Análise. Campinas. Instituto Agronômico. 1978. 24p. (Boletim Técnico n. 38).

BAIER, W. Crop-weather analysis model. International Journal of Biometeorology. Amsterdam. v.17. p.313-320. 1973.

BAIER, W. Note on the terminology of crop-weather models. Agricultural Meteorology. Amsterdam. v.20. p.137-145. 1979.

BARBIERI, V.; TUON, R. L.; ANGELOCCI, L. R. Programa para microcomputador do balanço hídrico (Thornthwaite \& Mather, 1955) para dados mensais e decendiais, normais e sequenciais. In: CONGRESSO BRASILEIRO DE AGROMETEOROLOGIA. 7. Viçosa, MG. 1991. Resumos. Sociedade Brasileira de Agrometeorologia. 1991. p.297-299. 
BERGAMASCHI, H. Desenvolvimento de déficit hídrico em culturas. In: BERGAMASCHI, H. (Coord.). Agrometeorologia Aplicada à Irrigação. Porto Alegre. Ed. da Universidade/ Universidade Federal do Rio Grande do Sul. 1992. p.25-35.

BERLATO, M. A.; FONTANA, D. C.; GONÇALVES, N. M. Relação entre o rendimento de grãos da soja e variáveis meteorológicas. Pesquisa Agropecuária Brasileira. v.27. n.5. p.695-702. 1992.

BERLATO, M. A.; MOLION, L. C. B. Modelo de relação entre rendimento de grãos da soja e déficit hídrico. In: CONGRESSO BRASILEIRO DE AGROMETEOROLOGIA. 3. Porto Alegre, RS. 1993. Resumos. Sociedade Brasileira de Agrometeorologia. 1993. p.144.

BROWN, D. M.; CHAPMAN, L. J. Soybean ecology III - Soybean development units for zones and varieties in the Great Lakes region. Agronomy Journal. Madison. v.53. n.5. p. 306-308. 1961.

BRUNINI, O. Zoneamento agroclimático, materiais e métodos. In: REUNIÃO BRASILEIRA DE MILHO E SORGO. 13. Londrina, PR. 1980. IAPAR 1980. . p.162-187.

BRUNINI, O.; MIRANDA, M. A. C.; MASCARENHAS, H. A. A.; PEREIRA, J.C.V. N. A.; SCHIMIDT, N. C. Teste de um modelo agroclimático que relacione o regime pluviométrico com as variações da produtividade agrícola. In: SEGOVIA, R. M. (Ed). Determinação do efeito da precipitação pluviométrica na 
produtividade agrícola. Brasilia. CFP. 1982. p.21-46. (Coleção Análise e Pesquisa, 24).

CAMARGO, A. P. Contribuição para a determinação da evapotranspiração potencial no Estado de São Paulo. Bragantia. Campinas. v.21 n.12. p.163-213. 1962.

CAMARGO, A. P. ; CHIARINI, J. V.; DONZELLI, P. L. et al. Zoneamento da aptidão ecológica para a cultura da soja, girassol e amendoim no Estado de São Paulo. INSTIÓLEOS. Secretaria da Agricultura do Estado de São Paulo. 1971. $35 \mathrm{p}$.

CAMARGO, M. B. P. Exigências bioclimáticas e estimativa da produtividade para quatro cultivares de soja no Estado de São Paulo. Piracicaba, SP. 1984. 96p. Dissertação (Mestrado) - Escola Superior de Agricultura "Luiz de Queiroz", Universidade de São Paulo.

CAMARGO, M. B. P. Determination of the water balance components and drought sensitivity indices for a sorghum crop. Lincoln/USA. 1993. 126p. Doctoral Dissertation - University of Nebraska.

CAMARGO, M. B. P.; BRUNINI, O.; MIRANDA, M. A. C. Modelo agrometeorológico para estimativa da produtividade para a cultura da soja no Estado de São Paulo. Bragantia. Campinas. v.45. n.2. p.279-292. 1986.

CAMARGO, M. B. P.; MIRANDA, M. A. C.; PEDRO JÚNIOR, M. J.; PEREIRA, J. C. V. N. A.; MASCARENHAS, H. A. A. Estimativa da produtividade potencial 
de cultivares de soja nas condições climáticas de Ribeirão Preto. SP. Bragantia. Campinas. v.47. n.2. p.277-288. 1988.

CAMARGO, M. B. P.; CAMARGO, A. P. Representação gráfica informatizada do extrato do balanço hídrico de Thornthwaite \& Mather. Bragantia. Campinas. v.52. n.2. p.169-172. 1993.

COSTA, L.C.; COSTA, M. H. Um modelo para se determinar a produtividade da cultura da soja. In: CONGRESSO BRASILEIRO DE AGROMETEOROLOGIA. 6. Maceió, AL. 1989. Anais. Sociedade Brasileira de Agrometeorologia. 1989. p.391-399.

CUNHA, G. R.; BERGAMASCHI, H. Efeitos da disponibilidade hídrica sobre o rendimento das culturas. In: BERGAMASCHI, H. (Coord.) Agrometeorologia aplicada à irrigação. Porto Alegre. Editora da Universidade/Universidade Federal do Rio Grande do Sul. 1992. p.85-97.

DALE, R. F. \& SHAW, R. H. The climatology of soil moisture atmospheric evaporative demand and resulting moisture stress days for corn at Ames, Iowa. Journal of Applied Meteorology. Boston, v.4. n.6. p.66-69. 1965.

DOORENBOS, J.; KASSAM, A. H. Yield response to water. Rome. FAO, 1979. 197p. (FAO Irrigation and Drainage Paper, 33).

FAHL, J. I.; CAMARGO, M. B. P; PIZZINATTO, M. A. ; BETTI, J.A.; MELO, A. M. T.; DeMARIA, I. C.; FURLANI, A. M. C. (Ed.). Instruções Agrícolas para 
as principais culturas econômicas. 6. ed. Instituto Agronômico-Campinas. 1998. 396 p. p. 297-98. (Boletim 200).

FISHER, R. A. The influence at rainfall on the yield of wheat at Rothamsted. Phil. Trans. Roy. Society. London. v. 213. p.89-142. 1924.

FUKUI, J.; OJIMA, M. Influence of soil moisture content on the growth and yield of soybean. Proceedings of Crop Science Society. Japan. v.26. p.40-42. 1957.

GANDOLFI, V. H.; MULLER, L.; MINOR, H. C.; BERLATO, M. A. Identificação de cultivares de soja menos sensíveis ao fotoperíodo entre cultivares tardios. Agronomia Sulriograndense. Porto Alegre, RS. v.13. n.1. p. 55-62. 1977.

GANDOLFI, V. H. ; MULLER, L. Fotoperiodismo. In: MIYASAKA, S. e J. C. MEDINA (Ed). A Soja no Brasil. Campinas. Fundação Cargill. 1981. p.129-142.

GANDOLFI, V.H. ; BÁN, A.D.; VILHORDO, B. W. ; MÜLLER, L. Morfologia, anatomia e desenvolvimento. In: VERNETTI, F. J. (Coord.). Soja-Planta, clima, pragas, moléstias e invasoras. Campinas. Fundação Cargill. 1983. v.1. p. 17-89.

HANKS, R. J. Model for prediction plant yield influenced by water use. Agronomy Journal. Madison. v.66. n.6. p.660-665. 1974.

HANKS, R. J.; RASMUSSEN, V. P. Predicting crop production as related to plant water stress. In: BRADY, N. C. (Ed.). Crop production and plant water stress. 1982. p.193-215. (Advances in Agronomy, 35). 
HILLEL, D.; GURON, V. Relation between evapotranspiration rate and maize yield. Water Resources Research. v.9. p.703-743. 1973.

HOWELL, R. W. Physiology of the soybean. In: NORMANN, A.G. (Ed). The Soybean. New York. Academic Press. 1967. p.75-124.

JENSEN, M. E. Water consumption by agricultural plants. In: KOZLOWSKI, T.T. (Ed.). Water deficits and plant growth. v.2. New York. Academic Press. 1968. p.1-22.

KANEMASU, E. T. Yield and water-use relationships: some problems of relating grain yield to transpiration. In: TAYLOR, H. M.; JORDAN, W. R.; SINCLAIR, T. R. (Ed.). Limitations to efficient water use in crop production. American Society of Agronomy. Madison. 1983. cap. 9B. p. 413-417.

LAZINSKI, L.R. Viabilidade da utilização do modelo Soygro para a região de Londrina, PR. Piracicaba, SP. 1993. 86p. Dissertação (Mestrado) - Escola Superior de Agricultura “Luiz de Queiroz”, Universidade de São Paulo.

MAJOR, D. J.; JOHNSON, D. R. Predict when your soybeans will flower, mature. Crops and Soils Management. Madison. v.27. n.5. p.13-17. 1975.

MAJOR, D. J.; JOHNSON, D. R.; LUEDDERS, V. D. Evaluation of eleven thermal unit methods for predicting soybean development. Crop Science. Madison. v.15. n.2. p.172-174. 1975. 
MASON, W.K; G. A. CONSTABLE; R. C. G. SMITH. Irrigation for crops in a subhumid environment: the water requirements of soybeans. Irrigation Science. Berlim. v.2. p.13-22. 1980.

MATZENAUER, R. Modelos agrometeorológicos para estimativa do rendimento de milho em função da disponibilidade hídrica no Estado do Rio Grande do Sul. Porto Alegre, 1994. 172p. Tese (Doutorado) - Universidade Federal do Rio Grande do Sul.

MEYER, S. J. The development of a crop specific drought index for com Lincoln/USA. 1990. 165p. Doctoral Dissertation - University of Nebraska.

MEYER, S. J.; HUBBARD, K.G. Extending the crop-specific drought index to soybean. In: CONFERENCE ON APPLIED CLIMATOLOGY. 9. Dallas, Texas. American Meteorological Society. 1995. p. 258-259.

MIRANDA, M. A. C.; BULISANI, E. A.; MASCARENHAS, H. A. A.; PEREIRA, J. C. V. N. A.; GALlO, P. B.; FREITAS, J. G.; FERREIRA FILHO, A. W. P. Novos cultivares de soja-IAC. O Agronômico. Campinas. v.37. n.2. p.89-105. 1985.

MOTA, F. S. Índice de seca para soja: contribuição para um modelo de previsão do rendimento da soja no Rio Grande do Sul. Pesquisa Agropecuária Brasileira. Brasília. v.16. n.3. p.371-383. 1981.

NIX, H. A.; FITZPATRICK, E. A. An index for crop water stress related to wheat and grain sorghum yield. Agricultural Meteorology. Amsterdam. v.6. p.32-37. 1969. 
NOGUEIRA, S. S. S. Ciclo biológico, características fisiológicas, produção e composição química da semente de cultivares de soja (Glycine max (L.) Merril) UFV-1 e IAC-7 em diversas épocas de semeadura. Piracicaba, SP. 1983. 96p. Tese (Doutorado) - Escola Superior de Agricultura 'Luiz de Queiroz”, Universidade de São Paulo.

ORTOLANI, A. A.; CAMARGO, M. B. P. Influência dos fatores climáticos na produção. In: CASTRO, P.R.C.; FERREIRA, S.O. \& YAMADA, T. (Ed). Ecofisiologia da produção agrícola. Associação Brasileira para Pesquisa da Potassa e do Fósforo. 1987. p.71-81.

ORTOLANI, A. A.; SENTElHAS, P. C.; CAMARGO, M. B. P.; PEZZOPANE, J. E. M.; GONÇALVES, P. S. Modelos agrometeorológicos para estimativa da produção anual e sazonal de látex em seringueira. Revista Brasileira de Agrometeorologia. Santa Maria, RS. v.4. n.1. p.147-150. 1996.

PASCALE, A. J. Agroclimatic types for soybean crop in Argentina. In: INTERNATIONAL BIOMETEOROLOGICAL CONGRESS. 5. Montreaux, Switzerland. 1969. p.1-19.

PASCALE, A. J.; REMUSSI, C. ; MARZO, L. Reacción de distintas variedades de soja a los factores bioclimáticos de Buenos Aires. Rev. Fac. Agron. Vet. Buenos Aires. v.15. n.3. p.29-54. 1963. 
PASCALE, A. J.; VILLEGAS, J. A.; MEDINA, L. F. Aptitud agroclimática del Noroeste Argentino para el cultivo de la soja. Rev. Agron. Noroeste Argentino. San Miguel de Tucumán. v.10. n. 3-4. p.173-203. 1973.

PEDRO JÚNIOR, M. J.; CAMARGO, M. B. P.; BRUNINI, O.; ALFONSI, R.R.; ORTOLANI, A. A. ; MIRANDA, M.A.C. Teste de um modelo para estimativa de produção da soja. In: CONGRESSO BRASILEIRO DE AGROMETEOROLOGIA. 3. Campinas. 1983. Anais. Campinas, SP. Sociedade Brasileira de Agrometeorologia. 1984. p.11-17.

PEREIRA, A. R. Simulação do crescimento e da produtividade. In: SIMPÓSIO SOBRE O MANEJO DE ÁGUA NA AGRICULTURA. Anais. Campinas, SP. Fundação Cargill. n.127. 1987. p.200-209.

RAO, N. H.; SARMA, P. B. S.; CHANDER, S. A simple dated water-production function for use in irrigated agriculture. Agricultural Water Management. Amsterdam. v.13. p.25-32. 1988.

ROBERTSON, G.W. Guidelines on crop-weather models. World Meteorological Organization. Geneve. 115p. 1983a. (World Climate Application Programme, 50).

ROBERTSON, G.W. Weather-based mathematical models for estimating development and ripening of crops. World Meteorological Organization. Geneve. 158p. 1983b. (Agricultural Meteorology-CAgM Report, 15).

SEDIYAMA, T.; PEREIRA, M. G. ; SEDIYAMA, C. S.; GOMES, J. L. G. A cultura da soja: I Parte. Viçosa. Universidade Federal de Viçosa. 1985. 95p. 
SEGOVIA, R. M.; ANDRADE, E. G. Um modelo de determinação do efeito da precipitação pluviométrica na produtividade agrícola. In: SEGOVIA, R. M. (Ed). Determinação do efeito da precipitação pluviométrica na produtividade agrícola. Brasília. CFP. 1982. p.10-18. (Coleção Análise e Pesquisa, 24).

SHAW, R. H. Use of a moisture-stress index for examining climate trends and corn yields in Iowa. Iowa State Journal Reseach. Ames. v.1. n.3. p.249-254. 1977.

SHAW, R. H. Modelling crop yields using climatic data. In: PROCEEDINGS OF 1978 LACIE CORN-SOYBEAN SEMINAR. Texas. NASA. 1978. p.129-143.

SHAW, R.H.; LAING, D. R. Moisture stress and plant response. In: PIERRE, W.H. (Ed.) Plant environment and efficient water use. Madison. American Society of Agronomy. p.73-94. 1965.

SPLINTER, W.E. Modelling of plant growth for yield prediction. Agricultural Meteorology. Amsterdam. v.14. n.2. p.243-253. 1974.

STEWART, J. I., HAGAN, R. M.; PRUITT, W. O. Production functions and predicted irrigation programmes for principal crops as required for water resources planning and increased water use efficiency. Final report, U.S. Department of Interior. Washington DC. 1976. 80p.

THOMPSON, L. M. Weather and technology in the production of soybeans in the Central United States. Agronomy Journal. Madison. v. 62. n.2. p.232-236. 1970. 
THORNTHWAITE, C. W. An approach toward a rational classification of climate. Geogr. Rev. v.38. p.55-94. 1948.

THORNTHWAITE, C. W.; MATHER, J. R. The water balance. Centerton, N. J. 1955. 104p. (Publications in Climatology. v.8. n.1.).

van LIER, Q. J. \& DOURADO NETO, D. Programa de balanço hídrico para microcomputador BHIDRICO (software), versão 3.21a. Escola Superior de Agricultura “Luiz de Queiroz"- Universidade de São Paulo. 1993.

VOSSEN, P. Comparative statistical validation of two ten-day water-use models and three yield-reduction hypotheses for yield assessment in Botswana. Agricultural and Forest Meteorology. Amsterdam. v.51. p.177-195. 1990.

WILLMOTT, C. J.; ACKLESON, S. G.; DAVIS, J. J.; FEDDEMA, K. M.; KLINK, D. R. Statistics for the evaluation and comparison of models. Journal of Geophysical Research. v.90. n.5. p.8995-9005. 1985.

YAO, A. Y. M. The R index for plant water requirements. Agricultural Meteorology. Amsterdam. v.6. n.4. p.259-273. 1969.

YAO, A. Y. M. Evaluating climatic limitations for a specific agricultural enterprise. Agricultural Meteorology. Amsterdam. v.12. n.1. p.65-73. 1973.

YAO, A. Y. M. Agricultural potencial estimated from the ratio of actual to potential evapotranspiration. Agricultural Meteorology. Amsterdam. v.13. n.3. p.405417. 1974. 
APÊNDICE 1. Dados do balanço hídrico climatológico (BHclim), em nível decendial, referente ao ano agrícola de 1983/84 (Setembro/83 a Maio/84), para a localidade de Ribeirão Preto, SP.

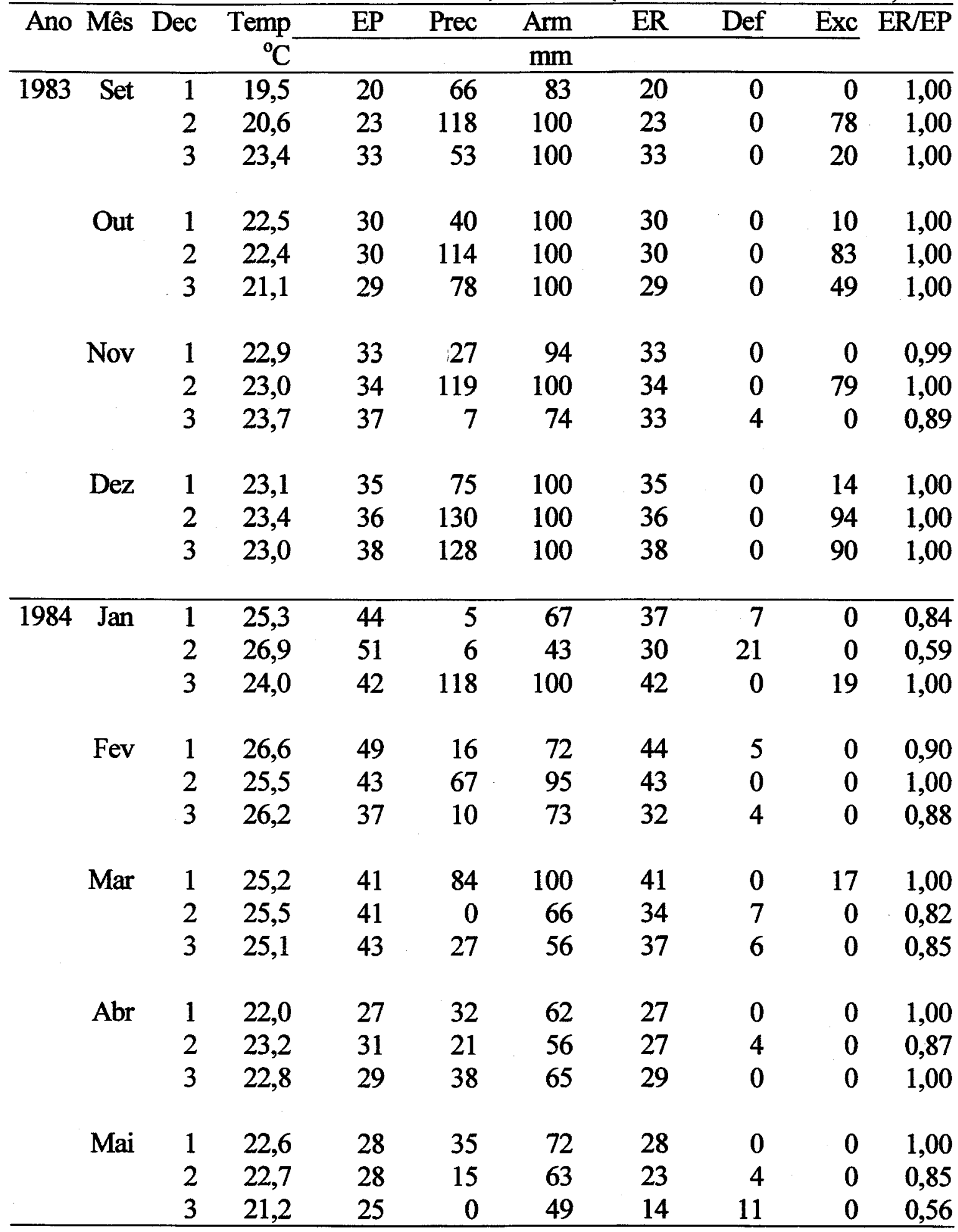


APÊNDICE 2. Dados do balanço hídrico climatológico (BHclim), em nível decendial, referente ao ano agrícola de 1984/85 (Setembro/84 a Maio/85), para a localidade de Ribeirão Preto, SP.

\begin{tabular}{|c|c|c|c|c|c|c|c|c|c|c|}
\hline \multirow[t]{2}{*}{ Ano } & \multirow[t]{2}{*}{ Mês } & \multirow[t]{2}{*}{ Dec } & \multirow{2}{*}{$\begin{array}{r}\text { Temp } \\
{ }^{\circ} \mathrm{C}\end{array}$} & \multirow[t]{2}{*}{$\mathrm{EP}$} & \multirow[t]{2}{*}{ Prec } & \multirow{2}{*}{$\frac{\text { Arm }}{\mathrm{mm}}$} & \multirow[t]{2}{*}{ ER } & \multirow[t]{2}{*}{ Def } & \multirow[t]{2}{*}{ Exc } & \multirow[t]{2}{*}{$\overline{\mathrm{ER} / \mathrm{EP}}$} \\
\hline & & & & & & & & & & \\
\hline \multirow[t]{12}{*}{1984} & Set & 1 & 20,0 & 21 & 36 & 49 & 21 & 0 & 0 & 1,00 \\
\hline & & 2 & 21,3 & 25 & 13 & 44 & 19 & 6 & 0 & 0,75 \\
\hline & & 3 & 21,3 & 26 & 61 & 79 & 26 & 0 & 0 & 1,00 \\
\hline & Out & 1 & 25,4 & 41 & 39 & 77 & 41 & 1 & 0 & 0,99 \\
\hline & & 2 & 24,0 & 36 & 15 & 62 & 30 & 7 & 0 & 0,82 \\
\hline & & 3 & 25,0 & 45 & 3 & 41 & 24 & 21 & 0 & 0,54 \\
\hline & Nov & 1 & 27,0 & 50 & 17 & 29 & 28 & 22 & 0 & 0,57 \\
\hline & & 2 & 23,2 & 35 & 57 & 51 & 35 & 0 & 0 & 1,00 \\
\hline & & 3 & 22,9 & 34 & 102 & 100 & 34 & 0 & 20 & 1,00 \\
\hline & Dez & 1 & 23,2 & 35 & 110 & 100 & 35 & 0 & 75 & 1,00 \\
\hline & & 2 & 23,3 & 36 & 80 & 100 & 36 & 0 & 45 & 1,00 \\
\hline & & 3 & 23,4 & 40 & 134 & 100 & 40 & 0 & 94 & 1,00 \\
\hline \multirow[t]{15}{*}{1985} & Jan & 1 & 22,9 & 34 & 169 & 100 & 34 & 0 & 135 & 1,00 \\
\hline & & 2 & 23,7 & 37 & 112 & 100 & 37 & 0 & 75 & 1,00 \\
\hline & & 3 & 23,1 & 38 & 115 & 100 & 38 & 0 & 77 & 1,00 \\
\hline & Fev & 1 & 25,1 & 42 & 38 & 96 & 42 & 0 & 0 & 1,00 \\
\hline & & 2 & 25,6 & 44 & 18 & 74 & 40 & 4 & 0 & 0,91 \\
\hline & & 3 & 23,7 & 28 & 75 & 100 & 28 & 0 & 21 & 1,00 \\
\hline & Mar & 1 & 22,3 & 30 & 25 & 95 & 30 & 0 & 0 & 1,00 \\
\hline & & 2 & 23,5 & 33 & 69 & 100 & 33 & 0 & 31 & 1,00 \\
\hline & & 3 & 25,5 & 45 & 90 & 100 & 45 & 0 & 45 & 1,00 \\
\hline & $\mathrm{Abr}$ & 1 & 24,0 & 34 & 7 & 76 & 31 & 3 & 0 & 0,90 \\
\hline & & 2 & 23,0 & 30 & 28 & 75 & 29 & 0 & 0 & 0,98 \\
\hline & & 3 & 21,9 & 26 & 13 & 66 & 22 & 4 & 0 & 0,86 \\
\hline & Mai & 1 & 20,2 & 21 & 12 & 60 & 17 & 3 & 0 & 0,84 \\
\hline & & 2 & 19,6 & 19 & 0 & 50 & 10 & 8 & 0 & 0,55 \\
\hline & & 3 & 20,2 & 22 & 3 & 41 & 12 & 10 & 0 & 0,53 \\
\hline
\end{tabular}


APÊNDICE 3. Dados do balanço hídrico climatológico (BHclim), em nível decendial, referente ao ano agrícola de 1989/90 (Setembro/89 a Maio/90), para a localidade de Ribeirão Preto, SP.

\begin{tabular}{|c|c|c|c|c|c|c|c|c|c|c|}
\hline Ano & Mês & Dec & Temp & EP & Prec & Arm & ER & Def & Exc & $\overline{\mathrm{ER} / \mathrm{EP}}$ \\
\hline & & & ${ }^{\circ} \mathrm{C}$ & & & $\mathrm{mm}$ & & & & \\
\hline 1989 & Set & 1 & 20,9 & 24 & 43 & 73 & 24 & 0 & 0 & 1,00 \\
\hline & & 2 & 21,7 & 26 & 12 & 63 & 22 & 5 & 0 & 0,82 \\
\hline & & 3 & 22,7 & 30 & 3 & 48 & 18 & 12 & 0 & 0,59 \\
\hline & Out & 1 & 23,6 & 34 & 7 & 36 & 18 & 16 & 0 & 0,54 \\
\hline & & 2 & 22,2 & 30 & 27 & 35 & 28 & 2 & 0 & 0,94 \\
\hline & & 3 & 24,9 & 44 & 78 & 68 & 44 & 0 & 0 & 1,00 \\
\hline & Nov & 1 & 23,1 & 34 & 5 & 52 & 22 & 11 & 0 & 0,66 \\
\hline & & 2 & 22,4 & 32 & 138 & 100 & 32 & 0 & 58 & 1,00 \\
\hline & & 3 & 23,9 & 38 & 177 & 100 & 38 & 0 & 140 & 1,00 \\
\hline & Dez & 1 & 25,4 & 45 & 21 & 79 & 42 & 3 & 0 & 0,94 \\
\hline & & 2 & 23,2 & 35 & 197 & 100 & 35 & 0 & 141 & 1,00 \\
\hline & & 3 & 22,9 & 38 & 123 & 100 & 38 & 0 & 86 & 1,00 \\
\hline 1990 & Jan & 1 & 22,7 & 33 & 157 & 100 & 33 & 0 & 123 & 1,00 \\
\hline & & 2 & 26,2 & 48 & 57 & 100 & 48 & 0 & 9 & 1,00 \\
\hline & & 3 & 25,8 & 50 & 17 & 71 & 45 & 5 & 0 & 0,90 \\
\hline & Fev & 1 & 25,1 & 42 & 58 & 88 & 42 & 0 & 0 & 1,00 \\
\hline & & 2 & 25,4 & 43 & 34 & 80 & 41 & 1 & 0 & 0,97 \\
\hline & & 3 & 22,6 & 25 & 52 & 100 & 25 & 0 & 7 & 1,00 \\
\hline & Mar & 1 & 23,8 & 35 & 35 & 100 & 35 & 0 & 0 & 1,00 \\
\hline & & 2 & 24,8 & 38 & 36 & 97 & 38 & 0 & 0 & 1,00 \\
\hline & & 3 & 23,4 & 36 & 149 & 100 & 36 & 0 & 110 & 1,00 \\
\hline & Abr & 1 & 24,7 & 37 & 12 & 78 & 34 & 3 & 0 & 0,93 \\
\hline & & 2 & 21,7 & 26 & 37 & 90 & 26 & 0 & 0 & 1,00 \\
\hline & & 3 & 22,6 & 28 & 0 & 68 & 22 & 6 & 0 & 0,78 \\
\hline & Mai & 1 & 20,7 & 22 & 30 & 76 & 22 & 0 & 0 & 1,00 \\
\hline & & 2 & 18,2 & 15 & 66 & 100 & 15 & 0 & 26 & 1,00 \\
\hline & & 3 & 18,6 & 18 & 0 & 84 & 16 & 2 & 0 & 0,92 \\
\hline
\end{tabular}


APÊNDICE 4. Dados do balanço hídrico climatológico (BHclim), em nível decendial, referente ao ano agrícola de 1990/91 (Setembro/90 a Maio/91), para a localidade de Ribeirão Preto, SP.

\begin{tabular}{|c|c|c|c|c|c|c|c|c|c|c|}
\hline Ano & Mês & Dec & Temp & EP & Prec & Arm & ER & Def & Exc & ER/EP \\
\hline & & & ${ }^{\circ} \mathrm{C}$ & & & $\mathrm{mm}$ & & & & \\
\hline 1990 & Set & 1 & 21,1 & 24 & 10 & 45 & 17 & 7 & 0 & 0,70 \\
\hline & & 2 & 20,5 & 23 & 4 & 37 & 11 & 11 & 0 & 0,50 \\
\hline & & 3 & 20,7 & 24 & 3 & 31 & 10 & 13 & 0 & 0,43 \\
\hline & Out & 1 & 24,1 & 36 & 16 & 25 & 21 & 15 & 0 & 0,60 \\
\hline & & 2 & 24,1 & 37 & 40 & 28 & 37 & 0 & 0 & 1,00 \\
\hline & & 3 & 24,6 & 43 & 3 & 19 & 12 & 31 & 0 & 0,29 \\
\hline & Nov & 1 & 24,7 & 40 & 60 & 38 & 40 & 0 & 0 & 1,00 \\
\hline & & 2 & 26,4 & 48 & 68 & 57 & 48 & 0 & 0 & 1,00 \\
\hline & & 3 & 24,2 & 39 & 14 & 45 & 27 & 12 & 0 & 0,69 \\
\hline & Dez & 1 & 25,9 & 47 & 7 & 30 & 22 & 25 & 0 & 0,47 \\
\hline & & 2 & 24,3 & 40 & 140 & 100 & 40 & 0 & 30 & 1,00 \\
\hline & & 3 & 23,1 & 38 & 17 & 80 & 36 & 2 & 0 & 0,94 \\
\hline 1991 & Jan & 1 & 23,8 & 38 & 33 & 77 & 37 & 1 & 0 & 0,97 \\
\hline & & 2 & 23,0 & 34 & 95 & 100 & 34 & 0 & 37 & 1,00 \\
\hline & & 3 & 23,2 & 38 & 150 & 100 & 38 & 0 & 112 & 1,00 \\
\hline & Fev & 1 & 22,9 & 33 & 101 & 100 & 33 & 0 & 68 & 1,00 \\
\hline & & 2 & 23,7 & 36 & 101 & 100 & 36 & 0 & 65 & 1,00 \\
\hline & & 3 & 24,2 & 30 & 19 & 89 & 29 & 1 & 0 & 0,98 \\
\hline & Mar & 1 & 23,3 & 33 & 80 & 100 & 33 & 0 & 36 & 1,00 \\
\hline & & 2 & 24,3 & 36 & 2 & 71 & 31 & 5 & 0 & 0,86 \\
\hline & & 3 & 21,2 & 28 & 189 & 100 & 28 & 0 & 133 & 1,00 \\
\hline & Abr & 1 & 22,5 & 29 & 122 & 100 & 29 & 0 & 93 & 1,00 \\
\hline & & 2 & 22,6 & 29 & 40 & 100 & 29 & 0 & 11 & 1,00 \\
\hline & & 3 & 19,8 & 20 & 101 & 100 & 20 & 0 & 81 & 1,00 \\
\hline & Mai & 1 & 19,9 & 20 & 2 & 84 & 18 & 1 & 0 & 0,93 \\
\hline & & 2 & 19,4 & 18 & 13 & 79 & 17 & 1 & 0 & 0,94 \\
\hline & & 3 & 20,6 & 23 & 36 & 92 & 23 & 0 & 0 & 1,00 \\
\hline
\end{tabular}


APÊNDICE 5. Dados do balanç o hí drico climatológico (BHclim), em ní vel decendial, referente ao ano agrí cola de 1995/96 (Setembro/95 a Maio/96), para a localidade de Ribeirão Preto, SP.

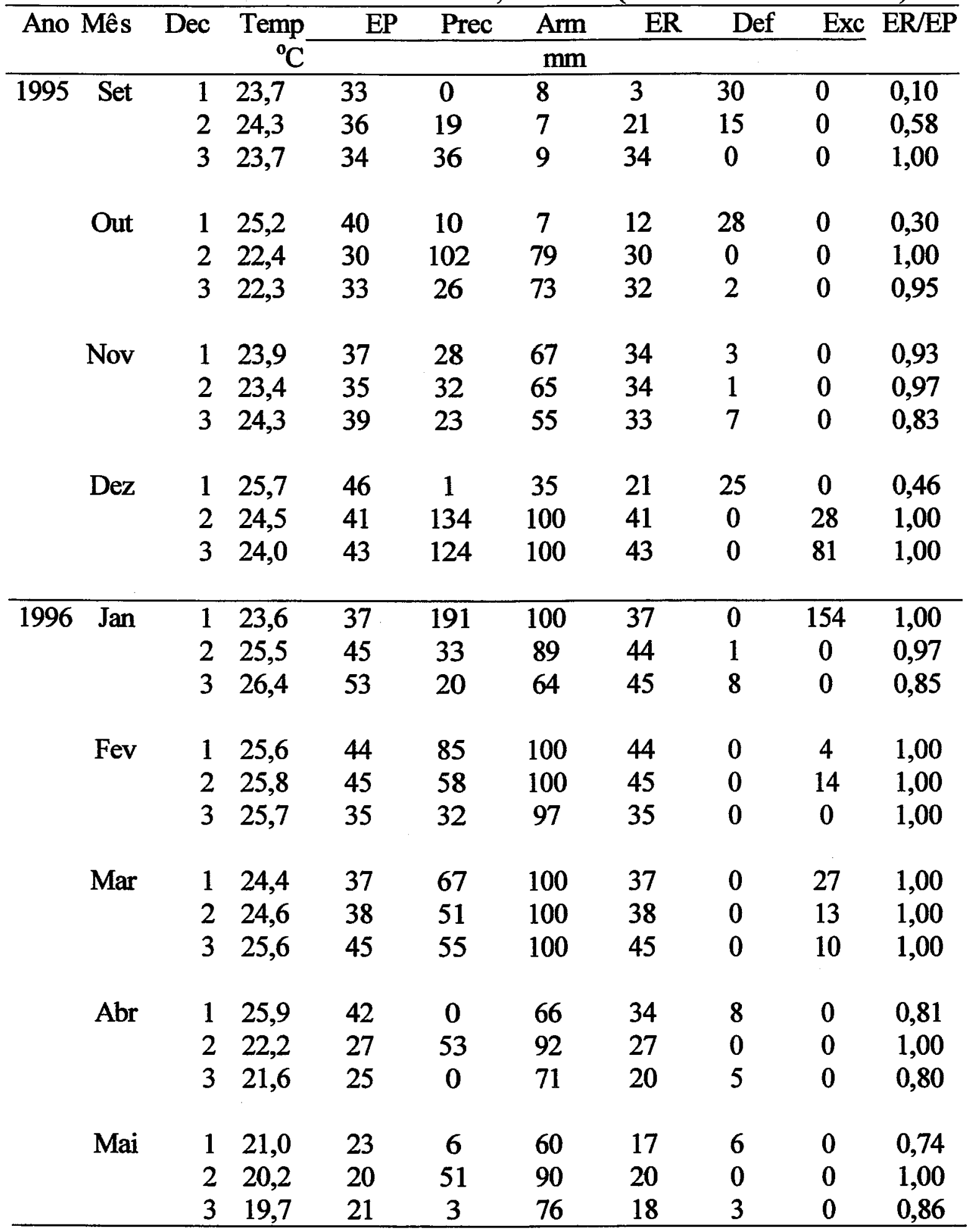


APÊNDICE 6. Dados do balanço hí drico climatológico (BHclim), em ní vel decendial, referente ao ano agrí cola de 1996/97 (Setembro/96 a Maio/97), para a localidade de Ribeirão Preto, SP.

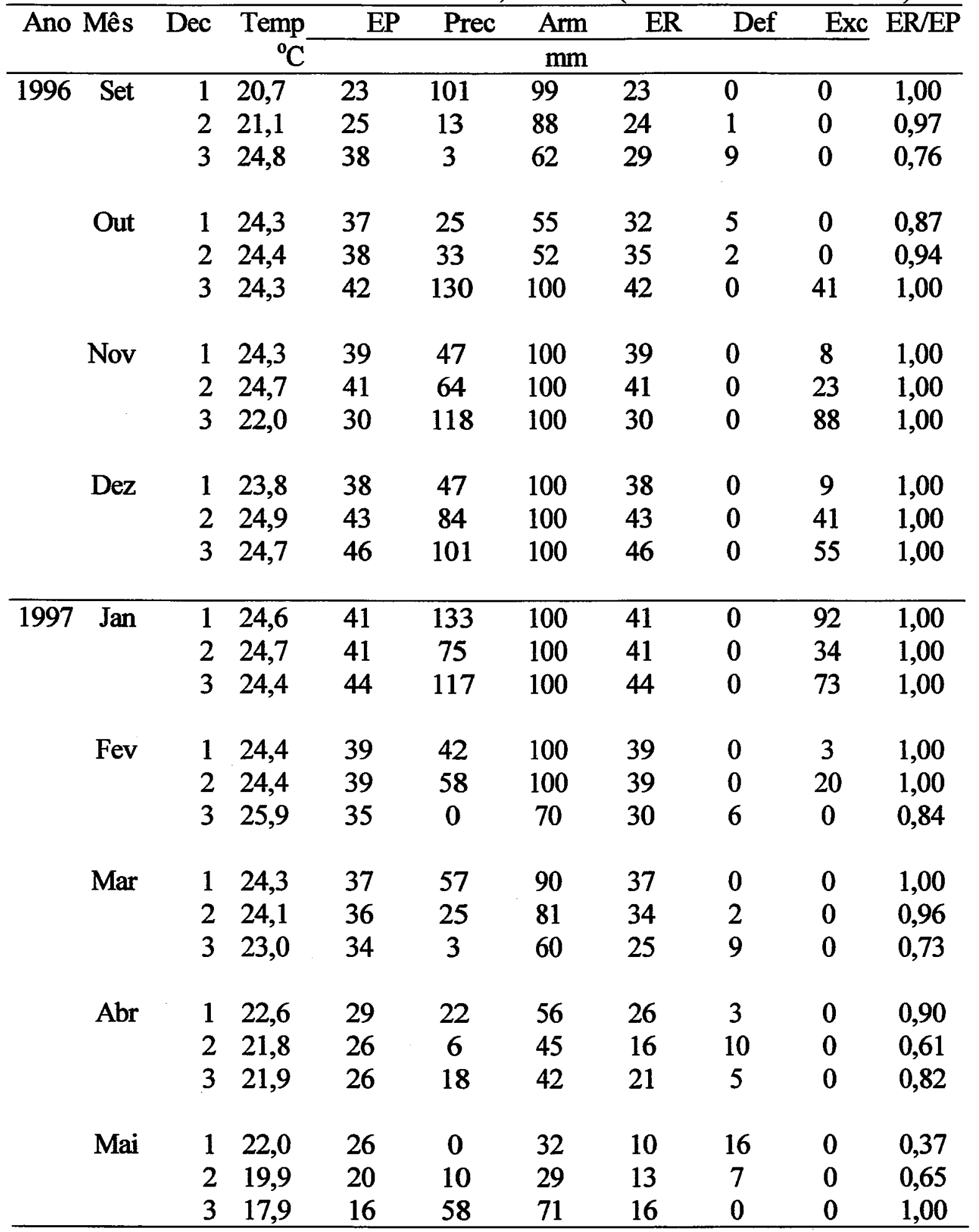




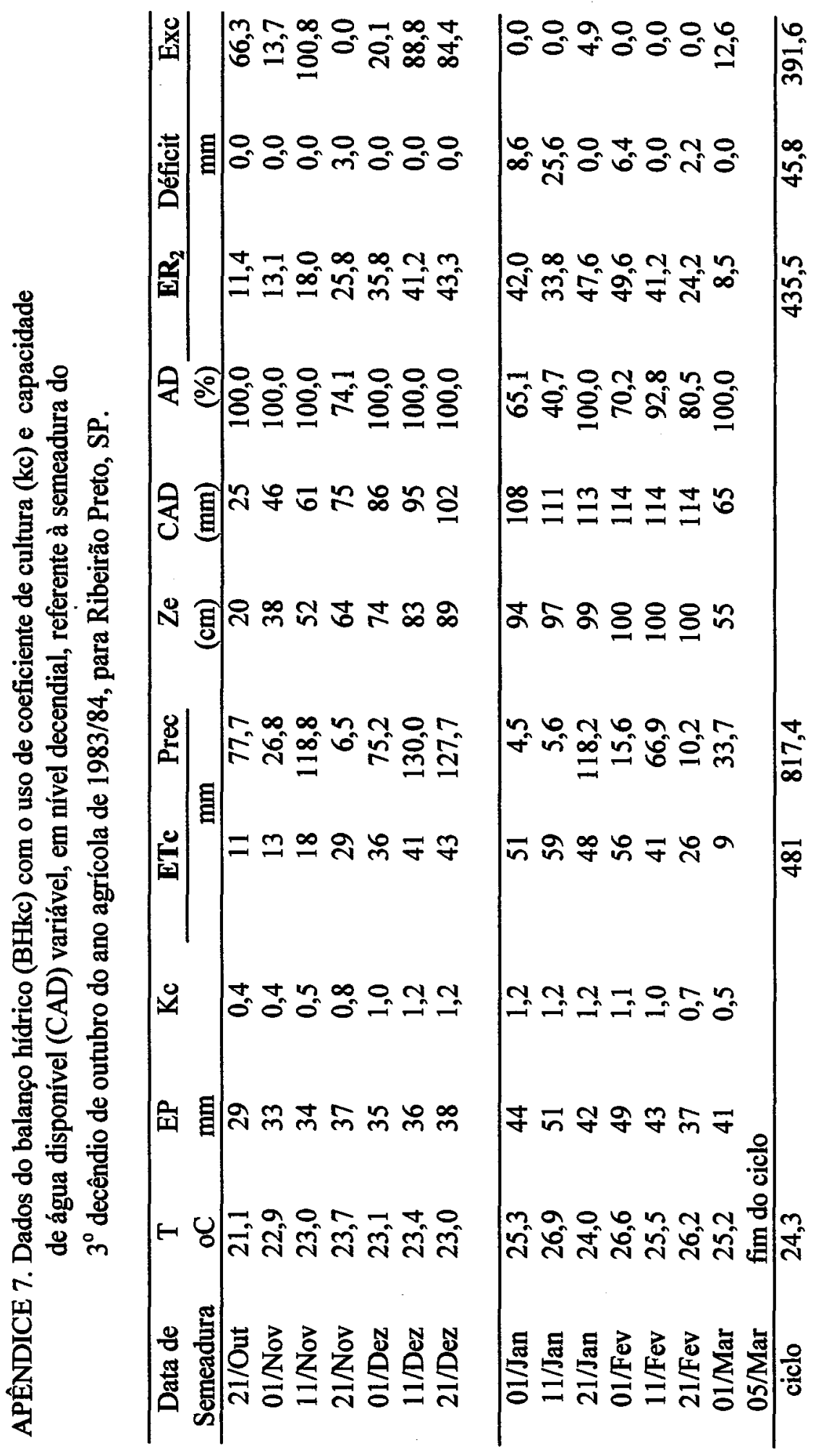




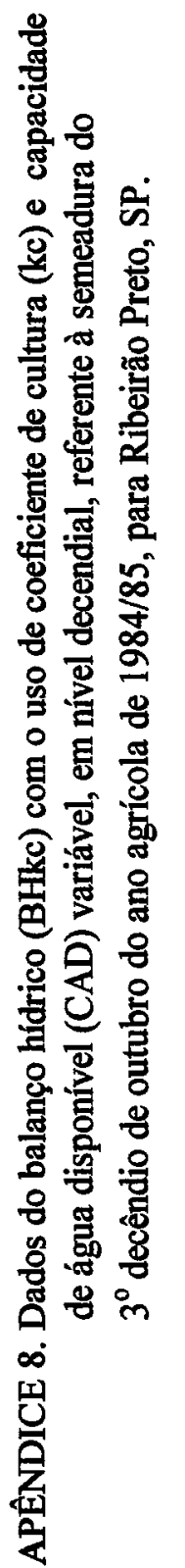

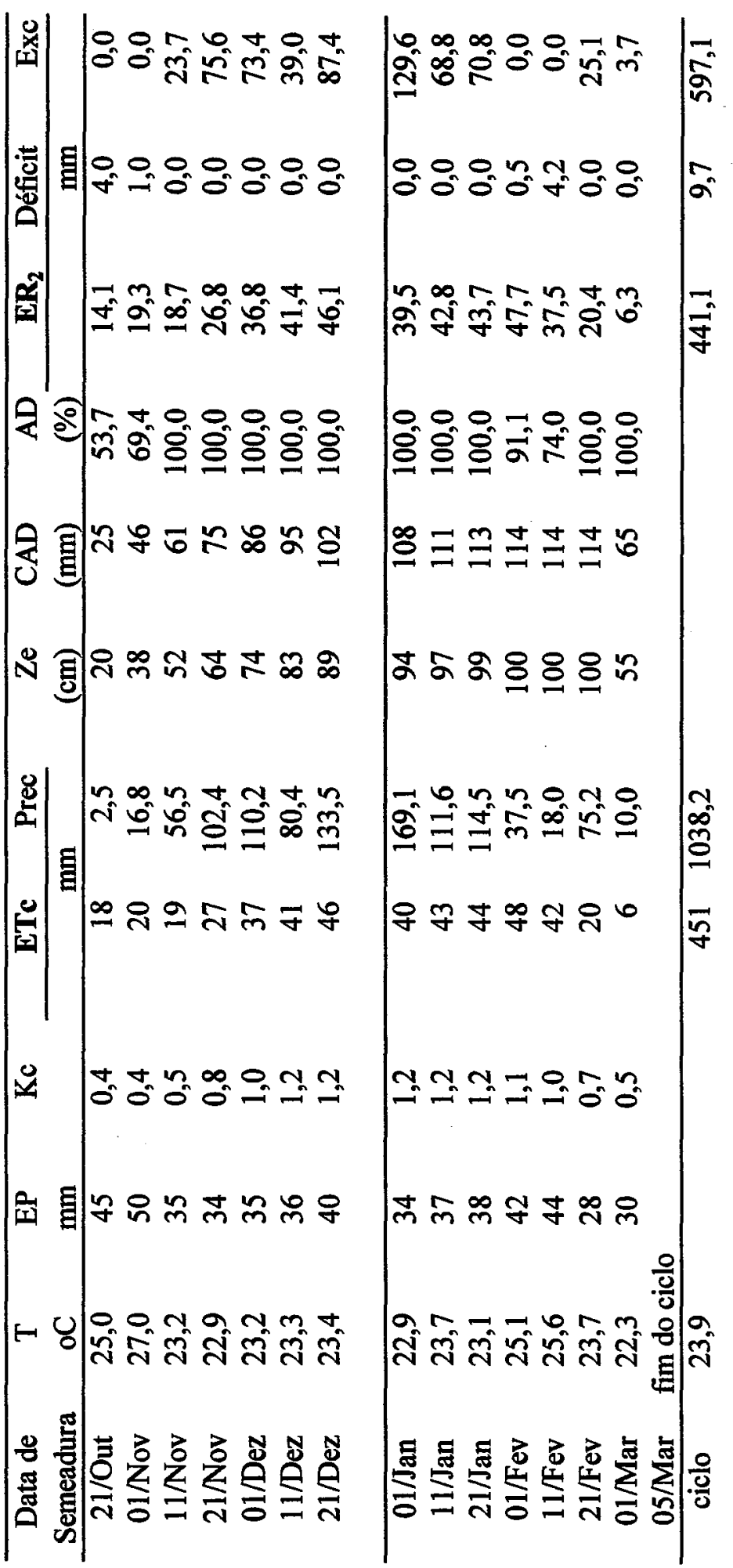




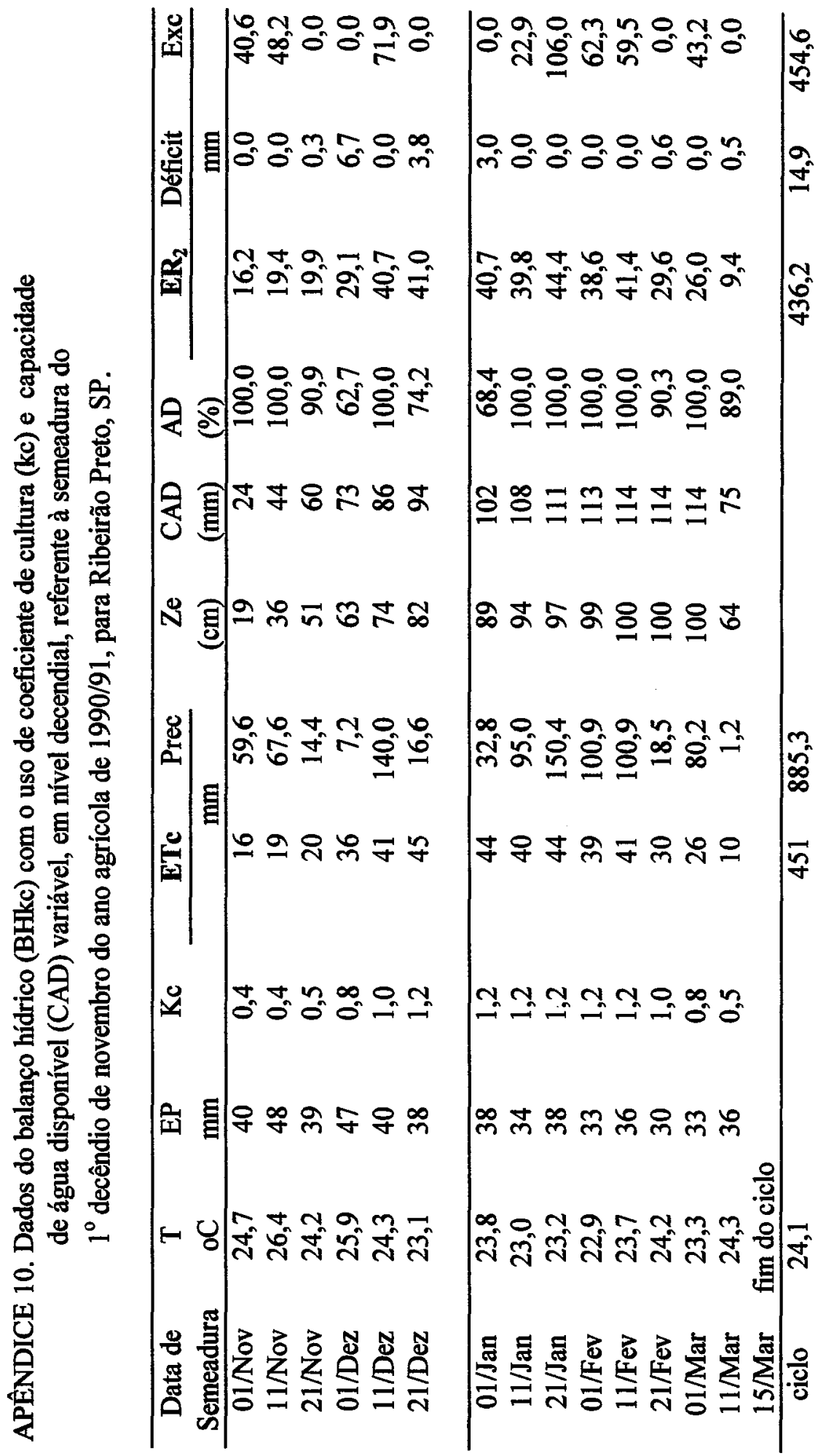



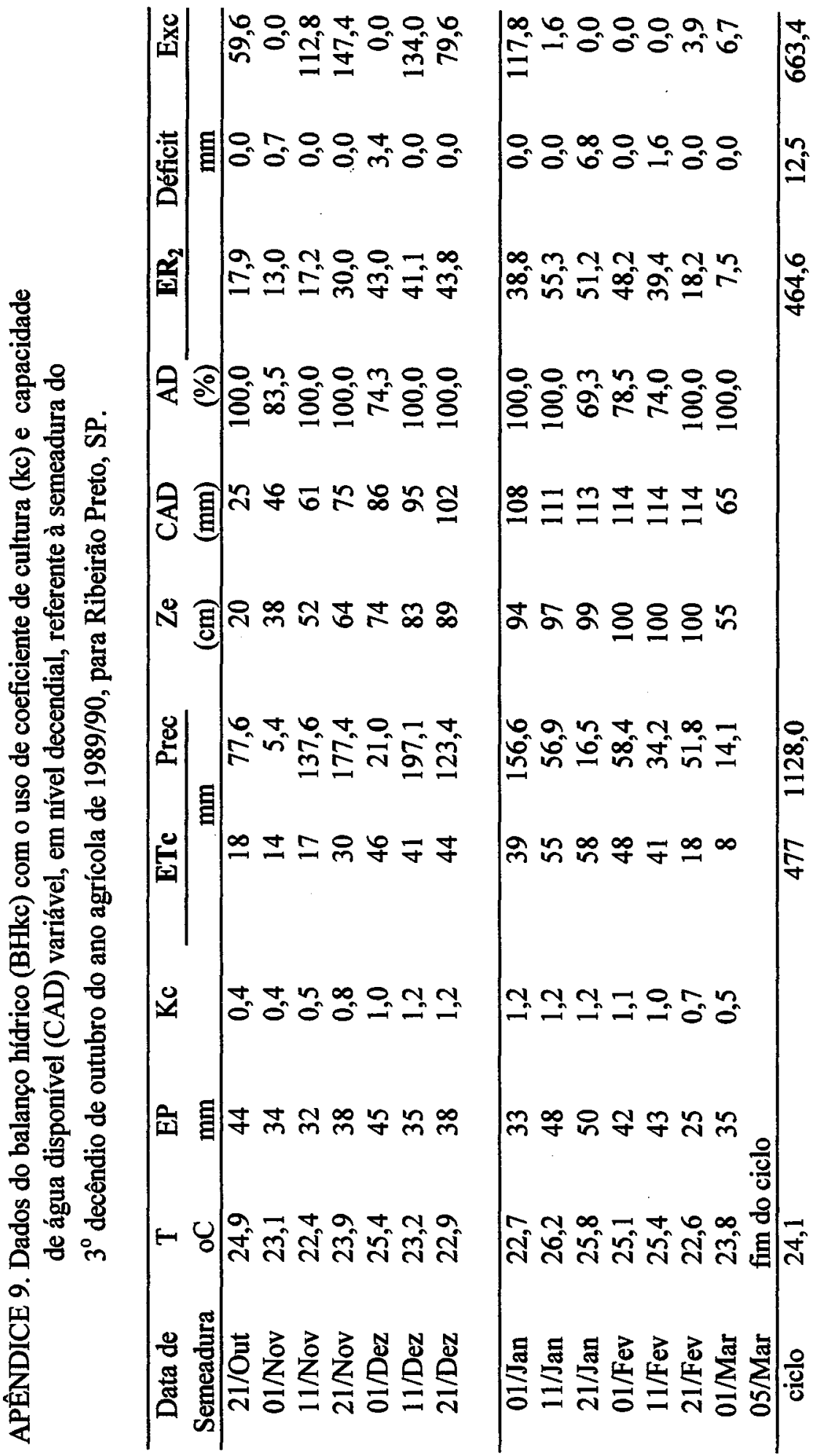